TAISE ARGOLO SENA

Implicações da contribuição endógena e exógena para obtenção do P300 utilizando paradigma de omissão

Tese apresentada à Faculdade de Medicina da

Universidade de São Paulo para a obtenção do título de Doutor em Ciências

Programa de Ciências da Reabilitação Orientadora: Profa. Dr ${ }^{\mathrm{a}}$. Eliane Schochat

SÃO PAULO

2016 


\section{Dados Internacionais de Catalogação na Publicação (CIP)}

Preparada pela Biblioteca da

Faculdade de Medicina da Universidade de São Paulo

Creprodução autorizada pelo autor

Sena, Taise Argolo

Implicações da contribuição endógena e exógena para obtenção do P300 utilizando paradigma de omissão / Taise Argolo Sena. -- São Paulo, 2016.

Tese(doutorado)--Faculdade de Medicina da Universidade de São Paulo.

Programa de Ciências da Reabilitação.

Orientadora: Eliane Schochat.

Descritores: 1.Potencial evocado P300 2.Potenciais evocados auditivos 3.Adulto 4.Audição 5.Estimulação acústica

USP/FM/DBD-455/16 
Aos meus amados pais, Antônio Sena e Carmen Lúcia, que nunca me deixaram desistir, mesmo nos momentos mais difíceis!

Amo vocês! 


\section{AGRADECIMENTOS}

Aos meus pais, Antônio de Sena e Carmen Lúcia, por estarem ao meu lado em cada conquista, em cada desafio (e sei que foram muitos!). Sem vocês eu não chegaria aqui! Obrigada pelo incentivo, pelas horas ao telefone, por aguentarem meus choros e continuarem firmes. Vocês são o meu sustento! Amo vocês.

Às minhas amadas irmãs, Ingrid Sena e Luiza Bernardes, e ao meu cunhado-irmão, Gustavo Bernardes, Não tenho palavras para demonstrar tamanha gratidão. Mesmo com a distância e a saudade, vocês sempre estiveram presentes! Saibam que cada palavra, cada abraço, cada viagem para nos encontramos, cada sorriso, só me fizeram crescer e ter forças pra seguir os meus objetivos. Não poderia ter família melhor! Amo vocês!

À minha babá, Maria Nascimento, por todo olhar sincero que me leva sempre à frente. Você é meu exemplo de coração puro!

À minha querida orientadora, Prof. ${ }^{a}$ Dr. ${ }^{a}$ Eliane Schochat, a qual admiro imensamente por sua competência, inteligência, sabedoria, humildade e alegria. Não foram só ensinamentos acadêmicos durante esses quatro anos, e sim ensinamentos para vida, que guardarei com muito carinho e respeito. Foi uma honra tê-la como orientadora. Muito obrigada por ter acreditado em mim, inclusive quando nem eu mesma acreditei. Obrigada por todos os conselhos, por todas as boas risadas e todo o ensinamento! 
Às minhas queridas amigas e fonoaudiólogas do Laboratório do Pesquisa

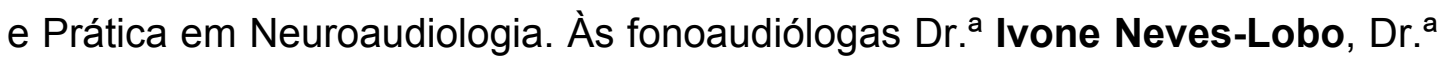
Camila Rabelo pelo incentivo, apoio e acolhimento durante toda essa jornada. Vocês são incriveis. Às grandes e estudiosas fonoaudiólogas Dr. ${ }^{a}$ Renata Fiippini, Dr. ${ }^{a}$ Caroline Rocha-Muniz e Dr. ${ }^{\text {a }}$ Cristina Murphy, por todos os ensinamentos. Vocês são minha inspiração, e as carregarei como exemplo de competência e comprometimento. Muito obrigada pela paciência e respeito, aprendi muito com vocês! À doutoranda Mayra Monteiro, por todos os momentos que tivemos juntas; foram desafios vencidos. Às mestres Karenina Calarga, Líbia Camargo e Aline Morais e às mestrandas Priscila Brasil, Ana Flavia e Thais Regina, vocês são muito especiais!! Muito obrigada por todos os cafés, almoços, conversas e alegrias!! Vocês foram maravilhosas!

À Profa ${ }^{\text {. Dr }}{ }^{\mathrm{a}}$ Doris Ruthi Lewis, pelas suas contribuições valiosas no exame de qualificação e por ter me inserido nesse mundo maravilhoso da pesquisa. Você foi uma grande orientadora e tenho muito orgulho em tê-la na minha vida.

À Dr. ${ }^{a}$ Fernanda Magliaro e à Dr. $^{a}$ Ivone Neves-Lobo, por compartilharem suas experiências profissionais, fundamentais para a qualificação e conclusão desse estudo.

Às minhas amadas amigas $\operatorname{Dr}^{a}{ }^{a}$ Mabel Gonçalves Almeida e $\mathrm{Dr}^{a}$ Isabela Freixo Côrtes-Andrade, por estarem ao meu lado a todo momento! Nas alegrias, nos descompassos, e por não me deixarem desistir, mesmo quando achei que tudo tivesse acabado. 
Às minhas amigas Fga. Amanda Rodrigues, Fga. Leilanny Lima, Thainá Cerqueira, Laize Valois, Juliana Vitali, Bruna Luiza e Ana Carolina pela força, pelas horas ao telefone, sempre com palavras de apoio e incentivo! Muito obrigada!

A toda minha família, em especial às minhas avós, Antônia Fontes e Reci Dias; aos meus tios e tias, meus primos e primas, que mesmo longe sempre me incentivaram. Vocês são a minha base. Obrigada por todas as orações e pensamentos positivos.

À CAPES, pela bolsa de estudos concedida para o desenvolvimento deste estudo.

A Wagner Arrais, pela dedicação e competência na preciosa correção de português.

À Dr. ${ }^{a}$ Caroline Rocha-Muniz, pela valiosa e trabalhosa análise estatística, obrigada pela paciência e conselhos durante essa etapa.

A todos que de alguma forma me auxiliaram e contribuíram para a realização deste trabalho. 
Não se pode criar experiência.

É preciso passar por ela.

Albert Camus 
Esta tese está de acordo com as seguintes normas:

Referências: adaptado de International Committee of Medical Journals Editors (Vancouver).

Universidade de São Paulo. Faculdade de Medicina. Divisão de Biblioteca e Documentação. Guia de apresentação de dissertações, teses e monografias. Elaborado por Anneliese Carneiro da Cunha, Maria Julia de A. L. Freddi, Maria F. Crestana, Marinalva de Souza Aragão, Suely Campos Cardoso, Valéria Vilhena. 3a ed. São Paulo: Divisão de Biblioteca e Documentação; 2011.

Abreviaturas dos títulos dos periódicos de acordo com List of Journals Indexed in Index Medicus 


\section{SUMÁRIO}

\section{Lista de abreviaturas}

Lista de figuras

Lista de tabelas

Lista de quadros

Resumo

Abstract

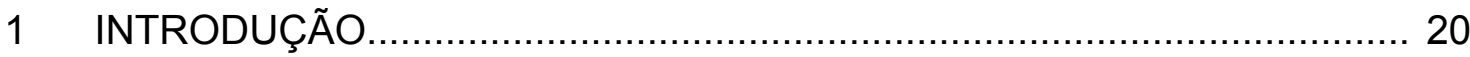

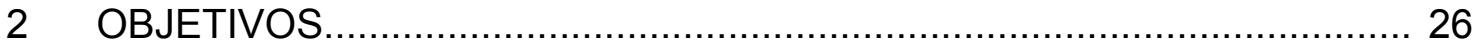

3 REVISÃO DE LITERATURA ........................................................ 28

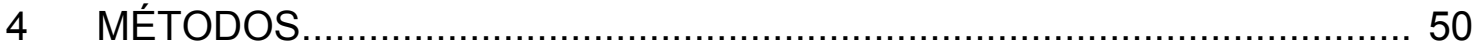

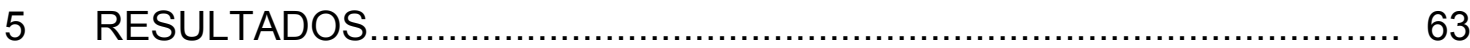

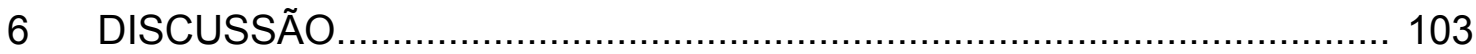

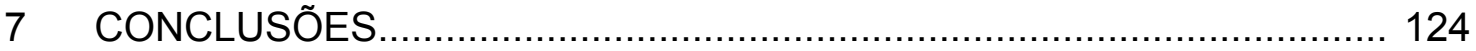

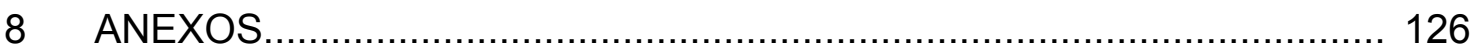

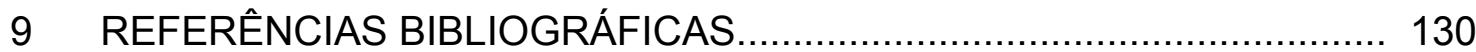




\section{LISTA DE ABREVIATURAS E SIGLAS}

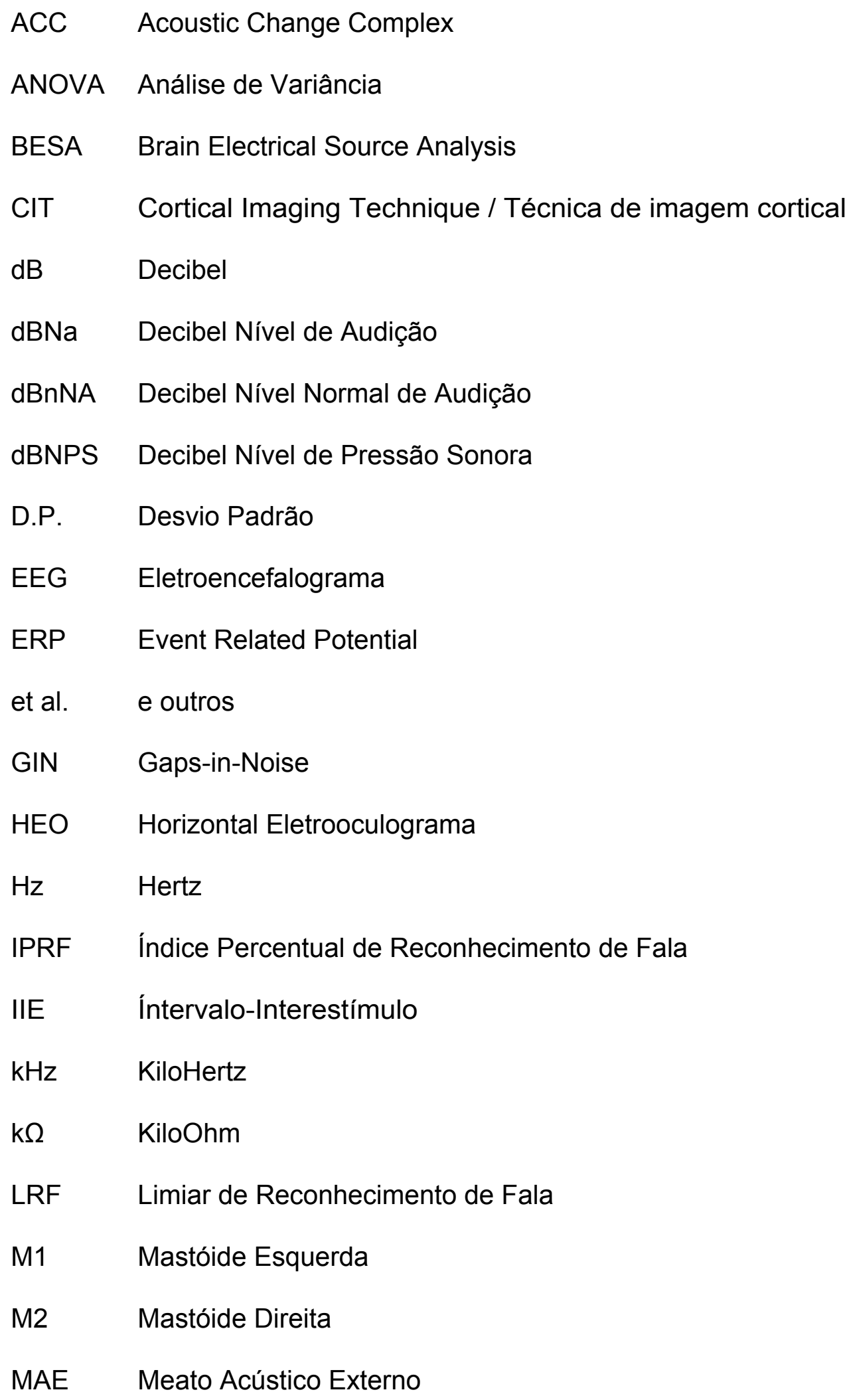




\begin{tabular}{ll} 
MÁX & Máximo \\
MÉD & Média \\
MÍN & Mínimo \\
MMN & Mismatch Negativity \\
MS & Milissegundo \\
OD & Orelha Direita \\
OE & Orelha Esquerda \\
PEALL & Potenciais Evocados Auditivos de Longa Latência \\
PEATE & Potencial Evocado Auditivo de Tronco Encefálico \\
fMRI & Ressonância Funcional \\
FMUSP & Faculdade de Medicina da Universidade de São Paulo \\
TCLE & Termo de Consentimento Livre e Esclarecido \\
TDD & Teste Dicótico de Dígitos \\
VEO & Vertical Eletrooculograma \\
$\mu V$ & Microvolt \\
\hline
\end{tabular}




\section{LISTA DE FIGURAS}

Figura 1 - Posicionamento dos eletrodos na "Quick-Cap 64 Channel" segundo o sistema internacional 10-20. Em círculos vermelhos, os eletrodos selecionados no escalpo para esse estudo na obtenção do P300; em verde, os eletrodos dipolos selecionados para monitorar o movimento ocular; em azul, os eletrodosreferência.

Figura 2 - Colocação dos eletrodos dipolos para controle do movimento ocular.

Figura 3 - Diagrama representando a apresentação dos dois paradigmas: a) Paradigma tradicional, utilizando as frequências de 800 e $1200 \mathrm{~Hz}$ para gerar o P300; b) Paradigma de omissão, usando a frequência de $800 \mathrm{~Hz}$ e a ausência de estímulo para gerar o P300.

Figura 4 - Representação gráfica da soma das 30 estimulações frequentes para visualização dos componentes N1-P2-N2 no paradigma tradicional e no paradigma de omissão na orelha direita.

Figura 5 - Representação gráfica da soma das 30 estimulações frequentes para visualização dos componentes N1-P2-N2 no paradigma tradicional e no paradigma de omissão na orelha esquerda.

Figura 6 - Representação gráfica de um eletrodo da subtração realizada no paradigma tradicional e no paradigma de omissão

Figura 7 - Representação gráfica da soma das 30 ondas resultantes para a visualização do P300 no paradigma tradicional e no paradigma de omissão na orelha direita.

Figura 8 - Representação gráfica da soma das 30 ondas resultantes para a visualização do P300 no paradigma tradicional e no paradigma de omissão na orelha esquerda.

Figura 9 - Mapa topográfico do escalpo mostrando a distribuição dos P300 no paradigma tradicional e no paradigma de omissão na orelha direita em cortes a cada $10 \mathrm{~ms}$ (250 a $450 \mathrm{~ms}$ ). 
Figura 10 - Mapa topográfico do escalpo mostrando a distribuição dos P300 no paradigma tradicional e no paradigma de omissão na orelha esquerda em cortes a cada $10 \mathrm{~ms}$ ( 250 a $450 \mathrm{~ms}$ ). 98

Figura 11 - Representação gráfica da soma das 30 ondas resultantes para o eletrodo $\mathrm{Cz}$ com corte do mapa topográfico do escalpo no paradigma tradicional e no paradigma de omissão na orelha direita.................................100

Figura 12 - Representação gráfica da soma das 30 ondas resultantes para o eletrodo $\mathrm{Cz}$ com corte do mapa topográfico do escalpo no paradigma tradicional e no paradigma de omissão na orelha esquerda.. 101 


\section{LISTA DE TABELAS}

Tabela 1 - Estatísticas descritivas para a idade (anos) para o gênero masculino e feminino. .64

Tabela 2 - Estatística descritiva (média, desvio padrão, mínimo, máximo e mediana) da latência (ms) do N1 para os 12 eletrodos da orelha direita no paradigma tradicional e no paradigma de omissão 65

Tabela 3 - Estatística descritiva (média, desvio padrão, mínimo, máximo e mediana) da latência (ms) do N1 para os 12 eletrodos da orelha esquerda no paradigma tradicional e no paradigma de omissão 66

Tabela 4 - Estatística descritiva (média, desvio padrão, mínimo, máximo e mediana) da latência (ms) do P2 para os 12 eletrodos da orelha direita no paradigma tradicional e no paradigma de omissão 67

Tabela 5 - Estatística descritiva (média, desvio padrão, mínimo, máximo e mediana) da latência (ms) do P2 para os 12 eletrodos da orelha esquerda no paradigma tradicional e no paradigma de omissão

Tabela 6 - Estatística descritiva (média, desvio padrão, mínimo, máximo e mediana) da latência (ms) do N2 para os 12 eletrodos da orelha direita no paradigma tradicional e no paradigma de omissão

Tabela 7 - Estatística descritiva (média, desvio padrão, mínimo, máximo e mediana) da latência (ms) do N2 para os 12 eletrodos da orelha esquerda no paradigma tradicional e no paradigma de omissão.

69

Tabela 8 - P-valor encontrado para latência (ms) do N1-P2-N2 entre o paradigma tradicional e o paradigma de omissão para orelha direita e esquerda. .72

Tabela 9 - Estatística descritiva (média, desvio padrão, mínimo, máximo e mediana) da latência (ms) do P300 para os 12 eletrodos da orelha direita no paradigma tradicional e no paradigma de omissão. 77

Tabela 10 - Estatística descritiva (média, desvio padrão, mínimo, máximo e mediana) da latência (ms) do P300 para os 12 eletrodos da orelha esquerda no paradigma tradicional e no paradigma de omissão .78 
Tabela 11 - Diferenças médias e p-valor encontrado para latência (ms) do P300 entre o paradigma tradicional e o paradigma de omissão para orelha

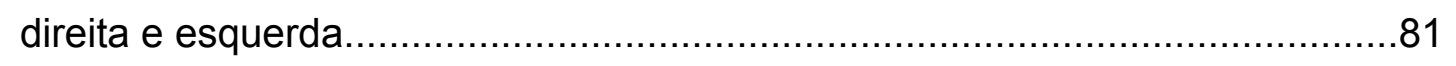

Tabela 12 - Estatística descritiva (média, desvio padrão, mínimo e máximo) da amplitude $(\mu \mathrm{V})$ do $\mathrm{P} 300$ para os 12 eletrodos da orelha direita no paradigma de tradicional e no paradigma de omissão................................................... 85

Tabela 13 - Estatística descritiva (média, desvio padrão, mínimo e máximo) da amplitude $(\mu \mathrm{V})$ do P300 para os 12 eletrodos da orelha esquerda no paradigma

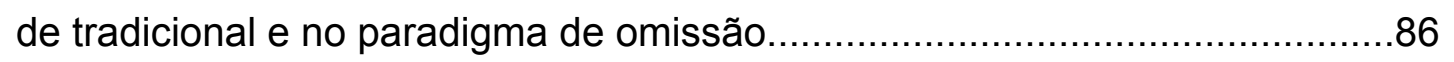

Tabela 14 - Diferenças médias e p-valor encontrado para amplitude $(\mu \mathrm{V})$ do P300 entre o paradigma tradicional e o paradigma de omissão para as orelhas direita e esquerda. 89 


\section{LISTA DE GRÁFICOS}

Gráfico 1 - Box-Plot para latência (ms) na orelha direita para os componentes N1-P2-N2 no paradigma tradicional e paradigma de omissão de acordo com o eletrodo avaliado.

Gráfico 2 - Box-Plot para latência (ms) na orelha esquerda para os componentes N1-P2-N2 no paradigma tradicional e paradigma de omissão de acordo com o eletrodo avaliado. .7

Gráfico 3 - Box-Plot para latência (ms) na orelha direita para o paradigma tradicional e paradigma de omissão de acordo com o eletrodo avaliado. .79 Gráfico 4 - Box-Plot para latência (ms) na orelha esquerda para o paradigma tradicional e paradigma de omissão de acordo com o eletrodo avaliado. 80

Gráfico 5 - Intervalo de confiança da média no nível de 95\% para a latência no paradigma tradicional e no paradigma de omissão na orelha direita 83

Gráfico 6 - Intervalo de confiança da média no nível de 95\% para a latência no paradigma tradicional e no paradigma de omissão na orelha esquerda. 84

Gráfico 7 - Box-Plot para amplitude $(\mu \mathrm{V})$ na orelha direita para o paradigma tradicional e paradigma de omissão de acordo com o eletrodo avaliado.

Gráfico 8 - Box-Plot para amplitude $(\mu \mathrm{V})$ na orelha esquerda para o paradigma tradicional e paradigma de omissão de acordo com o eletrodo avaliado. 88

Gráfico 9 - Intervalo de confiança da média no nível de 95\% para a amplitude $(\mu \mathrm{V})$ no paradigma tradicional e no paradigma de omissão na orelha direita 91

Gráfico 10 - Intervalo de confiança da média no nível de 95\% para a amplitude $(\mu \mathrm{V})$ no paradigma tradicional e no paradigma de omissão na orelha esquerda. .92 


\section{RESUMO}

Sena TA. Implicações da contribuição endógena e exógena para obtenção do P300 utilizando paradigma de omissão [tese]. São Paulo: "Faculdade de Medicina, Universidade de São Paulo"; 2016.

Introdução: O P300 é um potencial evocado auditivo que ocorre aproximadamente 300 milissegundos (ms) após a apresentação do estímulo. Geralmente, é evocado ao se utilizar o paradigma tradicional, no qual são apresentados dois estímulos perceptivelmente diferentes: um estímulo frequente $(85 \%)$ e um estímulo raro (15\%). Os indivíduos são orientados a indicar, de alguma maneira, a quantidade de estímulos raros que perceberam durante a realização do exame. O P300 é considerado um potencial endógeno, pois ocorre devido a um evento cognitivo (decisão da ocorrência do estímulo raro). Contudo, alguns estudos mostraram que as características acústicas do estímulo podem interferir no potencial, evidenciando uma contribuição exógena ou sensorial para evocar a resposta. Essas implicações endógenas e exógenas para evocar o P300 ainda não foram totalmente definidas. A avaliação desses aspectos específicos pode ajudar a identificar os geradores desse potencial. Objetivo: verificar o efeito da contribuição endógena e exógena para obtenção do P300, utilizando paradigma tradicional e o paradigma de omissão. Métodos: participaram desse estudo 30 indivíduos jovens adultos, normo-ouvintes sem alteração neurológica ou psiquiátrica aparente. Os indivíduos foram avaliados com o paradigma tradicional (estímulo frequente: $800 \mathrm{~Hz}$; estímulo raro $1200 \mathrm{~Hz}$ ) e com o paradigma de omissão (estímulo frequente: $800 \mathrm{~Hz}$; estímulo raro: ausência de som). Cada orelha foi avaliada separadamente por ambos os paradigmas na intensidade de 80 dBNPS. Foram apresentados 300 estímulos (45 raros) em cada estimulação. Para a obtenção do P300, foi utilizado o equipamento "Neuroscan Stim2" com 12 eletrodos ativos no escalpo, colocados nas seguintes posições: FPz, F4, Fz, F3, C4, Cz, C3, CP6, CP5, P4, Pz e P3. O maior pico após o complexo N1-P2-N2 foi considerado como P300. A amplitude foi medida considerando a linha de base do intervalo pré-estímulo, enquanto a latência foi medida no maior pico positivo. Nesse estudo, foi utilizada a Análise de Variância (ANOVA) com medidas repetidas. Foram realizados mapas topográficos do escalpo para ambas as estimulações. Resultados: para todos os 12 eletrodos analisados nesse estudo, a média da latência em milissegundos foi significantemente menor, e a média da amplitude foi significantemente maior para o paradigma tradicional quando comparado ao paradigma de omissão. Além disso, a morfologia da onda foi mais bem definida para o paradigma tradicional. Os mapas topográficos para ambos os paradigmas mostraram uma ativação mais generalizada e mais positiva na região centro-parietal, indicando que as mesmas áreas foram ativadas em ambos os paradigmas. Conclusão: o presente estudo demonstrou que o estímulo acústico, ausente no paradigma de omissão, influencia a latência, amplitude e morfologia da onda, evidenciando uma contribuição exógena/sensorial para obtenção do potencial.

Descritores: potencial evocado P300, potencial evocado auditivo, adultos, audição, estimulação acústica. 


\begin{abstract}
Sena TA. Implication of endogenous and exogenous contribution to obtain the P300 using the omission paradigm [thesis]. São Paulo: "Faculdade de Medicina, Universidade de São Paulo"; 2016

Introduction: The $\mathrm{P} 300$ is an auditory evoked potential that occurs approximately $300 \mathrm{~ms}$ after the stimulus presentation. It is usually elicited by a traditional paradigm in which two perceptually different stimuli are randomly presented with different proportions - one is frequent $(85 \%)$ and the other is rare $(15 \%)$. The tested individual is instructed to somehow indicate the amount of rare stimuli heard. According to the literature, P300 is considered an endogenous potential since it occurs in response to a cognitive event (i.e. decision of the occurrence or not of the rare stimulus). However, few studies have shown that the acoustic characteristics of the stimuli might influence the potential, evidencing some exogenous or sensorial contribution to the response formation. The implications that endogenous and exogenous contributions have to eliciting the P300 are not fully understood yet. The assessment of their specific roles would help to identify the P300 generators. Objective: To verify the effects of the endogenous and exogenous contribution to obtain/elicit the P300 using both the traditional and the omission paradigms. Methods: Thirty normal hearing young adults, without known neurological or psychiatric disorders, participated in this study. The individuals were assessed using P300 elicited by the traditional paradigm (frequent stimulus: $800 \mathrm{~Hz}$; rare stimulus: $1200 \mathrm{~Hz}$ ) and by the omission paradigm (frequent stimulus: $800 \mathrm{~Hz}$; rare stimulus: absence of sound). Both paradigms were presented to one ear at a time, at $80 \mathrm{dBSPL}$, and 300 stimuli (45 rare) were presented in each stimulation. The "Neuroscan Stim2" was used to obtain the P300 with 12 active electrodes fixed at the following positions: FPz, F4, Fz, F3, C4, Cz, C3, CP6, CP5, P4, Pz e P3. The largest peak after the N1-P2-N2 complex was considered the P300. Its amplitude was measured considering the pre-stimulation response baseline, while its latency was measured at the most positive peak. The Analysis of Variance (ANOVA) with repeated measures was used in this study. Topographic maps from the scalp to both paradigms were also analyzed. Results: To all 12 electrodes positions analyzed in this study, the mean latency $(\mathrm{ms})$ was significantly earlier and the mean amplitude $(\mu \mathrm{V})$ was significantly larger for the traditional paradigm compared to the omission paradigm. Also, better wave morphology was obtained for the traditional paradigm. The topographic maps to both paradigms has shown more generalized and positive activation at the centro-parietal region, indicating that the same brain areas were involved in both paradigms. Conclusion: The current study has demonstrated that the acoustic stimulus, absent on the omission paradigm, have an impact on the wave formation in respect to its latency, amplitude and morphology, evidencing the influence of sensorial information to the P300.
\end{abstract}

Descriptors: event related potential, P300; evoked potential, auditory; adults; hearing, acoustic stimulation; 
Introdução 


\section{INTRODUÇÃO}

Os Potenciais Evocados Auditivos de Longa Latência (PEALL) são os potenciais mais informativos e dinâmicos de monitoramento da informação provinda de indivíduos com performance cerebral ativa. Esses potenciais dizem respeito à recepção e ao processamento da informação sensorial, assim como ao processamento em níveis corticais que envolvem a atenção seletiva, memória, discriminação, compreensão e outras atividades cognitivas (Duncan et al., 2009).

Os componentes dos potenciais de longa latência são sensíveis às variações do processamento da informação. As operações refletidas nos componentes do PEALL são geradas por sistemas e estruturas cerebrais mais complexas do que os potenciais de curta latência (Hall, 1992; Duncan et al., 2009).

O P300, componente positivo do PEALL que ocorre aproximadamente a 300 ms após a apresentação do estímulo, está relacionado com um evento físico (estímulo) e mental, extraído do eletroencefalograma EEG. É um método não invasivo, que ocorre no domínio do tempo, com uma excelente resolução temporal, para estudar os processos cognitivos do cérebro humano (Picton, 1992; Cone-Wesson e Wunderlich, 2003; Duncan et al., 2009). Foi um dos primeiros potenciais auditivos a ser descrito (Davis et al., 1939; Sutton et al., 1965) e é o mais comum de longa latência. 
Esse potencial fornece informações a respeito dos processos que ocorrem no córtex cerebral relacionados com a cognição, a memória e a atenção auditiva necessária para o processamento auditivo central (Sutton, et al., 1965). As áreas auditivas cerebrais específicas que participam na geração dos P300 não são totalmente definidas. Sabe-se que essa geração é o resultado da participação conjunta de vários sítios geradores.

A forma mais comum para evocar o P300 é utilizando o paradigma tradicional (também chamado de oddball), por meio do qual são apresentados dois estímulos, um frequente e um raro, perceptivelmente diferentes, de forma randomizada. Os estímulos frequentes são deflagrados $80 \%$ ou $85 \%$ das vezes, e os estímulos raros, $20 \%$ ou $15 \%$. O indivíduo é orientado a indicar de alguma maneira a quantidade de estímulos raros que percebeu durante a realização do exame. Esse procedimento produz um potencial robusto, relativamente fácil de ser identificado na maioria da população normo-ouvinte. As respostas são registradas separadamente, sendo um traçado com a média das respostas ao tom frequente e a outro ao tom raro (Sutton et al., 1965; Hall, 1992; Picton, 1992; Polich et al., 1996; Cone-Wesson e Wunderlich, 2003, Duncan et al., 2009).

O P300 pode ser evocado utilizando vários tipos de estímulos, tais como tone burts, dois tipos de sílaba, palavras em meio a frases, intervalos sem som em meio a estímulos sonoros, entre outros (Hall, 1992; Cone-Wesson e Wunderlich, 2003). 
Estes potenciais são considerados potenciais endógenos, pois são gerados voluntariamente de forma ativa, como resultado de um evento cognitivo (ou seja, a decisão da ocorrência do tom raro durante a estimulação) diferentemente dos potenciais exógenos, como o Potencial Evocado Auditivo de Tronco Encefálico (PEATE), que surgem de forma passiva e reflexa, sendo resultado de uma estimulação acústica que sofre influência das características acústicas do estímulo (Hall, 1992; Polich et al., 1996; Musiek et al., 2005).

No entanto, alguns estudos mostraram que as características acústicas do estímulo do P300 podem interferir na amplitude e na latência da resposta, evidenciando, também, a existência de uma origem exógena para evocar o potencial (Papanicolau et al., 1985; Polich et al., 1996; Musiek et al., 2005; McCullagh et al. 2009).

Polich et al. (1996) mostraram que a intensidade interfere na amplitude e na latência da resposta, pois quanto maior a intensidade utilizada, maior a amplitude e menor a latência do potencial. Entretanto, cabe ressaltar que ao se definir que o potencial é endógeno, as amplitudes e as latências não deveriam ser influenciadas significativamente com o aumento ou a diminuição da intensidade.

Uma vez que a característica acústica do estímulo afeta o P300, é evidente que existe uma contribuição do estímulo para a formação da onda. Considerando que o P300 é um potencial puramente endógeno, ao se comparar o P300 ao paradigma tradicional de estimulação, com dois estímulos distintos, com o P300 com paradigma de omissão, ou seja, ausência de som 
para o estímulo raro, as ondas deveriam ser similares, visto que a decisão (cognitiva) seria a mesma para ambas as estimulações (McCullagh et al., 2009).

Do ponto de vista audiológico, esta contribuição, até agora, não foi completamente determinada. Experimentalmente, é importante determinar as contribuições exógena e endógena, e se o procedimento ainda é válido para avaliar situações em que não se tem certeza de que o P300 está ausente devido ao déficit sensorial (audição) ou à cognição. Teoricamente, ao se utilizar um paradigma com a ausência de som para o tom raro, chamado de paradigma de omissão, elimina-se o componente exógeno/sensorial para a formação do potencial, deixando, desta forma, o P300 essencialmente endógeno.

Desde que constatou-se que o estímulo acústico influencia o P300, a comparação entre os $\mathrm{P} 300$ gerados pelo paradigma tradicional e os gerados pelo paradigma de omissão pode ser usada para determinar as contribuições exógenas na formação da onda do P300.

É importante estabelecer qual a influência dos componentes endógenos e exógenos do P300 e estudar as áreas envolvidas na aquisição destes, visto que a localização exata da origem do P300 ainda é uma incógnita, embora alguns estudos apontem que as regiões central e parietal participem na geração das respostas (Picton e Hillyard, 1974; Ford et al. 1993; Takka e Stoki, 1998; Duncan et al. 2009; Kalaiah e Shastri, 2016). 
A hipótese deste estudo é que, com o paradigma de omissão, devem-se encontrar latências maiores e amplitudes menores comparadas ao paradigma tradicional, pois supõe-se que há uma contribuição exógena do estímulo acústico na formação do potencial. Ao realizar a estimulação com a ausência da parte sensorial, presume-se eliminar a contribuição exógena para a formação da onda. Utilizando-se a comparação entre os dois paradigmas, espera-se mensurar a contribuição exógena no P300 e contribuir para a visualização dos mapas topográficos nessas duas condições. 
Objetivos 


\section{OBJETIVOS}

\subsection{Objetivo Geral}

Verificar o efeito das contribuições endógena e exógena para a obtenção do P300 utilizando o paradigma tradicional e o paradigma de omissão em indivíduos jovens adultos e normo-ouvintes.

\subsection{Objetivos Específicos}

- Comparar as latências das ondas do complexo N1-P2-N2 utilizando paradigma tradicional e paradigma de omissão;

- Comparar as amplitudes, latências e morfologia das ondas do P300 utilizando o paradigma tradicional e o paradigma de omissão;

- Verificar as áreas cerebrais envolvidas nos dois paradigmas. 
Revisão da Literatura 


\section{REVISÃO DA LITERATURA}

Neste capítulo serão apresentados os trabalhos que serviram de base para a fundamentação teórica deste estudo. Devido ao fato de não ter sido encontrado, na literatura, um número vasto de estudos que tivessem investigado a contribuição exógena do P300 utilizando o paradigma de omissão, outras pesquisas que estudaram o P300 foram incluídas, assim como a literatura-base a respeito dos potenciais de longa latência. Os estudos foram apresentados priorizando a ordem cronológica, e optou-se por manter os termos utilizados pelos autores em cada trabalho.

Davis et al. (1939) gravou os primeiros registros de atividades elétricas cerebrais em resposta à apresentação de estímulos auditivos em seres humanos. O autor observou mudanças no eletroencefalograma (EEG) em resposta a um estímulo auditivo utilizando o termo K-complex para descrever os potenciais.

Sutton et al. (1965) estudaram os PEALL e mostraram que o potencial de longa latência, que ocorre próximo a 300 ms após a apresentação do estímulo, é influenciado pela probabilidade de o estímulo acústico ocorrer. Os autores realizaram diferentes estimulações com probabilidades de ocorrência diferentes e concluíram que os potenciais auditivos podem ser gravados no escalpo humano e sofrem dois tipos de influência: exógena, relativa à característica acústica do estímulo, e endógena, referente à reação e atitude do sujeito em relação ao estímulo. 
Segundo Picton et al. (1974), esses potenciais podem ser classificados segundo a latência com que ocorrem, ou seja, o intervalo de tempo entre o estímulo apresentado e a resposta originada. Esses registros podem ser classificados como potenciais de curta latência, quando ocorrem até $10 \mathrm{~ms}$ após a apresentação do estímulo, com origem na via auditiva periférica até o tronco encefálico; de média latência, quando ocorrem entre 12 e 50 ms, com origem predominante em áreas primárias do córtex auditivo; e como potenciais tardios ou de longa latência, quando ocorrem a partir de $50 \mathrm{~ms}$. Os autores relataram que houve uma controvérsia: a resposta refletia a ativação do córtex auditivo primário ou se tratava de uma resposta cortical mais generalizada.

Picton e Hillyard (1974) avaliaram o efeito da atenção nos potenciais evocados auditivos em todos os níveis do sistema auditivo para delinear a influência do processamento do estímulo acústico. Os indivíduos foram submetidos a várias estimulações em duas condições, sendo uma com atenção ao estímulo e outra ignorando-o. Em relação aos PEALL, os autores observaram que não há mudança nos componentes que antecedem o N1-P2 em relação à atenção, e notaram que esta envolve mudanças na resposta do córtex de associação, o qual é o principal gerador dos componentes N1-P2.

Estes componentes são dependentes dos parâmetros do estímulo acústico, contudo, também há uma dependência da atenção. Os autores descobriram que o maior efeito da atenção foi encontrado para evocar o P300. Em uma parte desse estudo foram avaliados os potenciais de longa latência utilizando o paradigma de omissão com 16 eletrodos ativos no escalpo. A distribuição topográfica encontrada para o P300 com paradigma de omissão 
demonstra ser mais generalizada e posteriormente distribuída no cérebro. As latências foram encontradas próximas a 400 ms. No entanto, esse estudo não avaliou a contribuição exógena para gerar o P300.

Ruchkin e Sutton (1978) nomearam o P300 evocado com dois estímulos auditivos como Evoked P300 e o evocado com a ausência do estímulo raro como Emitted P300. Os autores relataram que a amplitude do Emitted P300 é menor quando comparada à do Evoked P300. Dessa forma, o propósito do estudo foi investigar se a menor amplitude do Emitted P300 seria um equívoco temporal e analisar a relação entre a latência e a estimativa temporal.

Foram analisados oito voluntários com paradigmas de um ou dois cliques apresentados de forma randomizada. Os intervalos entre os cliques foram fixados em 750 e 1500 ms. Os autores mostraram um decréscimo maior na amplitude do Emitted P300 do que na do Evoked P300. No geral, o decréscimo para ambos os paradigmas foi maior para o intervalo de 1500 ms. Esse decréscimo foi atribuído à maior incerteza temporal relacionada à ocorrência do estimulo.

Ruchkin et al. (1981) realizaram um estudo para avaliar a equivalência funcional do "Emitted P300" (evocado com a omissão do estímulo raro) e o “Evoked P300" (evocado com dois estímulos auditivos). Foram avaliados oito indivíduos, com média de idade de 24,5 anos, com os paradigmas Emitted P300 e Evoked P300. Foram realizados vários protocolos, com 
intervalos interestímulos (IEE) e intensidade diferentes para ambos os paradigmas.

A fim de minimizar a incerteza temporal para o Emitted P300 foi realizado um treino antes da coleta e as respostas foram coletadas dos eletrodos $\mathrm{Oz}, \mathrm{Pz}, \mathrm{Cz}, \mathrm{Fz}$ e Fpz. Notou-se que a latência encontrada para o Emitted P300 foi maior do que para o Evoked P300 e maior nos eletrodos fronto-parietais. A amplitude encontrada foi maior para o Evoked P300 quando comparada ao Emitted P300. No entanto, não foram encontradas diferenças significantes. Os autores concluíram que há P300 em ambas as condições de estimulação e que elas são distintas.

Papanicolau et al. (1985) avaliaram o efeito da intensidade do estímulo no componente do P300 em indivíduos adultos com audição normal. Foram avaliados 13 indivíduos com o paradigma tradicional (1000 $\mathrm{Hz}$ para o estímulo raro e $1500 \mathrm{~Hz}$ para o estímulo frequente) com a probabilidade de $15 \%$ para o estímulo raro ocorrer. Pelo menos 30 respostas para o estímulo raro foram coletadas para as intensidades de 65 , $55,45,35,25$ e 15 dBNPS.

Os autores observaram diferenças significante para os componentes N1 e P2 no estímulo raro conforme a intensidade diminuía. Para o P300, não foram observadas diferenças de amplitude com a variação da intensidade. No entanto, os autores concluíram que esse achado não resolve a questão referente a se o P300 é puramente endógeno ou não. 
Outro ponto importante do estudo foi o aumento significativo da latência com a redução da intensidade do estímulo para o P300. Segundo a pesquisa, a latência do P300 é usada para avaliar mudanças na eficiência do processamento da informação no envelhecimento, demências, lesões cerebrais e outras condições clínicas. Tendo em vista esses achados, os autores observam que é importante verificar em outros grupos os efeitos das mudanças de intensidade do estímulo.

Por sua vez, Polich (1986) realizou um estudo com o P300 utilizando um paradigma com dois tons distintos ( $20 \%$ para o estímulo raro) com os eletrodos Fz, Cz e Pz. Foram avaliados 100 indivíduos normo-ouvintes, por meio de dois blocos de estimulação, com o objetivo de avaliar a variação da morfologia intrassujeito, as diferenças entre os sexos feminino e masculino e a relação entre a amplitude e latência do P300.

Não foram verificadas diferenças significante entre os blocos de estimulação para a amplitude e latência do P300, confirmando que a morfologia geralmente é constante para este potencial. Foram encontradas médias de $313,94,305,35,306,74$ ms para latência e médias de 9,71, 12,14 e 12,68 $\mu \mathrm{V}$ para amplitude nos eletrodos $\mathrm{Fz}, \mathrm{Cz}$ e $\mathrm{Pz}$ respectivamente, demonstrando que as maiores amplitudes estavam associadas às menores latências nos eletrodos localizados na região parietal e central do escalpo. Foram observadas maiores amplitudes para o sexo feminino quando comparadas ao sexo masculino. O autor concluiu que os achados dão suporte à interpretação teórica de que o P3 está relacionado a processos de memória concernentes ao lobo parietal. 
Já Smith et al. (1990) apontaram que o P300 tem sido estudado como um marcador neural relacionado à cognição, e que a identificação dos geradores neurais do P300 ainda é assunto de estudo. Essa pesquisa foi realizada para identificar, de forma confiável, as regiões anatômicas específicas que contribuem para a geração do P300 e ilustrar a variação intrassujeito nas áreas avaliadas. Foram avaliados 10 indivíduos que apresentavam convulsão clinicamente intratável (epilepsia), por meio de eletrodos intracanianos posicionados na região média-lateral do lobo frontal, parietal e temporal. O número de eletrodos e o posicionamento foram delimitados de acordo com critérios clínicos. Foram relatados os resultados encontrados para o lobo frontal, temporal e parietal.

Os autores concluíram que a localização principal dos geradores do P300 é o neocórtex lateral e o lobo parietal inferior. Os autores também deixaram claro que ocorrem atividades no hipocampo, e que provavelmente o lobo temporal e o lobo frontal são ativados simultaneamente para eliciar o P300.

Polich (1990) afirma que a probabilidade de ocorrência do estímulo influencia a amplitude do P300. A relação entre a probabilidade de ocorrência do estímulo e o tamanho do componente P300 é diretamente inversa: quanto menos frequente for o estímulo raro, maior a amplitude e vice-versa. A probabilidade de ocorrência do estímulo é determinante para a amplitude, assim como o intervalo interestímulo (IIE), que também afeta o potencial. 
Sabe-se que IIE curtos evocam menores amplitudes do que IIE maiores. Dessa forma, o objetivo deste estudo foi verificar a relação entre a probabilidade de ocorrência do P300 e o IIE. Neste trabalho, dois grupos diferentes com 16 indivíduos foram avaliados, com eletrodos ativos no Fz Cz e Pz.

Foram realizados dois experimentos com o paradigma tradicional (1000 Hz para o frequente e $2000 \mathrm{~Hz}$ para o raro): no primeiro experimento, foram avaliadas as taxas de probabilidade de $10 \%, 30 \%$ e $50 \%$, com IIE de 1,5 e 3 segundos. No segundo experimento, foram avaliadas as taxas de probabilidade de $20 \%, 50 \%$ e $80 \%$, com IIE de 4 e 10 segundos.

No primeiro experimento, a amplitude foi menor para o IIE menor e diminuiu com o decréscimo da probabilidade de ocorrência do estímulo, de $10 \%$ para $50 \%$. Esses achados foram confirmados nos três eletrodos. A latência para o IIE de 1,5 segundo produziu respostas menores do que no IIE de 3 segundos. No segundo experimento, a única diferença significativa encontrada foi a diminuição da amplitude da onda no eletrodo frontal em relação ao parietal. A latência diminuiu, apresentando diferença estatisticamente significante, com o aumento da probabilidade de ocorrência de $20 \%$ para $80 \%$. Os componentes N1-P2-N2 foram avaliados no eletrodo $\mathrm{Cz}$ com respostas entre $80-120 \mathrm{~ms}, 100-200 \mathrm{~ms}$ e $160-240 \mathrm{~ms}$ respectivamente. Os autores concluíram que quando o estímulo ocorre frequentemente devido ao fato de o IIE ser mais curto, mais recursos são utilizados em um menor tempo, gerando, dessa forma, menores amplitudes. Quando o estímulo ocorre raramente (IIE maiores de 4 
segundos), há maior recuperação do sistema, levando a maiores amplitudes.

Hall (1992) diz que os PEALL podem ser evocados 50 ms após a ocorrência do estímulo, geralmente utilizando uma baixa taxa de apresentação do estímulo, em torno de 1 ou 2 por segundo. O autor relata que as amplitudes dos PEALL ocorrem em torno de 3 a $10 \mu \mathrm{V}$ para os componentes P1, N1, P2, N2.

Em relação ao P300, Hall (1992) relatou que a terminologia endógena seria ambígua e inadequada para esse potencial, visto que este é produzido por um estimulo exógeno. No entanto, apesar de considerar inadequado, o autor se refere às respostas como "endógenas" ou como “Event-Related Potential - ERP”, visto que são os termos consistentes e convencionalmente utilizados na literatura. Os ERP podem ser evocados com tons, sílabas, omissão de tons, com atenção e desatenção ao estímulo etc. O paradigma mais comum para evocar o potencial utiliza dois estímulos: um estímulo frequente e um estímulo raro. A probabilidade de ocorrência do estímulo raro é, geralmente, de 10 a $15 \%$ dos estímulos. A amplitude da resposta é comumente grande, entre 5 a $20 \mu \mathrm{V}$, e ocorre aproximadamente em 300 ms. No entanto, a amplitude e a latência desse potencial podem variar imensamente dependendo das condições de medidas, tais como tipo de estímulo, probabilidade de ocorrência, intervalo interestímulo, intensidade etc. As aplicações clínicas para o PEALL geralmente ocorrem em paralelo com neurodiagnóstico de distúrbio auditivo acima do nível do tronco encefálico. O mais utilizado na prática clínica é o 
P300. A literatura aponta um número grande de estudos com pessoas que apresenta, suspeita ou diagnóstico de alteração de processamento auditivo, variando de distúrbios de aprendizagem a lesões cerebrais.

Picton (1992) realizou uma revisão do conhecimento do P300 e sugeriu algumas direções para futuras pesquisas. Essa revisão se baseou em estudos com o paradigma tradicional (dois estímulos distintos para evocar o P300). A revisão apresentou informações a respeito dos aspectos técnicos para gravação do $\mathrm{P} 300$, aspectos fisiológicos do potencial, diferenças individuais, aspectos farmacológicos (álcool, drogas, anestésico etc.), utilização do P300 na clínica e outras questões para as quais ainda não havia respostas na época.

As pesquisas incluídas na revisão sugerem que a amplitude varia de acordo com a quantidade de atenção dada ao estímulo, o que mostra que as repostas mais proeminentes ocorrem quando os pacientes estão atentos e que o P300 é maior quando o estimulo ocorre em menor quantidade (pouco provável, 10 a 20\%). A distribuição no escalpo é generalizada e com maiores amplitudes na região centro-parietal, no entanto, mostra que a distribuição do escalpo do P300 variou em alguns estudos e explica que isso pode ter ocorrido devido à variação da estimulação de um estudo para outro (que pode ter sobreposto outro potencial) ou que se pode desconsiderar a ideia de um gerador único e levar em conta a ideia de múltiplos geradores no escalpo para gravar o P300. 
O autor referido anteriormente conclui afirmando que, provavelmente, a mais importante questão a respeito do P300 é a natureza da sua origem no cérebro e reforça a necessidade de estudos em animais para se saber o que acontece no córtex durante a geração do potencial.

Ford et al. (1993) com o intuito de analisar a progressão espaçotemporal dos componentes N2/P3/N3, utilizaram a técnica de imagem cortical (Cortical Imaging Technique - CIT) para avaliar o potencial. O principal objetivo de pesquisas com eletroencefalografia (EEG) é a localização e a descrição dos geradores neurais dos potenciais gravados no escalpo. A utilização de mapas topográficos mostra a distribuição dos geradores neurais, no entanto, as gravações no escalpo são afetadas pelos efeitos atenuantes e difusores do couro cabeludo. Sendo assim, os autores utilizaram a CIT, a qual é um método matemático que remove esses efeitos.

Os pesquisadores avaliaram 30 indivíduos adultos com audição normal, utilizando o equipamento "NeuroScience Brain Imager" com 28 canais, e o P300 foi evocado com o paradigma tradicional (1 $\mathrm{kHz}$ para o tom frequente e $2 \mathrm{kHz}$ para o tom raro). Segundo os autores, o componente $\mathrm{N} 1$ (média 118 ms no eletrodo $\mathrm{Cz}$ ) é um componente exógeno dependente do estímulo, e os geradores desse componente estão aparentemente localizados no córtex auditivo primário. O P300 ocorreu em média a 346 ms e reflete processos cognitivos envolvidos na tarefa. 
Ford et al., (1993) ainda sugerem múltiplos geradores para o P300, confirmando os achados de outras pesquisas que realizaram mapas topográficos no escalpo sem a técnica de imagem cortical. Os autores mostraram que as características dos mapas topográficos corticais quando comparadas às dos mapas topográficos corticais com CIT são semelhantes. Concluíram que a utilização dos mapas facilita a mensuração das simetrias encontradas no escalpo, o que pode auxiliar no caso de alterações assimétricas.

Polich et al. (1996), com o objetivo de avaliar a influência da intensidade no P300, tanto visual quanto auditiva, avaliaram 32 jovens adultos com audição normal. As razões para o estímulo acústico afetar as medidas do P300 ainda não estavam claras, diferentemente dos componentes exógenos N100, P200 e N200 que, como se sabe, são dependentes do estímulo auditivo. Para evocar o P300 auditivo, fez-se uso do paradigma tradicional $(1000 \mathrm{~Hz}$ para o estímulo frequente e $2000 \mathrm{~Hz}$ para o estímulo raro). Além disso, foram utilizadas intensidades baixas e altas em três probabilidades de ocorrência do estímulo-alvo: $20 \%, 50 \%$ e $80 \%$, apresentados em diferentes blocos. Captaram as respostas nos eletrodos Fz, $\mathrm{Cz}$ e Pz. Os pesquisadores notaram que a amplitude do P300 se reduzia à medida que a intensidade do estímulo decrescia, e diminuía também quando a probabilidade aumentava.

Em relação à latência, notaram que aumentava significativamente à medida que a intensidade do estímulo decrescia. Para os componentes N100, P200 e N200, quando a intensidade reduzia, a amplitude dos 
componentes diminuía similarmente ao P300. Os achados desses estudos indicaram que a intensidade influencia nas medidas do P300.

Desta forma, pode-se perceber que se o P300 fosse exclusivamente endógeno, as amplitudes e as latências não seriam influenciadas com o aumento ou a diminuição da intensidade.

Polich e Heine (1996) realizaram o P300 de forma visual e auditiva em duas condições: paradigma tradicional e paradigma de um-estímulo (omissão do estímulo frequente mantendo os mesmos intervalos e condições do paradigma tradicional) para avaliar a topografia da resposta e os efeitos da mudança de paradigma. Avaliaram 32 voluntários jovens adultos com audição normal. Foram utilizados 15 eletrodos para analisar a distribuição topográfica do escalpo entre a região frontal e parietal, por meio dos eletrodos laterais (dipolos). Os autores mostraram que o P300 pode ser realizado em ambas as condições, no entanto, a amplitude foi maior no paradigma tradicional do que no de um-estímulo, e a latência também foi maior no paradigma tradicional.

As amplitudes diminuíram da linha mediana até os eletrodos temporais, e os sítios parietais tiveram maior amplitude e, consequentemente, o maior declínio ocorreu para os eletrodos laterais. A maior vantagem do paradigma de um estímulo é ser um método muito simples para eliciar o $\mathrm{P} 300$, que pode ser especialmente útil para a aplicação na clínica, quando o paradigma tradicional for excessivamente 
complexo para alguns indivíduos ou situações como avaliação de crianças ou pessoas com alteração cognitiva.

Tarkka e Stokic (1998) avaliaram sete indivíduos utilizando o Brain Electrical Source Analysis (BESA), com 30 eletrodos ativos no escalpo. Usaram três paradigmas: 1) paradigma tradicional clássico (2000 Hz para tom frequente e $1000 \mathrm{~Hz}$ para tom raro); 2) paradigma com a omissão do estímulo frequente; e 3) paradigma com a omissão do estímulo raro. 0 objetivo desse estudo foi verificar se os componentes do P300 difeririam em morfologia e/ou nas estruturas cerebrais responsáveis por gerar os potenciais de acordo com o paradigma utilizado. O P300 foi encontrado nas três condições de estimulação. O paradigma tradicional e o paradigma com omissão do estímulo frequente apresentaram latência (338,6 ms e 289,6 ms), amplitude e topografia do escalpo parecidas. Os pesquisadores encontraram, no paradigma com omissão do estímulo raro, que o pico do P300 estava atrasado em relação às outras estimulações, 380,6 ms. Os autores concluíram que os resultados encontrados dão suporte à noção de que áreas do lobo temporal superior, córtex auditivo primário e secundário são ativadas para formação do potencial, e também sugerem que áreas do lobo temporal medial, como hipocampo e para-hipocampo, assim como a ativação da insula, contribuem para a formação do componente do P300. Os resultados mostram os mesmos geradores neurais para o P300 nos três paradigmas pesquisados.

Cone-Wesson e Wunderlich (2003) mostraram que os potenciais corticais apresentam algumas vantagens quando comparados às técnicas, como os 
potenciais de tronco encefálico, porque são mais ligados à percepção do som e podem ser evocados por sons complexos como a fala.

As autoras realizaram uma revisão considerando como os potenciais evocados corticais podem ser utilizados para estimar limiares, inferir habilidades de discriminação e indicar os efeitos da reabilitação. Relataram que existem dois tipos de ERP, os obrigatórios e os cognitivos. Os ERPs obrigatórios são determinados primariamente pelos parâmetros do estímulo acústico e pela integridade da via auditiva.

São três os potenciais obrigatórios, N1-P2-N2, gerados no córtex auditivo primário e na associação de áreas do lobo temporal. Já o ERP cognitivo ou endógeno, P300, têm características que variam de acordo com a atenção e performance cognitiva do sujeito. O paradigma frequentemente utilizado para evocar a resposta envolve dois estímulos: frequente, apresentado em 80 a $90 \%$ das vezes, e raro, apresentado de 10 a $20 \%$ das vezes. Os geradores neurais para esses ERP incluem o córtex auditivo primário, a associação de áreas centroparietais e do lobo frontal, e áreas do cérebro que envolvem memória, como hipocampo. As autoras relatam ainda que os tone-burts de longa duração, com espectro similar aos tons puros, podem ser usados para evocar os componentes obrigatórios.

Fjell e Walhovd (2003) realizaram o P300 em dois experimentos para isolar os efeitos da cognição e audição. Ambos os experimentos foram comparados para estudar os efeitos da variação na intensidade do estímulo. No primeiro experimento, 18 participantes realizaram o paradigma tradicional 
com cinco diferentes intensidades. No segundo experimento, o P300 foi realizado em três grupos, que somavam 57 participantes, com variações de limiares de audição dentro dos limites da normalidade $(0-5,10-15,20-25$ dBNA como média dos limiares auditivos), com as mesmas cinco intensidades realizadas no primeiro experimento. Os autores observaram que a variação de intensidade influencia a latência e amplitude do P300. Mesmo as mudanças não sendo significantes, elas tendem a ser consistentes. Concluíram que o P300 tem um alto índice de função cognitiva, sendo realmente um potencial endógeno, visto que, mesmo com a manipulação da intensidade, há presença de respostas. Relataram também que pode ser considerado um marcador válido para avaliar o declínio cognitivo relacionado à idade.

Em outro experimento, Musiek et al. (2005) avaliaram 16 indivíduos com idade entre 12 e 43 anos para comparar o P300 com o paradigma tradicional em diferentes intensidades. O objetivo desse estudo foi verificar se a amplitude aumentava e a latência diminuía com o aumento da intensidade do estímulo. A pesquisa foi iniciada a $75 \mathrm{~dB}$ e foi diminuindo em passo de $10 \mathrm{~dB}$ e aumentando a $5 \mathrm{~dB}$ para replicação das ondas N1-N2 e P3.

Os pesquisadores também analisaram os efeitos exógenos (intensidade) na amplitude e morfologia da onda. Esse estudo mostrou que a resposta do P300 é considerada satisfatória mesmo nos limiares de audibilidade. A partir desse experimento, várias observações puderam ser feitas: N1-P2 podem ser evocados sem necessitar de nenhum processamento cognitivo; a amplitude do P3 é provavelmente reforçada pela tarefa cognitiva e requer maior atenção 
subjetiva e atividade neural do que a mera detecção ou reconhecimento de um estímulo.

Comparando as intensidades, notaram diferenças nas amplitudes e latências dando suporte a estudos que demonstraram um provável componente exógeno para o P300 com base tanto nas alterações de latência como nas de amplitude relacionadas à mudança de intensidade do estímulo, mostrando que as diferenças nos resultados podem estar relacionadas aos componentes exógenos ao invés dos componentes endógenos.

Duncan et al. (2009) realizaram uma revisão com a descrição dos métodos recomendados para a realização dos ERPs e aplicação clínica nos distúrbios psiquiátricos e neurológicos. Foram incluídos, nesse estudo, o Mismatch Negativity (MMN), P300 e N400. Os autores relatam que os ERPs são associados no tempo a um evento físico ou mental e são extraídos do EEG. Observou-se que o P300 tem uma distribuição centro-parietal, sendo maximizada em relação à amplitude na linha média do escalpo. Usualmente é evocado com o paradigma tradicional, com dois estímulos distintos e randomizados. Constataram que a estimulação acústica que normalmente evoca o P300 não tem efeito no potencial quando é ignorada ou quando não tem atenção ao estímulo, mostrando, assim, que a percepção e a variação da atenção contribuem para a amplitude desse potencial, enquanto as características acústicas do estímulo têm pouco ou nenhum efeito sobre a resposta deste. 
Os autores apontaram também que há uma relação entre a probabilidade de ocorrência do estímulo e a formação do potencial e que o P300 somente é evocado após o estímulo ser avaliado e categorizado pelo indivíduo. Dessa forma, dois tons que diferem apenas por poucos hertz evocam P300 com latências mais longas, pois quanto mais complexo for o processamento/diferenciação do estímulo, maior a latência. $O$ tempo de latência é composto pela variação do tempo de reação do indivíduo e pela variação associada ao estímulo em relação aos geradores neurais.

Alguns estudos sugerem que o P300 é produzido por geradores múltiplos, relativamente independentes, ou que é um reflexo de um sistema central integrado com conexões difundidas em todo o cérebro. De acordo com ambas as visões, o P300 pode ser registrado a partir de várias localizações corticais e subcorticais, e os principais geradores do P300 estão no hipocampo, sulco temporal superior, córtex pré-frontal ventrolateral e, provavelmente, no sulco intraparietal. Segundo o estudo, a recomendação para evocar o potencial com o paradigma tradicional é a seguinte: duas categorias de estímulo (frequente e raro), que podem ser tons, sílabas, palavras etc., com duração de 50-150 ms e intensidade de 70 dBnNA, intervalo interestímulo de 1-2 segundos, com probabilidade de $10 \%$ a $20 \%$ para o estímulo raro, e $80-90 \%$ para o estímulo frequente. Os autores sugerem uma montagem mínima com os seguintes eletrodos ativos: Fz, Cz e Pz.

McCullagh et al. (2009) compararam as amplitudes, as morfologias e as latências do P300 geradas pelo paradigma de omissão, assim como pelo paradigma tradicional acima do limiar e no limiar auditivo, para determinar a 
contribuição exógena para a formação do P300. O principal objetivo desse estudo foi investigar qual o paradigma que produziu a melhor onda em níveis supralimiares e próximos aos níveis de limiar. O segundo objetivo foi quantificar o componente exógeno do P300 comparando a amplitude das ondas nos dois paradigmas utilizados em níveis de limiar. Analisaram 15 jovens adultos normoouvintes, submetidos à gravação do P300 apenas na orelha direita. Para o paradigma tradicional foram utilizadas as frequências de $1000 \mathrm{~Hz}(85 \%)$ e 2000 $\mathrm{Hz}(15 \%)$, com $10 \mathrm{~ms}$ rise and fall e $20 \mathrm{~ms}$ de plateau, com taxa de apresentação de $0.9 \mathrm{~Hz}$ e 300 estímulos. Para o paradigma de omissão, foi utilizada apenas a frequência de 1000 (85\%). O estímulo raro foi omitido.

Para cada paradigma, o P300 foi mensurado acima do limiar (60dB) e no limiar. O limiar do P300 foi estabelecido por decréscimos de $10 \mathrm{~dB}$ e acréscimos de $5 \mathrm{~dB}$ até que a onda fosse reproduzida. Não foram encontradas diferenças significantes para latência entre ambos os paradigmas. No entanto, as latências foram significantemente afetadas pela intensidade. As amplitudes foram significantemente maiores quando geradas pelo paradigma tradicional quando comparadas com o paradigma de omissão. Pode ser observada uma diferença significativa para ambos os paradigmas.

Dessa forma concluíram que o P300 é maior em amplitude e menor em latência quando gerado pelo paradigma tradicional e comparado com o paradigma de omissão, além de apresentar melhor morfologia, indicando, dessa forma, uma contribuição exógena para a formação do potencial. 
Rusiniak et al. (2013) tiveram o objetivo de desenvolver e avaliar um protocolo de registro simultâneo de ERP e ressonância funcional (fMRI) durante o paradigma tradicional de estimulação. Foram avaliadas 11 crianças (média 13a e $6 \mathrm{~m}$ ) com audição normal, e foram realizadas duas sessões com o paradigma de omissão: uma dentro do scanner e outra fora do scanner. Utilizaram o equipamento "Neuroscan System" de 64 canais para o ERP e o equipamento "Siemes Magneton Trio" para a ressonância.

As comparações entre os ERP realizados dentro e fora do scanner mostraram uma diferença significativa para o componente $\mathrm{N} 1$, o qual depende das caraterísticas acústicas do estímulo. As diferenças observadas para o P3 não foram significativas, no entanto foram encontradas diferenças para a amplitude que podem ser justificadas pelo efeito de aprendizado, habituação e estresse na combinação do ERP-fMRI, além de os números de eventos e randomizações serem diferentes nas duas estimulações.

A localização do P300 correspondeu parcialmente aos resultados da fMRI nas regiões frontal e parietal. Na ressonância, foram encontradas atividades no giro frontal médio, insula, lobo parietal, tálamo e cerebelo. Esse protocolo de registro simultâneo forneceu dados com alto nível de significância, mostrando que ambas as estimulações (dentro e fora do scanner) podem ser comparadas. Estes resultados podem contribuir para uma melhor compreensão da atividade cerebral para formação do P300 e seus subcomponentes, concluindo que o ERP-fMRI pode ser útil na investigação de correlações neurais de atenção auditiva para evocar o P300. 
Kalaiah e Shastri (2016) mostraram que, para investigar a natureza do P300 com um estímulo dinâmico, o potencial pode ser realizado com estímulos linguísticos ou não linguísticos, no entanto, quando o estímulo linguístico é utilizado os sujeitos dependem de habilidades linguísticas para tomar a decisão da ocorrência do estímulo raro. Dessa forma, os autores eliminaram o processamento linguístico e usaram um estímulo não linguístico com variação de frequência. O objetivo desse estudo foi investigar a diferença entre o P300 realizado por meio de estímulo não linguístico, com variação de frequência durante a estimulação, e o estímulo raro e comparar com os estímulos convencionais que são estáticos ou diferem do estímulo frequente já no início da estimulação.

Foram avaliados nove adultos com audição normal. O P300 foi evocado com o paradigma tradicional, e para montar os protocolos foram usados seis estímulos: dois tons puros (1 kHz e $2 \mathrm{kHz}$ ) e quatro tons com variação de frequência. A frequência inicial dos quatro tons com variação foi de $1000 \mathrm{~Hz}$, com mudança para 3000 Hz, $2000 \mathrm{~Hz}, 500 \mathrm{~Hz}$ e 750 Hz. Os estímulos tinham duração de 400 ms e a mudança de frequência ocorreu em 200 ms após o início da estimulação (10 ms rise/fall).

Os autores realizaram cinco estimulações $(1 / 2 \mathrm{kHz} ; 1 / 1-3 \mathrm{kHz} ; 1-2 \mathrm{kHz}$; 1/1-0.5 kHz; 1/1-0.75 kHz), sempre com o tom de $1 \mathrm{kHz}$ para a estimulação frequente. Os autores avaliaram os componentes N1-P2-N2 nas cinco estimulações e não encontraram diferença significativa na latência dos picos, mostrando que são componentes obrigatórios e dependentes do estímulo acústico. No entanto, apenas para a estimulação por meio do estímulo raro de 
$2000 \mathrm{~Hz}$ foi observado o P300 em contraste, com as estimulações que apresentavam tons com variação de frequência que evocaram múltiplos picos rotulados, como P270, N330, P450, N470 e P600.

A distribuição do escalpo para o N330 é parecida com a distribuição do $\mathrm{N} 1$, portanto, com base nessa similaridade, sugeriram que o $\mathrm{N} 1$ e o N330 refletem a mesma atividade do cérebro. Concluíram que é possível que o P270, N330 e P450 sejam respostas obrigatórias como P1-N2-P2 evocada pela variação de frequência nos estímulos. A distribuição do escalpo para o P300 (1/2kHz) mostrou ativação na região posterior do escalpo, indicando boa ativação da região parietal. O P600 encontrado tem a mesma distribuição no escalpo que o P300 (1/2kHz), assumindo dessa forma os mesmos processos envolvidos na geração do P300 ou na tomada de decisão. A latência reflete o tempo necessário para a classificação do estímulo, a qual é proporcional ao tempo necessário para detectar e avaliar o estímulo-alvo, sendo que nesse estudo a mudança de tom ocorreu 200 ms após o início do estimulo.

Desta forma era esperado que os voluntários demorassem mais para detectar e avaliar o tom raro, resultando em um prolongamento da latência. Alguns estudos mostraram que essa variação de frequência do estímulo é denominada Acoustic Change Complex (ACC). Os autores concluíram que as características do potencial cortical no paradigma tradicional, usando um estímulo com variação de frequência, são diferentes do paradigma tradicional com tom puro, estático. Os tons com variação de frequência podem evocar o ACC com o mesmo paradigma do P300. 
Métodos 


\section{MÉTODOS}

O presente estudo obteve aprovação da Comissão de Ética e Pesquisa da Faculdade de Medicina da Universidade de São Paulo (CEP-FMUSP), processo $n^{0}$ 501/2013 (Anexo A).

As avaliações foram realizadas no Ambulatório do Hospital Universitário da Universidade de São Paulo (FMUSP), com o apoio financeiro da Coordenação de Aperfeiçoamento de Pessoal de Ensino de Nível Superior (CAPES).

\subsection{Casuística}

Participaram do estudo 30 voluntários normo-ouvintes, com idade entre 18 e 40 anos, que atendiam aos seguintes critérios de elegibilidade:

a) Apresentar limiares audiométricos menores ou iguais a 20 dBNA nas frequências de 250, 500, 1000, 2000,3000, 4000, 60000 e $8000 \mathrm{~Hz}$, bilateralmente;

b) Apresentar curva timpanométrica tipo "A" bilateralmente e reflexos acústicos contralaterais presentes (Jerger, 1970);

c) Apresentar integridade das vias auditivas no Potencial Evocado Auditivo de Tronco Encefálico (PEATE);

d) Apresentar resultados dentro dos limites da normalidade para o teste Dicótico de Dígitos (TDD) e no teste Gaps-in-Noise (GIN) usados como triagem para o Processamento Auditivo; 
e) Não apresentar histórico de comprometimento otológico, cognitivo ou neurológico evidente.

Todos os voluntários tiveram acesso às informações sobre o estudo e sobre os procedimentos realizados por meio do Termo de Consentimento Livre e Esclarecido (TCLE) e das informações transmitidas verbalmente pela pesquisadora (Anexo B). O TCLE foi assinado antes do início das avaliações.

\subsection{Procedimentos}

Antes do início da avaliação, os voluntários responderam a uma breve anamnese, com o objetivo de obter informações sobre dados pessoais e histórico audiológico. Todos os voluntários foram submetidos à avaliação audiológica básica, que englobou: meatoscopia, audiometria tonal e vocal, medidas de imitância acústica, testes comportamentais do processamento auditivo e avaliação eletrofisiológica.

\subsubsection{Avaliação Audiológica}

A meatoscopia fornece dados importantes a respeito do Meato Acústico Externo (MAE), principalmente quando se utilizam fones de inserção, com os quais há grande risco de o excesso de cera bloquear o tubo condutor do estímulo. Os indivíduos que apresentaram excesso de cerúmen na inspeção otoscópica do MAE foram encaminhados para o otorrinolaringologista e instruídos a retornar após conduta otorrinolaringológica.

Para a realização da audiometria tonal e vocal, utilizou-se o equipamento da marca "Interacoustics", modelo "AC33", em cabina acústica da marca 
Siemens (ANSI, 1991) com os fones supra-aurais TDH-50. Para determinação do limiar de audibilidade na audiometria tonal, foram testadas as frequências de 250 a $8000 \mathrm{~Hz}$ por via aérea. O limiar de audibilidade foi considerado na intensidade à qual o paciente respondeu duas das quatro apresentações (50\% das vezes).

Para a pesquisa da audiometria vocal, foi realizada a pesquisa do Limiar de Reconhecimento de Fala (LRF) e do Índice Percentual de Reconhecimento de Fala (IPRF), utilizando a lista de vocábulos proposta por Santos e Russo (1986).

As medidas de imitância acústica foram realizadas com o equipamento "Interacoustics", modelo "AT235", visando avaliar a integridade do sistema tímpano-ossicular por meio da obtenção da curva timpanométrica e da pesquisa do reflexo acústico contralateral nas frequências de 500, 1000, 2000 e $4000 \mathrm{~Hz}$.

\subsubsection{Testes comportamentais do Processamento Auditivo}

Após a avaliação audiológica, os voluntários realizaram os testes comportamentais utilizando o equipamento da marca "Interacoustics", modelo "AC33", em cabina acústica da marca "Siemens" (ANSI, 1991), com os fones supra-aurais TDH-50. Foi utilizado um Compact Disc Player com saída direta para o audiômetro e gravação do teste dicótico de dígitos (TDD) (Pereira e Schochat, 2011) e do teste Gaps-in-Noise (GIN) (Musiek et. al., 2005b). 
O teste dicótico de dígitos foi escolhido como triagem e serve para avaliar a habilidade de integração binaural e figura fundo para sons linguísticos. Consiste na apresentação de 20 sequências de quatro dígitos, os quais são apresentados em pares simultaneamente nas duas orelhas. Os voluntários foram instruídos a repetir os quatro números ouvidos. Foram levados em consideração os valores normativos apresentados no Quadro 1.

Quadro 1 - Valores normativos para o teste dicótico de dígitos, de acordo com a idade

\begin{tabular}{|cccc|}
\hline & $7 / 8$ anos & $9 / 10$ anos & $\geq 11$ anos \\
DC & $85 \%$ & $95 \%$ & $95 \%$ \\
ED & $82 \%$ & $95 \%$ & $95 \%$ \\
\hline
\end{tabular}

Legenda: $\mathrm{DC}=$ Direita competitiva, $\mathrm{ED}=$ Esquerda Competitiva

FONTE: Pereira e Schochat (2011)

O teste GIN foi escolhido para avaliar resolução temporal e também porque de certa forma reflete de maneira comportamental a habilidade que deve ser avaliada no teste eletrofisiológico quando for utilizado o paradigma de omissão. Nesse teste, são apresentadas várias sequências de estímulos de seis segundos de ruído branco, nos quais foram inseridos, randomicamente, intervalos de silêncio de diferentes durações $(2,3,4,5,6,8,10,12,15,20$ milissegundos). Os voluntários foram instruídos a identificar os intervalos de silêncio. Foram levados em consideração os valores normativos apresentados no Quadro 2.

Quadro 2 - Valores normativos para o Teste Gaps in Noise, de acordo com a idade

\begin{tabular}{|cc|}
\hline & $\geq 9$ anos \\
OD & $5 \mathrm{~ms}$ \\
OE & $5 \mathrm{~ms}$ \\
\hline
\end{tabular}

FONTE: Musiek et. al. (2005) 


\subsubsection{Avaliação Eletrofisiológica}

Iniciou-se a avaliação eletrofisiológica realizando o Potencial Evocado Auditivo de Tronco Encefálico (PEATE) com o equipamento da marca "Grason Stadler", modelo "AUDERA", com estímulo clique, duração de 100 ms, na intensidade de 80 dBnNA para avaliar a integridade das vias auditivas e evitar distorções, visto que disfunções no sistema auditivo periférico ou no tronco encefálico podem contaminar os resultados obtidos no P300.

Para esse registro, os voluntários foram acomodados confortavelmente em uma cadeira reclinável. Além disso, foi necessária a utilização de eletrodos de superfície dispostos nas mastoides direita (M2) e esquerda (M1) e na fronte (Fpz) (Jasper, 1958). Visando tirar a oleosidade da pele nos locais de fixação dos eletrodos para facilitar a condução do estímulo, utilizou-se gel abrasivo “Nuprep" e pasta eletrolítica "Ten20". Por meio do medidor localizado no préamplificador, as impedâncias da interface pele-eletrodos foram verificadas até que todas assumissem valor igual ou menor que $5 \mathrm{k} \Omega$. Para condução do estímulo sonoro, utilizou-se fones de inserção EAR-phones $3 A$.

Para a realização do PEATE, os seguintes parâmetros foram levados em consideração:

- Estímulo: clique com duração de 100 ms;

- Polaridade: Rarefeita;

- Filtro: 100 - $1000 \mathrm{~Hz}$;

- Janela: $15 \mathrm{~ms}$;

- Intensidade: 80 dBnNA. 
Os voluntários somente foram submetidos à gravação do P300 quando confirmada a normalidade no PEATE, tanto na morfologia das ondas quanto nos valores das latências absolutas e das latências interpicos das ondas I, III e V.

Para realização do P300, utilizou-se o equipamento da marca "Neuroscan electroencephalographic system®”, modelo “Stim2”. Esse equipamento permite a colocação de eletrodos de superfície no escalpo tanto para o registro das ondas como para a visualização da área cerebral ativada durante as estimulações. Nesse estudo, utilizou-se o “Quick-Cap 64 Channel”, que é uma touca com 64 eletrodos, a qual permite a visualização de uma neuroimagem, proporcionando, dessa maneira, melhor visualização das áreas envolvidas na aquisição das respostas com os diferentes paradigmas.

O EEG foi coletado em 12 eletrodos ativos dentro dos 64 disponíveis para a análise dos dados (Figura 1), seguindo os parâmetros internacionais 10-20 (10-20 International System) (Jasper, 1958). Os eletrodos escolhidos contemplavam a região frontal $(\mathrm{FPZ}, \mathrm{F} 4, \mathrm{Fz}, \mathrm{F} 3)$, região central $(\mathrm{C} 4, \mathrm{Cz}, \mathrm{C}$, CP5 e CP6) e a região parietal (P4, Pz e P3).

Os voluntários foram instruídos a lavarem o cabelo apenas com xampu até no máximo 24 horas antes do exame e virem com o cabelo seco. Para a colocação dos eletrodos na touca foi necessário o uso do Quick-cel (uma esponja condutora específica para a coleta de EEG) ativada com ajuda de uma solução alcalina para os 12 eletrodos ativos na touca e para o terra localizado na fronte. 
Para as referências localizadas nas mastoides M1 e M2 foram utilizados eletrodos de prata com a pasta eletrolítica, com todas as impedâncias abaixo de $5 \mathrm{k} \Omega$. A fim de monitorar o movimento ocular, também foram usados eletrodos de prata com pasta eletrolítica. Selecionaram-se os eletrodos dipolos VEOL-VEOU (vertical eletro-oculograma), colocados verticalmente no olho esquerdo em cima e embaixo, e os eletrodos HEOL-HEOU (horizontal eletrooculograma) colocados horizontalmente no canto do olho direito e esquerdo (Figura 2).

Durante a coleta dos dados, os voluntários foram instruídos a fixarem o olho em uma gravura (cruz de fixação) localizada aproximadamente na altura dos olhos.

Ambas as orelhas foram avaliadas, e tanto a orelha testada como o protocolo a ser utilizado foram escolhidos de modo aleatório, por meio do aplicativo "iRandomizer". 


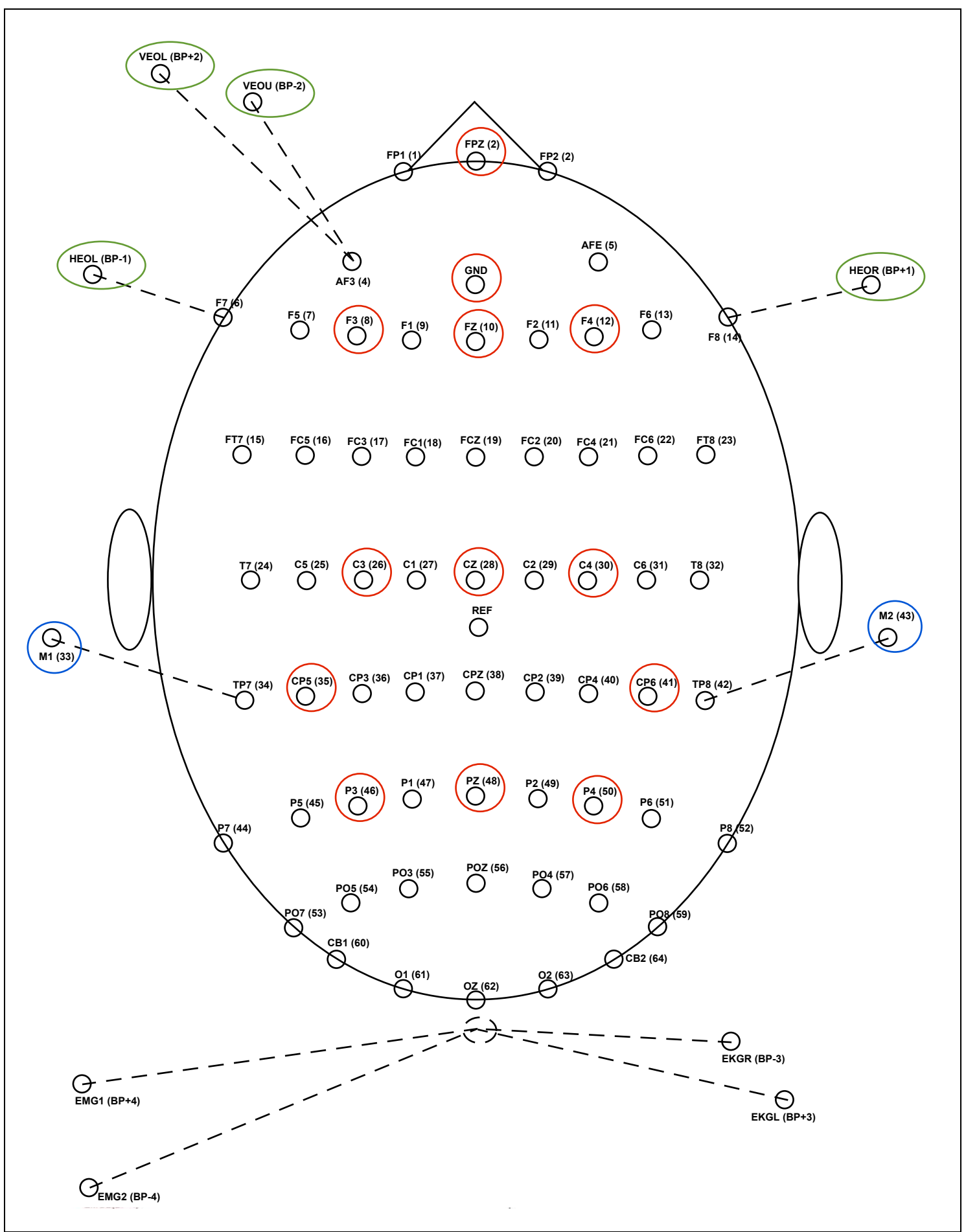

Figura 1 - Posicionamento dos eletrodos na "Quick-Cap 64 Channel" segundo o sistema internacional 10-20. Em círculos vermelhos, os eletrodos selecionados no escalpo para esse estudo na obtenção do P300; em verde, os eletrodos dipolos selecionados para monitorar o movimento ocular; em azul, os eletrodos referência. 


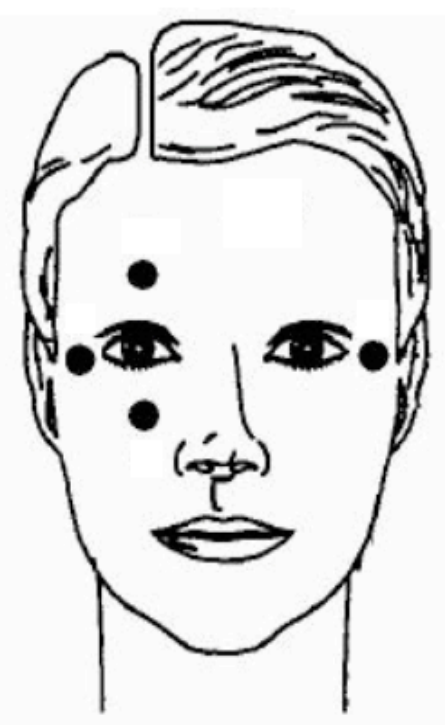

Figura 2 - Colocação dos eletrodos dipolos para controle do movimento ocular

Foram utilizadas duas estimulações diferentes para a realização do P300: paradigma tradicional e paradigma de omissão. Em cada varredura foram utilizados 300 estímulos.

f) Paradigma Tradicional:

Utilizou-se o estímulo tone burt com duração de 100 ms nas frequências de $800 \mathrm{~Hz}(85 \%$ - estímulo frequente) e $1200 \mathrm{~Hz}$ (15\% - estímulo raro), apresentados de forma aleatória, com a taxa de apresentação de $1 \mathrm{~Hz}$, intensidade de 80 dBNPS e janela de 600 ms (Figura 3).

g) Paradigma de Omissão:

Foi utilizado apenas com o estímulo tone brust na frequência de $800 \mathrm{~Hz}$ (85\% - estímulo frequente) e ausência de estímulo (15\% - estímulo raro), apresentados de forma aleatória. Os mesmos parâmetros do paradigma tradicional foram mantidos nessa estimulação (Figura 3). 
a)

Paradigma tradicional

$800 \mathrm{~Hz}$

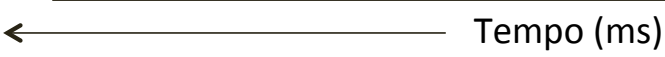

b)

Paradigma de Omissão

\section{$800 \mathrm{~Hz}$}

Ausência
de
Estímulo

$800 \mathrm{~Hz}$

Tempo (ms)

FONTE: Adaptada McCullagh et al., 2009

Figura 3 - Diagrama representando a apresentação dos dois paradigmas: a) Paradigma Tradicional, utilizando as frequências de 800 e $1200 \mathrm{~Hz}$ para gerar o P300; b) Paradigma de Omissão, usando a frequência de $800 \mathrm{~Hz}$ e a ausência de estímulo para gerar o P300.

Os voluntários foram instruídos a ficar em alerta. Os estímulos raros foram contados mentalmente, e o total dito ao final de cada estimulação, tanto para o paradigma tradicional quanto para o paradigma de omissão, em ambas as orelhas.

\subsection{Análise Estatística}

Para a análise dos componentes P300, a onda correspondente à estimulação rara foi subtraída da onda referente à estimulação frequente, gerando uma nova onda, a partir da qual foram analisadas as amplitudes e as latências do P300. Essa subtração foi realizada para eliminar a parte sensorial, 
deixando apenas o componente endógeno/cognitivo no paradigma de omissão (Hall, 1992). Isso será melhor exemplificado no capítulo de resultados.

O P300 foi considerado o maior pico positivo após o complexo N1-P2-N2. As medidas de latência e amplitude foram analisadas no paradigma tradicional e no de omissão para os 12 eletrodos ativos no escalpo Fpz, F3, Fz, F4, C3, $\mathrm{Cz}, \mathrm{C} 4, \mathrm{CP} 5, \mathrm{CP} 6, \mathrm{P} 3, \mathrm{Pz}$ e P4 na orelha direita e na esquerda.

Os componentes N1, P2 e N2 foram analisados levando em consideração as medidas de latência, em ambos os paradigmas, para os 12 eletrodos ativos no escalpo. Para a análise dos componentes N1, P2 e N2, a onda correspondente que se refere à estimulação frequente foi escolhida para determinar o tempo de latência das ondas de acordo com os picos negativos e positivos correspondentes.

Os dados foram analisados utilizando SPSS, version 20.0 (SPSS, Chicago, IL). Realizaram-se análises descritivas dos resultados eletrofisiológicos por meio da construção de tabelas com os valores observados nas estatísticas descritivas: média, mínimo, máximo e desvio padrão (Bussab e Morettin, 2002).

Para complementar a análise descritiva, utilizou-se o intervalo de confiança para verificar o quanto a média pode variar numa determinada probabilidade de confiança. O intervalo de confiança estabelecido para a análise dos dados foi de $95 \%$ de probabilidade de confiança e um nível de significância (p) de 0,05 (5\%). 
A Análise de Variância (ANOVA) com medidas repetidas foi utilizada para verificar se houve diferença estatisticamente significante entre os dois paradigmas utilizados. $O$ teste de Mauchly foi usado para verificar a esfericidade dos dados. Para análise estatística dos dados, adotou-se o nível de significância $0,05 \quad(5 \%)$. Os valores considerados estatisticamente significantes foram marcados com um asterisco $\left(^{*}\right)$ quando igual ou menor a 0,05, com dois asteriscos $\left({ }^{* *}\right)$ quando igual ou menor a 0,01 e com três asteriscos $\left({ }^{* *}\right)$ quando igual ou menor a 0,001 . O sinal \# foi utilizado para mostrar as tendências à significância. 



\section{Resultados}

\section{RESULTADOS}

Neste capítulo, serão apresentados os resultados e análises encontrados para os 30 voluntários, normo-ouvintes, participantes do estudo no paradigma tradicional e no paradigma de omissão.

Como já comentado no capítulo anterior, o nível de significância adotado foi de $0,05(5 \%)$, uma vez que havia amostragem considerável, compatível com tal nível de significância. Todos os intervalos aplicados ao longo dos resultados foram construídos com $95 \%$ de confiança estatística.

Para facilitar a apresentação, esse capítulo será dividido da seguinte maneira:

5.1 - Descrição da amostra;

5.2 - Descrição dos resultados encontrados para latência do N1-P2-N2;

5.3 - Descrição dos resultados encontrados para a latência do P300;

5.4 - Descrição dos resultados encontrados para a amplitude do P300;

5.5 - Descrição dos resultados encontrados no mapas topográficos do escalpo. 


\subsection{Descrição da amostra}

Foram avaliados 30 indivíduos normo-ouvintes (17 do gênero feminino e 13 do masculino) os quais estavam de acordo com os critérios de inclusão e exclusão mencionados anteriormente no capítulo 4 (Métodos). Na Tabela 1 encontram-se as medidas descritivas para a idade dos sujeitos de acordo com o gênero, em que podemos observar que não há diferença significativa.

Tabela 1 - Estatísticas descritivas para a idade (anos) para o gênero masculino e feminino

\begin{tabular}{llllll}
\hline Gênero & $\%$ & Média & Desv. Pad. & Mínimo & Máximo \\
\hline Feminino & 56,66 & 26,0 & 5,2 & 19,7 & 34,2 \\
Masculino & 43,33 & 25,4 & 3,4 & 19,2 & 30,4
\end{tabular}

1\%- = porcentagem

${ }^{2}$ Desv. Pad. $=$ desvio padrão

Todos os voluntários avaliados apresentaram resposta em ambos os paradigmas tanto para a orelha direita quanto para a esquerda.

\subsection{Descrição dos resultados encontrados para latência do N1-P2-N2}

Em uma primeira análise, foram realizadas as estatísticas descritivas para os 12 eletrodos ativos (FPz, F3, Fz, F4, C3, Cz, C4, CP5, CP6, P3, Pz e P4), tanto para o paradigma tradicional quanto para o paradigma de omissão, considerando a latência dos componentes N1-P2-N2.

Devido ao fato de as estimulações apenas diferirem no quesito da presença ou ausência do estímulo raro, optou-se por analisar as latências dos componentes N1-P2-N2 em ambos os paradigmas e confirmar a participação apenas sensorial para a formação desses componentes. 
A onda correspondente à estimulação frequente foi analisada em ambos os paradigmas para ambas as orelhas.

Foram realizadas estatísticas descritivas (média, desvio padrão, mínimo e máximo) para os 12 eletrodos ativos no escalpo para o componente $\mathrm{N} 1$, no paradigma de omissão e no paradigma tradicional, para a orelha direita (Tabela 2) e para orelha esquerda (Tabela 3).

Tabela 2 - Estatística descritiva (média, desvio padrão, mínimo, máximo e mediana) da latência $(\mathrm{ms})$ do $\mathrm{N} 1$ para os 12 eletrodos da orelha direita no paradigma tradicional e no paradigma de omissão

\begin{tabular}{|c|c|c|c|c|c|c|c|c|c|}
\hline \multirow[b]{2}{*}{ Eletrodo } & \multirow[b]{2}{*}{$n^{1}$} & \multicolumn{4}{|c|}{ Paradigma Tradicional } & \multicolumn{4}{|c|}{ Paradigma de Omissão } \\
\hline & & Méd. $^{2}$ & D.P. ${ }^{3}$ & Mín. ${ }^{4}$ & Máx. $^{5}$ & Méd. & D.P. & Mín. & Máx. \\
\hline $\mathrm{FPz}$ & 30 & 151,12 & 15,90 & 119,20 & 198,32 & 151,84 & 14,66 & 121,55 & 195,07 \\
\hline F4 & 30 & 151,07 & 16,74 & 115,29 & 197,54 & 150,69 & 13,36 & 129,42 & 192,71 \\
\hline $\mathrm{Fz}$ & 30 & 150,21 & 16,57 & 116,85 & 197,54 & 149,86 & 15,21 & 117,64 & 193,50 \\
\hline F3 & 30 & 150,86 & 15,71 & 119,20 & 192,84 & 152,78 & 16,89 & 117,64 & 193,50 \\
\hline C4 & 30 & 148,55 & 17,21 & 115,29 & 197,54 & 150,10 & 14,33 & 123,15 & 193,50 \\
\hline $\mathrm{Cz}$ & 30 & 149,65 & 16,51 & 115,29 & 195,97 & 148,37 & 15,51 & 115,29 & 191,14 \\
\hline C3 & 30 & 149,54 & 16,47 & 115,29 & 199,11 & 148,03 & 15,47 & 115,29 & 187,22 \\
\hline CP5 & 30 & 148,97 & 19,29 & 111,16 & 197,54 & 150,30 & 13,60 & 123,15 & 185,65 \\
\hline CP6 & 30 & 149,86 & 20,18 & 116,85 & 204,59 & 151,70 & 14,38 & 123,15 & 193,50 \\
\hline P4 & 30 & 153,54 & 17,99 & 114,51 & 198,32 & 153,32 & 15,55 & 123,15 & 192,71 \\
\hline $\mathrm{Pz}$ & 30 & 152,33 & 16,77 & 114,51 & 198,32 & 151,19 & 15,34 & 123,15 & 192,71 \\
\hline P3 & 30 & 151,53 & 17,37 & 114,51 & 198,32 & 151,50 & 15,19 & 123,15 & 190,49 \\
\hline
\end{tabular}


Tabela 3 - Estatística descritiva (média, desvio padrão, mínimo, máximo e mediana) da latência (ms) do N1 para os 12 eletrodos da orelha esquerda no paradigma tradicional e no paradigma de omissão

\begin{tabular}{|c|c|c|c|c|c|c|c|c|c|}
\hline \multirow[b]{2}{*}{ Eletrodo } & \multirow[b]{2}{*}{$\mathrm{n}^{1}$} & \multicolumn{4}{|c|}{ Paradigma Tradicional } & \multicolumn{4}{|c|}{ Paradigma de Omissão } \\
\hline & & Méd. $^{2}$ & D.P. ${ }^{3}$ & Mín. ${ }^{4}$ & Máx. $^{5}$ & Méd. & D.P. & Mín. & Máx. \\
\hline $\mathrm{FPz}$ & 30 & 153,64 & 14,44 & 127,07 & 182,51 & 153,90 & 12,54 & 125,47 & 188,79 \\
\hline $\mathrm{F} 4$ & 30 & 152,25 & 14,03 & 124,72 & 181,73 & 151,95 & 14,07 & 125,50 & 187,22 \\
\hline $\mathrm{Fz}$ & 30 & 152,88 & 15,29 & 124,72 & 188,00 & 153,22 & 12,42 & 132,51 & 186,43 \\
\hline F3 & 30 & 153,42 & 14,69 & 124,72 & 183,30 & 154,61 & 12,38 & 130,95 & 186,43 \\
\hline $\mathrm{C} 4$ & 30 & 153,12 & 14,98 & 124,72 & 182,51 & 150,12 & 16,39 & 119,20 & 187,22 \\
\hline $\mathrm{Cz}$ & 30 & 152,44 & 14,20 & 126,29 & 182,51 & 151,43 & 14,94 & 122,34 & 184,08 \\
\hline C3 & 30 & 153,72 & 14,84 & 128,64 & 181,73 & 151,70 & 14,28 & 125,50 & 184,08 \\
\hline CP5 & 30 & 154,70 & 15,75 & 127,85 & 182,51 & 150,10 & 15,68 & 119,20 & 185,65 \\
\hline CP6 & 30 & 156,80 & 17,37 & 120,81 & 184,57 & 153,47 & 20,03 & 116,85 & 195,97 \\
\hline P4 & 30 & 157,25 & 19,71 & 120,81 & 196,64 & 152,27 & 20,57 & 116,85 & 197,42 \\
\hline $\mathrm{Pz}$ & 30 & 153,98 & 17,03 & 120,81 & 183,30 & 151,12 & 16,58 & 116,85 & 184,37 \\
\hline P3 & 30 & 152,60 & 17,06 & 121,59 & 183,30 & 151,18 & 16,61 & 116,85 & 184,37 \\
\hline \multicolumn{10}{|c|}{$\begin{array}{l}{ }^{1} \mathrm{n}=\text { Número de sujeitos } \\
{ }^{2} \text { Méd. = Média } \\
{ }^{3} \mathrm{D} . P .=\text { Desvio Padrão } \\
{ }^{4} \text { Mín. = Mínimo } \\
{ }^{5} \text { Máx. = Máximo }\end{array}$} \\
\hline
\end{tabular}

Nota-se que os valores médios para ambas as estimulações são equivalentes. $\mathrm{Na}$ orelha direita, o maior valor médio encontrado para o $\mathrm{N} 1$ foi 153,54, e o menor, 149,54, para o paradigma tradicional; e de 153,32 e 148,37 para o paradigma de omissão, respectivamente. $\mathrm{Na}$ orelha esquerda, para o paradigma tradicional, o maior valor médio encontrado foi de 157,98 , e o menor, de 152,25. Para o paradigma de omissão, os valores corresponderam a 154,61 e 150,10 , respectivamente. Analisando as duas orelhas, o maior valor encontrado para a latência foi no eletrodo CP6 da orelha direita, para o paradigma tradicional, e no eletrodo P4 da orelha esquerda, quando considerase o paradigma de omissão.

As estatísticas descritivas (média, desvio padrão, mínimo e máximo) encontradas para o componente P2 nos 12 eletrodos ativos no escalpo no 
paradigma de omissão e no paradigma tradicional para a orelha direita podem ser observados na Tabela 4, e para orelha esquerda, na Tabela 5.

Tabela 4 - Estatística descritiva (média, desvio padrão, mínimo, máximo e mediana) da latência (ms) do P2 para os 12 eletrodos da orelha direita no paradigma tradicional e no paradigma de omissão

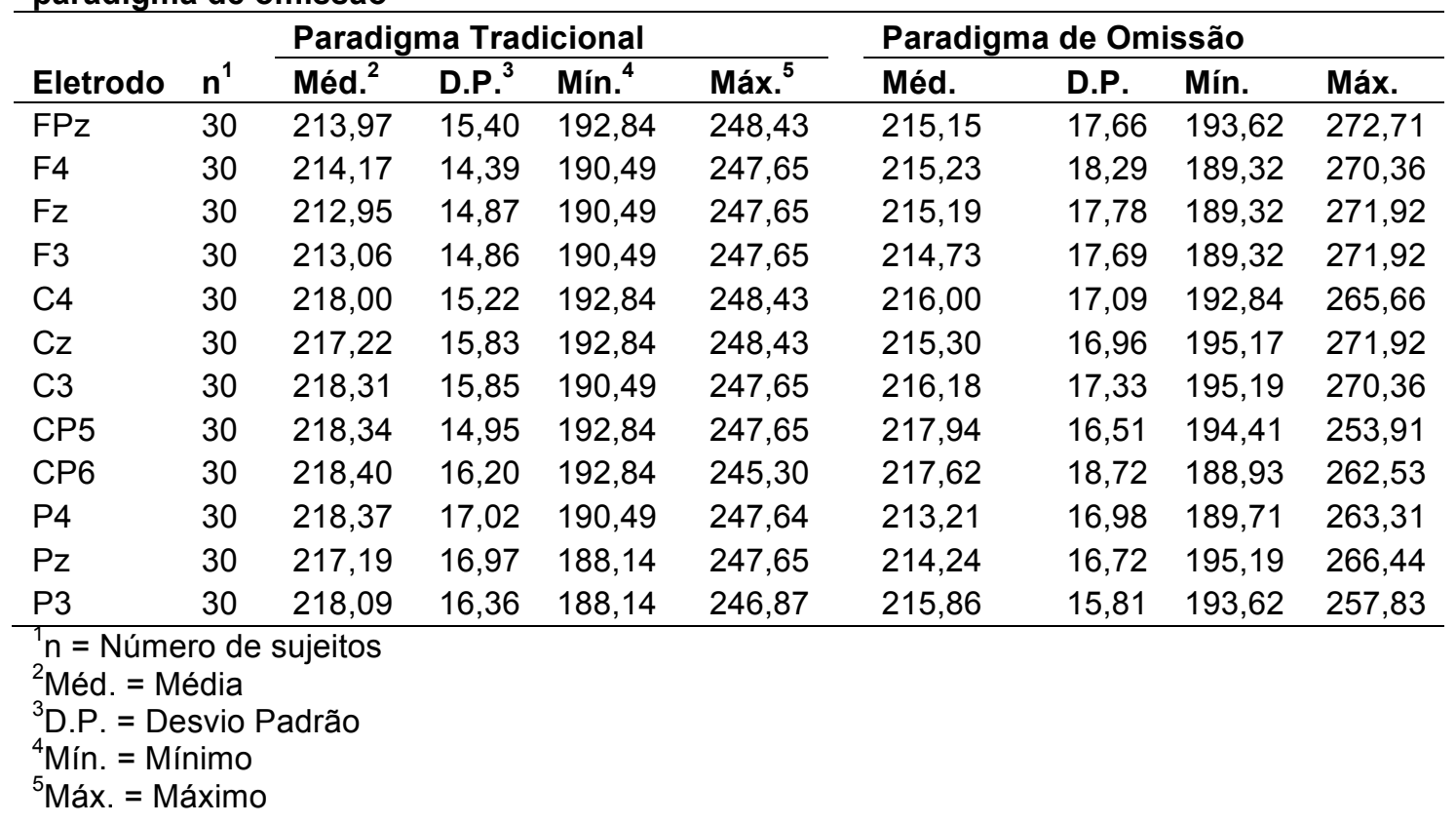

Tabela 5 - Estatística descritiva (média, desvio padrão, mínimo, máximo e mediana) da latência (ms) do P2 para os 12 eletrodos da orelha esquerda no paradigma tradicional e no paradigma de omissão

\begin{tabular}{|c|c|c|c|c|c|c|c|c|c|}
\hline \multirow[b]{2}{*}{ Eletrodo } & \multirow[b]{2}{*}{$n^{1}$} & \multicolumn{4}{|c|}{ Paradigma Tradicional } & \multicolumn{4}{|c|}{ Paradigma de Omissão } \\
\hline & & Méd. $^{2}$ & D.P. ${ }^{3}$ & Mín. ${ }^{4}$ & Máx. $^{5}$ & Méd. & D.P. & Mín. & Máx. \\
\hline FPz & 30 & 214,26 & 15,23 & 192,77 & 245,30 & 216,68 & 20,82 & 188,14 & 261,74 \\
\hline F4 & 30 & 213,85 & 16,52 & 178,75 & 248,43 & 217,37 & 21,81 & 187,36 & 263,31 \\
\hline $\mathrm{Fz}$ & 30 & 213,68 & 14,50 & 190,57 & 242,95 & 216,28 & 21,22 & 188,14 & 262,53 \\
\hline F3 & 30 & 214,18 & 15,43 & 189,83 & 242,95 & 217,42 & 21,43 & 184,23 & 262,53 \\
\hline C4 & 30 & 214,54 & 15,99 & 181,88 & 244,52 & 218,36 & 22,45 & 175,62 & 262,53 \\
\hline $\mathrm{Cz}$ & 30 & 215,15 & 14,86 & 192,03 & 242,95 & 217,95 & 20,20 & 188,14 & 262,53 \\
\hline C3 & 30 & 216,28 & 15,02 & 190,57 & 242,95 & 218,79 & 21,28 & 188,14 & 263,31 \\
\hline CP5 & 30 & 217,67 & 16,92 & 185,01 & 256,26 & 219,60 & 22,66 & 186,53 & 268,79 \\
\hline CP6 & 30 & 217,18 & 19,51 & 165,44 & 256,28 & 218,66 & 23,19 & 176,40 & 273,49 \\
\hline P4 & 30 & 216,46 & 18,56 & 185,01 & 256,80 & 218,39 & 24,51 & 178,75 & 266,44 \\
\hline $\mathrm{Pz}$ & 30 & 214,74 & 20,25 & 178,83 & 258,63 & 217,34 & 21,67 & 187,36 & 266,44 \\
\hline P3 & 30 & 215,06 & 19,12 & 178,75 & 254,70 & 217,84 & 22,08 & 186,16 & 267,23 \\
\hline $\begin{array}{l}{ }^{3} \text { D.P. }= \\
{ }^{4} \text { Mín. }= \\
{ }^{5} \text { Máx. }=\end{array}$ & $\mathrm{m}$ & ujeitos & & & & & & & \\
\hline
\end{tabular}


Na orelha direita, o menor valor médio encontrado para P2 foi 212,95 e o maior, 218,40, para o paradigma tradicional; e de 213,21 e 217,62 para o paradigma de omissão, respectivamente. Na orelha esquerda o menor valor médio encontrado para P2 o foi de 213,68 e o maior, 217,67 , para o paradigma tradicional; e de 216,28 e 219,60 para o paradigma de omissão, respectivamente. Analisando as duas orelhas o maior valor encontrado para a latência foi no eletrodo $\mathrm{Pz}$ da orelha esquerda, quando foi considerado o paradigma tradicional, e no eletrodo $\mathrm{Fpz}$ da orelha direita, quando foi levado em conta o paradigma de omissão.

Para o componente N2 também foram realizadas estatísticas descritivas (média, desvio padrão, mínimo e máximo) para os 12 eletrodos ativos no escalpo no paradigma de omissão e no paradigma tradicional para a orelha direita (Tabela 6) e para orelha esquerda (Tabela 7).

Tabela 6 - Estatística descritiva (média, desvio padrão, mínimo, máximo e mediana) da latência (ms) do N2 para os 12 eletrodos da orelha direita no paradigma tradicional e no paradigma de omissão

\begin{tabular}{|c|c|c|c|c|c|c|c|c|c|}
\hline \multirow[b]{2}{*}{ Eletrodo } & \multirow[b]{2}{*}{$n^{1}$} & \multicolumn{4}{|c|}{ Paradigma Tradicional } & \multicolumn{4}{|c|}{ Paradigma de Omissão } \\
\hline & & Méd. & D.P. ${ }^{3}$ & Mín. ${ }^{4}$ & Máx. $^{5}$ & Méd. & D.P. & Mín. & Máx. \\
\hline $\mathrm{FPz}$ & 30 & 253,37 & 26,13 & 221,03 & 318,97 & 251,56 & 22,04 & 224,10 & 301,68 \\
\hline $\mathrm{F} 4$ & 30 & 252,26 & 26,63 & 221,03 & 318,97 & 254,20 & 22,55 & 223,32 & 307,16 \\
\hline $\mathrm{Fz}$ & 30 & 251,04 & 26,44 & 218,68 & 317,51 & 251,21 & 21,79 & 223,32 & 307,16 \\
\hline F3 & 30 & 251,94 & 27,15 & 216,33 & 319,51 & 253,12 & 22,05 & 223,32 & 307,16 \\
\hline $\mathrm{C} 4$ & 30 & 253,35 & 26,85 & 210,07 & 316,77 & 255,38 & 22,86 & 222,53 & 311,86 \\
\hline $\mathrm{Cz}$ & 30 & 253,55 & 27,04 & 210,07 & 317,51 & 254,20 & 22,84 & 223,32 & 311,07 \\
\hline C3 & 30 & 254,03 & 26,08 & 217,90 & 318,24 & 254,72 & 21,48 & 223,32 & 309,51 \\
\hline CP5 & 30 & 254,27 & 28,00 & 206,15 & 317,51 & 257,80 & 24,30 & 222,53 & 311,86 \\
\hline CP6 & 30 & 250,27 & 25,26 & 206,94 & 291,59 & 258,50 & 24,37 & 221,81 & 297,69 \\
\hline P4 & 30 & 254,30 & 25,11 & 208,52 & 312,64 & 255,95 & 22,24 & 220,96 & 300,89 \\
\hline$P z$ & 30 & 252,93 & 28,63 & 207,72 & 316,70 & 255,30 & 21,56 & 222,53 & 300,89 \\
\hline P3 & 30 & 250,67 & 26,66 & 207,72 & 311,07 & 256,66 & 21,91 & 222,53 & 296,20 \\
\hline \multicolumn{10}{|c|}{$\begin{array}{l}{ }^{1} \mathrm{n}=\text { Número de sujeitos } \\
{ }^{2} \text { Méd. = Média } \\
{ }^{3} \text { D.P. = Desvio Padrão } \\
{ }^{4} \text { Mín. = Mínimo } \\
{ }^{5} \text { Máx. = Máximo }\end{array}$} \\
\hline
\end{tabular}


Tabela 7 - Estatística descritiva (média, desvio padrão, mínimo, máximo e mediana) da latência (ms) do N2 para os 12 eletrodos da orelha esquerda no paradigma tradicional e no paradigma de omissão

\begin{tabular}{|c|c|c|c|c|c|c|c|c|c|}
\hline \multirow[b]{2}{*}{ Eletrodo } & \multirow[b]{2}{*}{$n^{1}$} & \multicolumn{4}{|c|}{ Paradigma Tradicional } & \multicolumn{4}{|c|}{ Paradigma de Omissão } \\
\hline & & Méd. $^{2}$ & D.P. ${ }^{3}$ & Mín. ${ }^{4}$ & Máx. $^{5}$ & Méd. & D.P. & Mín. & Máx. \\
\hline $\mathrm{FPz}$ & 30 & 246,58 & 22,68 & 208,50 & 307,16 & 247,89 & 25,32 & 212,42 & 308,72 \\
\hline $\mathrm{F} 4$ & 30 & 246,96 & 24,35 & 206,06 & 306,38 & 245,72 & 25,26 & 211,63 & 304,81 \\
\hline $\mathrm{Fz}$ & 30 & 246,55 & 24,31 & 207,72 & 308,72 & 247,44 & 25,22 & 210,85 & 304,81 \\
\hline F3 & 30 & 246,83 & 23,39 & 210,85 & 307,16 & 248,92 & 24,82 & 210,38 & 306,38 \\
\hline C4 & 30 & 247,42 & 26,15 & 206,94 & 307,16 & 251,61 & 25,50 & 210,85 & 305,59 \\
\hline $\mathrm{Cz}$ & 30 & 249,97 & 24,82 & 211,63 & 308,72 & 251,54 & 26,27 & 209,23 & 305,59 \\
\hline C3 & 30 & 249,77 & 25,44 & 209,80 & 308,72 & 252,90 & 25,36 & 209,23 & 304,81 \\
\hline CP5 & 30 & 255,33 & 24,23 & 212,42 & 309,51 & 252,94 & 25,85 & 210,07 & 309,51 \\
\hline CP6 & 30 & 249,16 & 24,89 & 209,28 & 306,38 & 250,86 & 28,77 & 196,76 & 309,51 \\
\hline P4 & 30 & 250,95 & 26,38 & 206,94 & 307,94 & 254,46 & 30,62 & 195,19 & 311,86 \\
\hline $\mathrm{Pz}$ & 30 & 249,81 & 27,67 & 206,94 & 307,94 & 250,07 & 27,47 & 210,07 & 309,51 \\
\hline P3 & 30 & 249,59 & 28,35 & 192,84 & 307,94 & 251,34 & 26,08 & 209,28 & 309,51 \\
\hline
\end{tabular}

Os valores mínimos e máximos encontrados para o componente N2 no paradigma tradicional variaram entre 210,07 e 318,24 na orelha direita e de 206,06 a 308,72 na orelha esquerda. No paradigma de omissão os valores máximos e mínimos variaram entre 220,06 e 311,07 na orelha direita e de 209,23 a 309,51 na orelha esquerda. As médias são equivalente em ambos os paradigmas para as duas orelhas.

Analisando as duas orelhas, o maior valor encontrado para a latência foi no eletrodo P3 da orelha direita, quando considera-se o paradigma tradicional; e nos eletrodos CP5 e CP6 da orelha esquerda, quando leva-se em conta o paradigma de omissão.

Para complementar a análise descritiva e melhorar a visualização dos resultados, foram realizados box-plots para o paradigma de omissão e para o paradigma tradicional nas orelhas direita (Gráfico 1) e esquerda (Gráfico 2). 


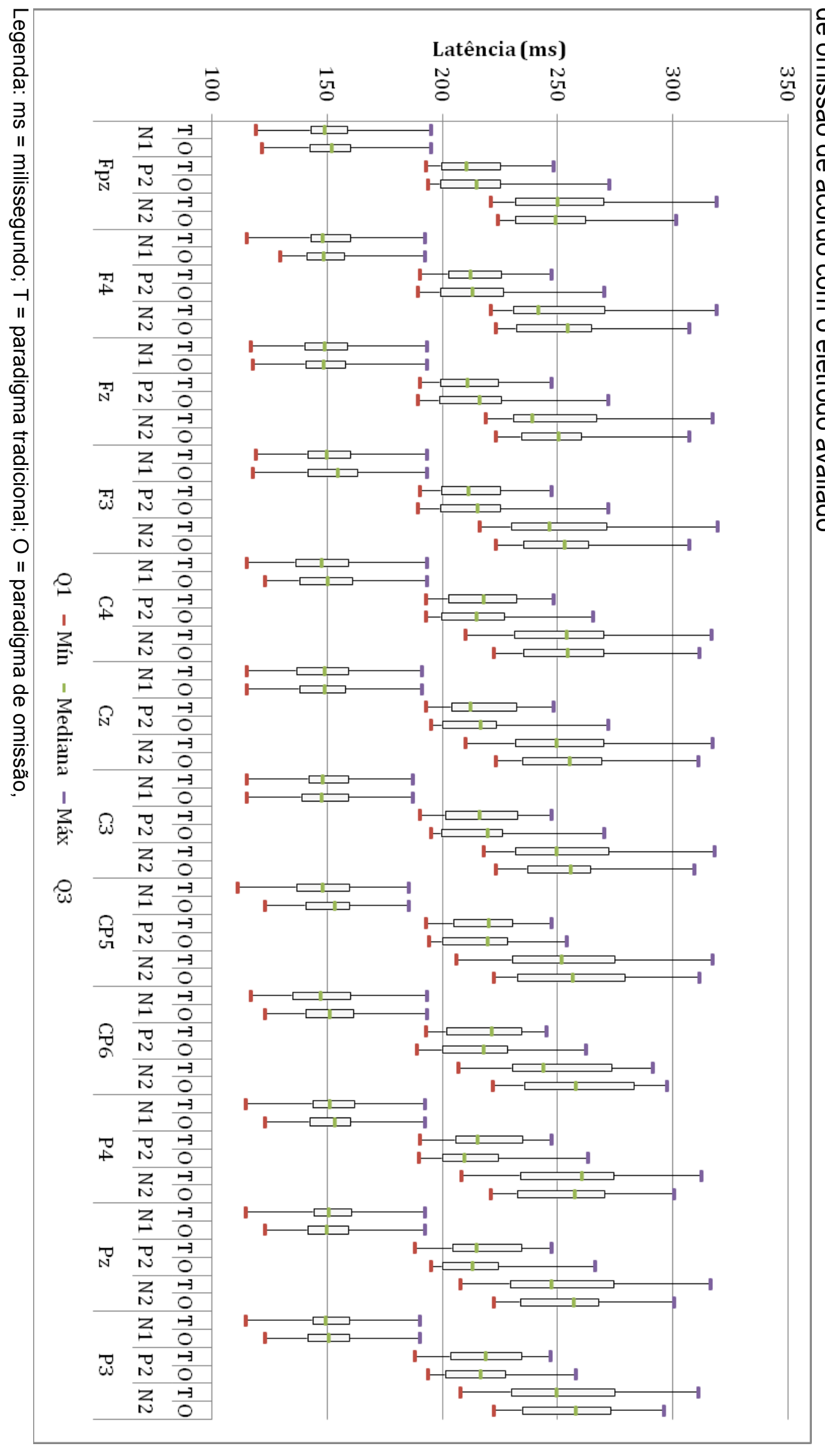

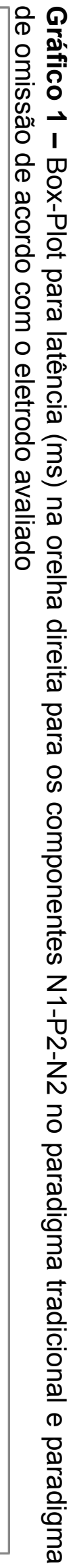




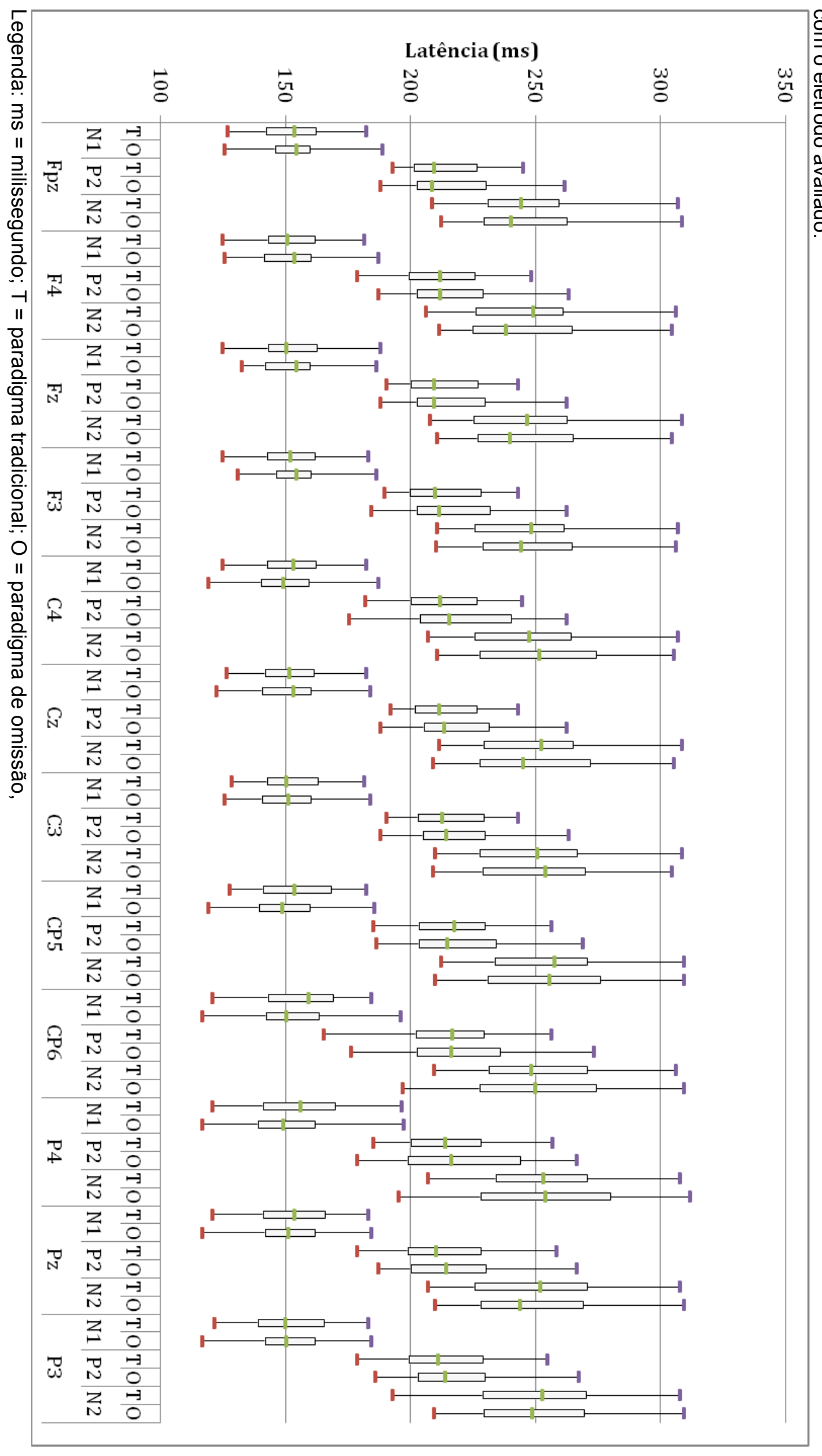

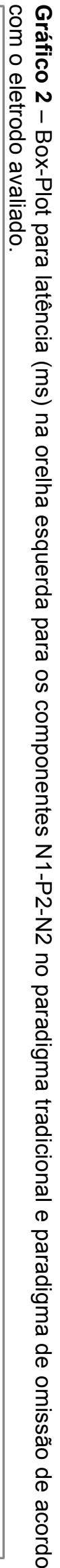


Pode-se observar que todas as medianas no paradigma tradicional e no paradigma de omissão estão bem próximas para os componentes N1-P2-N2 em ambas as orelhas. Tanto para a direita quanto para a esquerda, os componentes N1 e N2 têm os valores mínimos e máximos equivalentes; para o componente $\mathrm{P} 2$, os valores máximos são menores no paradigma tradicional.

Com o intuito de verificar se houve mudança significante entre as estimulações, foi aplicado o teste estatístico ANOVA com medidas repetidas para comparar os componentes N1-P2-N2 em ambas estimulações (Tabela 8).

Tabela 8 - P-valor encontrado para latência $(\mathrm{ms})$ do N1-P2-N2 entre o paradigma tradicional e o paradigma de omissão para orelha direita e esquerda

\begin{tabular}{|c|c|c|c|c|c|c|}
\hline \multirow[b]{2}{*}{ Eletrodo } & \multicolumn{2}{|l|}{ N1 } & \multicolumn{2}{|l|}{ P2 } & \multicolumn{2}{|l|}{ N2 } \\
\hline & OD & OE & OD & OE & OD & $\mathrm{OE}$ \\
\hline FPz & 0,254 & 0,829 & 0,943 & 0,328 & 0,349 & 0,845 \\
\hline F4 & 0,943 & 0,885 & 0,846 & 0,355 & 0,673 & 0,309 \\
\hline $\mathrm{Fz}$ & 0,643 & 0,991 & 0,704 & 0,370 & 0,812 & 0,943 \\
\hline F3 & 0,320 & 0,620 & 0,897 & 0,213 & 0,765 & 0,642 \\
\hline $\mathrm{C} 4$ & 0,405 & 0,666 & 0,336 & 0,405 & 0,411 & 0,428 \\
\hline $\mathrm{Cz}$ & 0,933 & 0,983 & 0,399 & 0,434 & 0,871 & 0,719 \\
\hline $\mathrm{C} 3$ & 0,869 & 0,585 & 0,315 & 0,504 & 0,666 & 0,465 \\
\hline CP5 & 0,966 & 0,416 & 0,754 & 0,711 & 0,579 & 0,496 \\
\hline CP6 & 0,388 & 0,558 & 0,905 & 0,959 & 0,213 & 0,845 \\
\hline P4 & 0,537 & 0,371 & 0,069 & 0,491 & 0,821 & 0,544 \\
\hline $\mathrm{Pz}$ & 0,537 & 0,478 & 0,178 & 0,405 & 0,967 & 0,869 \\
\hline P3 & 0,965 & 0,742 & 0,274 & 0,544 & 0,411 & 0,696 \\
\hline
\end{tabular}


Não houve diferença estatisticamente significante para nenhum dos componentes analisados nem para qualquer dos eletrodos em ambas as orelhas.

Nas Figuras 4 e 5 podem ser observadas as representações gráficas para os doze eletrodos ativos no escalpo para a estimulação frequente no paradigmas tradicional e de omissão nas orelhas direita e esquerda, respectivamente. Essas ondas foram obtidas após a soma das trinta estimulações frequentes para ambos os paradigmas. Notam-se morfologia e tempos de latência parecidos nas duas estimulações, para ambas as orelhas. Os mesmos parâmetros de apresentação foram adotados para todos os eletrodos. Para facilitar a visualização, as ondas do paradigma de omissão foram sobrepostas às ondas do paradigma tradicional. 


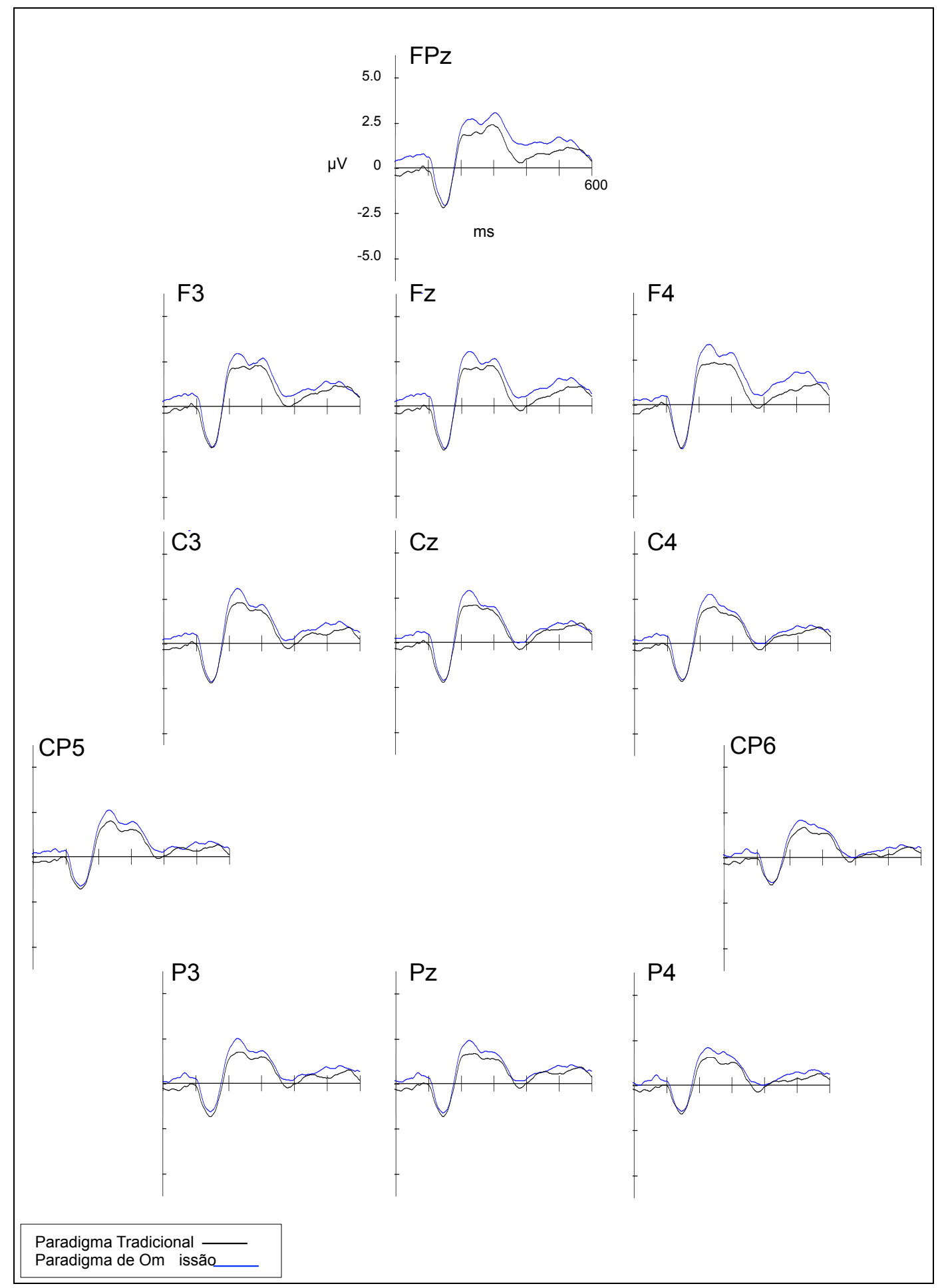

FONTE: Retirada do equipamento Neuroscan, modelo Stim2

Figura 4 - Representação gráfica da soma das 30 estimulações frequentes para visualização dos componentes N1-P2-N2 no paradigma tradicional e no paradigma de omissão na orelha direita.

Legenda: $\mu \mathrm{V}=$ microvolts, $\mathrm{ms}=$ milissegundos; em preto, o paradigma tradicional; em azul, o paradigma de omissão. 


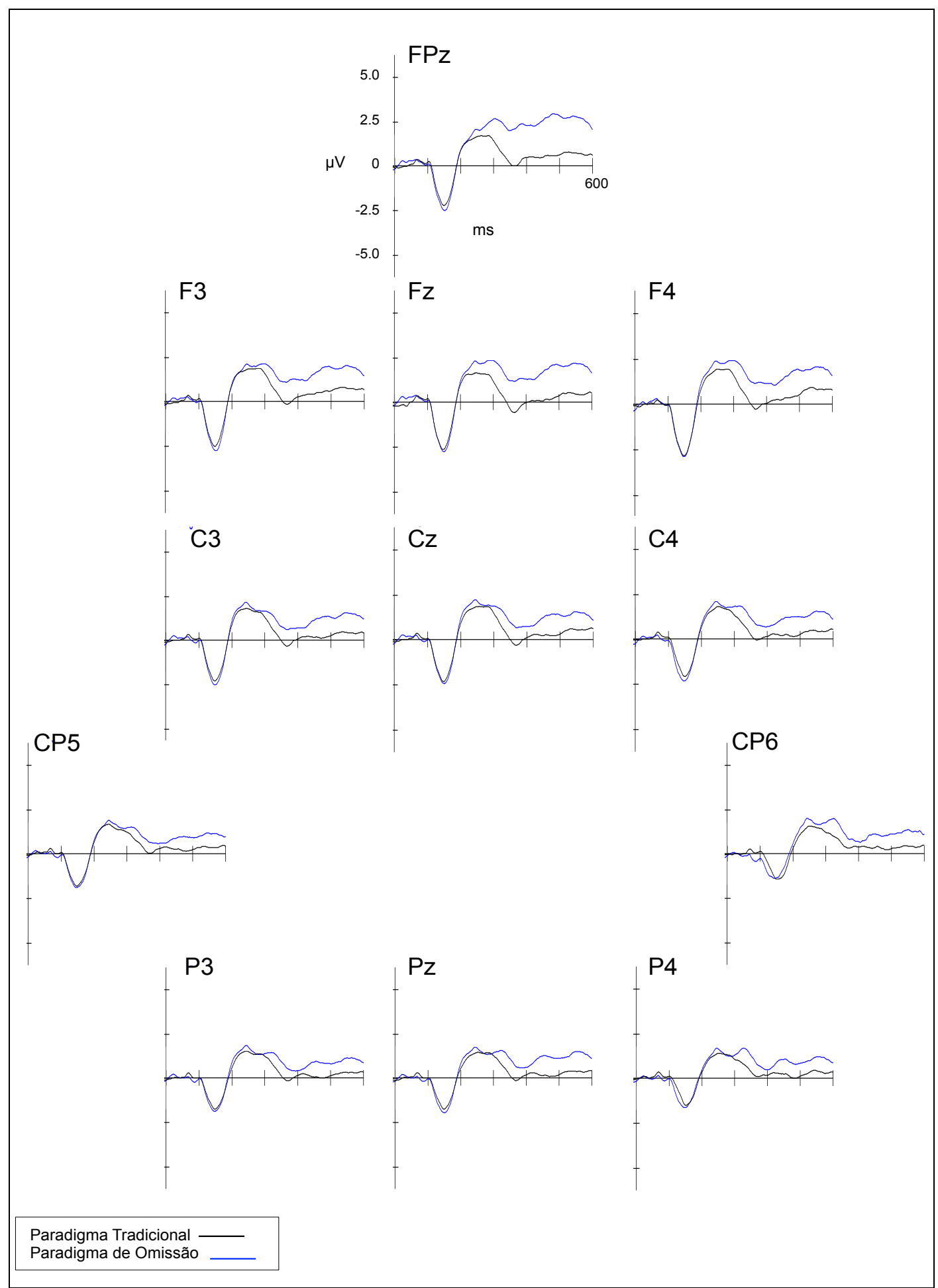

FONTE: Retirada do equipamento Neuroscan, modelo Stim2

Figura 5 - Representação gráfica da soma das 30 estimulações frequentes para visualização dos componentes N1-P2-N2 no paradigma tradicional e no paradigma de omissão na orelha esquerda.

Legenda: $\mu \mathrm{V}=$ microvolts, $\mathrm{ms}=$ milissegundos, em preto o paradigma tradicional, em azul o paradigma de omissão. 
5.3 Descrição dos resultados encontrados para a Latência do P300

Foram realizadas as estatísticas descritivas para os 12 eletrodos ativos (FPz, F3, Fz, F4, C3, Cz, C4, CP5, CP6, P3, Pz e P4), para o paradigma tradicional e para o paradigma de omissão, considerando a latência (ms).

Para ambos os paradigmas, todos os indivíduos identificaram mais do que 95\% dos estímulos-alvo. As medidas de latência foram analisadas de acordo com o maior pico positivo após o complexo N1-P2-N2. Quando o P300 apresentou duplo pico, considerou-se como resultado a média da latência entre os picos.

A Tabela 9 apresenta os valores médios, desvio padrão, mínimo e máximo para cada eletrodo na orelha direita, tanto para o paradigma tradicional quanto para o paradigma de omissão. 
Tabela 9 - Estatística descritiva (média, desvio padrão, mínimo, máximo e mediana) da latência (ms) do P300 para os 12 eletrodos da orelha direita no paradigma tradicional e no paradigma de omissão

\begin{tabular}{|c|c|c|c|c|c|c|c|c|c|}
\hline \multirow{2}{*}{\multicolumn{2}{|c|}{ Eletrodo $n$}} & \multicolumn{4}{|c|}{ Paradigma Tradicional } & \multicolumn{4}{|c|}{ Paradigma de Omissão } \\
\hline & $n^{1}$ & Méd. ${ }^{2}$ & D.P. ${ }^{3}$ & Mín. ${ }^{4}$ & Máx. ${ }^{5}$ & Méd. & D.P. & Mín. & Máx. \\
\hline $\mathrm{FPz}$ & 30 & 339,53 & 26,99 & 263,31 & 395,64 & 361,43 & 22,33 & 303,71 & 398,32 \\
\hline $\mathrm{F} 4$ & 30 & 337,57 & 26,64 & 260,96 & 394,85 & 361,40 & 19,28 & 320,47 & 391,26 \\
\hline $\mathrm{Fz}$ & 30 & 337,78 & 27,44 & 260,96 & 394,85 & 359,65 & 21,22 & 303,71 & 391,26 \\
\hline F3 & 30 & 338,64 & 26,99 & 268,01 & 394,85 & 361,97 & 19,13 & 321,25 & 391,26 \\
\hline $\mathrm{C} 4$ & 30 & 332,98 & 27,69 & 260,18 & 393,29 & 361,10 & 17,71 & 318,12 & 383,89 \\
\hline $\mathrm{Cz}$ & 30 & 333,60 & 27,47 & 264,09 & 393,29 & 359,47 & 17,71 & 318,12 & 389,69 \\
\hline C3 & 30 & 332,65 & 27,31 & 260,96 & 393,29 & 360,04 & 18,95 & 316,55 & 391,26 \\
\hline CP5 & 30 & 332,07 & 27,23 & 260,18 & 393,29 & 361,41 & 20,36 & 318,12 & 398,22 \\
\hline CP6 & 30 & 333,88 & 29,04 & 260,18 & 393,29 & 360,37 & 17,98 & 318,12 & 391,26 \\
\hline $\mathrm{P} 4$ & 30 & 333,45 & 29,00 & 260,18 & 394,07 & 355,8 & 22,92 & 315,77 & 418,72 \\
\hline $\mathrm{Pz}$ & 30 & 332,92 & 27,87 & 260,18 & 394,07 & 356,54 & 18,89 & 314,99 & 393,29 \\
\hline P3 & 30 & 333,31 & 28,61 & 260,18 & 394,07 & 357,68 & 19,23 & 314,99 & 397,2 \\
\hline
\end{tabular}

Para a orelha esquerda também foram realizadas estatísticas descritivas acerca dos resultados encontrados nos 12 eletrodos para os paradigmas tradicional e de omissão, considerando a latência (ms) apresentada na Tabela 10. 
Tabela 10 - Estatística descritiva (média, desvio padrão, mínimo, máximo e mediana) da latência (ms) do P300 para os 12 eletrodos da orelha esquerda no paradigma tradicional e no paradigma de omissão

\begin{tabular}{|c|c|c|c|c|c|c|c|c|c|}
\hline \multirow[b]{2}{*}{ Eletrodo } & \multirow[b]{2}{*}{$n^{1}$} & \multicolumn{4}{|c|}{ Paradigma Tradicional } & \multicolumn{4}{|c|}{ Paradigma de Omissão } \\
\hline & & Méd $^{2}$ & D.P. ${ }^{3}$ & Mín ${ }^{4}$ & Máx ${ }^{5}$ & Méd & D.P. & Mínimo & Máximo \\
\hline $\mathrm{FPz}$ & 30 & 337,53 & 24,75 & 291,82 & 389,37 & 358,27 & 25,84 & 301,36 & 404,09 \\
\hline $\mathrm{F} 4$ & 30 & 335,63 & 22,24 & 294,03 & 393,29 & 356,99 & 25,92 & 301,36 & 411,43 \\
\hline $\mathrm{Fz}$ & 30 & 337,33 & 23,53 & 288,89 & 389,37 & 356,15 & 25,56 & 301,36 & 407,02 \\
\hline F3 & 30 & 337,07 & 22,29 & 294,76 & 389,37 & 355,06 & 24,72 & 301,36 & 403,35 \\
\hline $\mathrm{C} 4$ & 30 & 335,90 & 22,84 & 293,29 & 393,29 & 360,64 & 28,14 & 293,29 & 407,76 \\
\hline $\mathrm{Cz}$ & 30 & 335,12 & 22,78 & 294,03 & 393,29 & 359,99 & 27,95 & 294,76 & 412,89 \\
\hline $\mathrm{C} 3$ & 30 & 336,11 & 22,85 & 294,49 & 397,99 & 355,97 & 27,33 & 292,55 & 403,47 \\
\hline CP5 & 30 & 337,58 & 23,79 & 296,96 & 401,9 & 360,08 & 27,56 & 298,43 & 407,76 \\
\hline CP6 & 30 & 337,69 & 24,9 & 292,56 & 390,16 & 359,37 & 27,92 & 288,69 & 407,75 \\
\hline P4 & 30 & 340,60 & 25,13 & 295,49 & 401,12 & 361,95 & 26,76 & 316,77 & 412,89 \\
\hline $\mathrm{Pz}$ & 30 & 339,50 & 25,33 & 304,03 & 405,82 & 360,62 & 27,03 & 312,37 & 405,03 \\
\hline P3 & 30 & 340,69 & 24,81 & 304,81 & 405,82 & 356,23 & 26,81 & 307,38 & 405,03 \\
\hline
\end{tabular}

A média das respostas na orelha direita variou de 333,57 a 339,53 para o paradigma tradicional, e de 359,47 a 361,43 para o paradigma de omissão. $\mathrm{Na}$ orelha esquerda, variou de 335,12 a 340,69 para o paradigma tradicional, e de 355,06 a 360,64 para o paradigma de omissão, o que demonstra uma diferença entre os paradigmas, pois o máximo de resposta no paradigma tradicional não chega ao mínimo da resposta no paradigma de omissão em ambas as orelhas.

Para complementar a análise descritiva, foram realizados box-plots tanto para a orelha direita (Gráfico 3) quanto para a esquerda (Gráfico 4), nos quais estão exemplificadas as diferenças encontradas entre os paradigmas. 


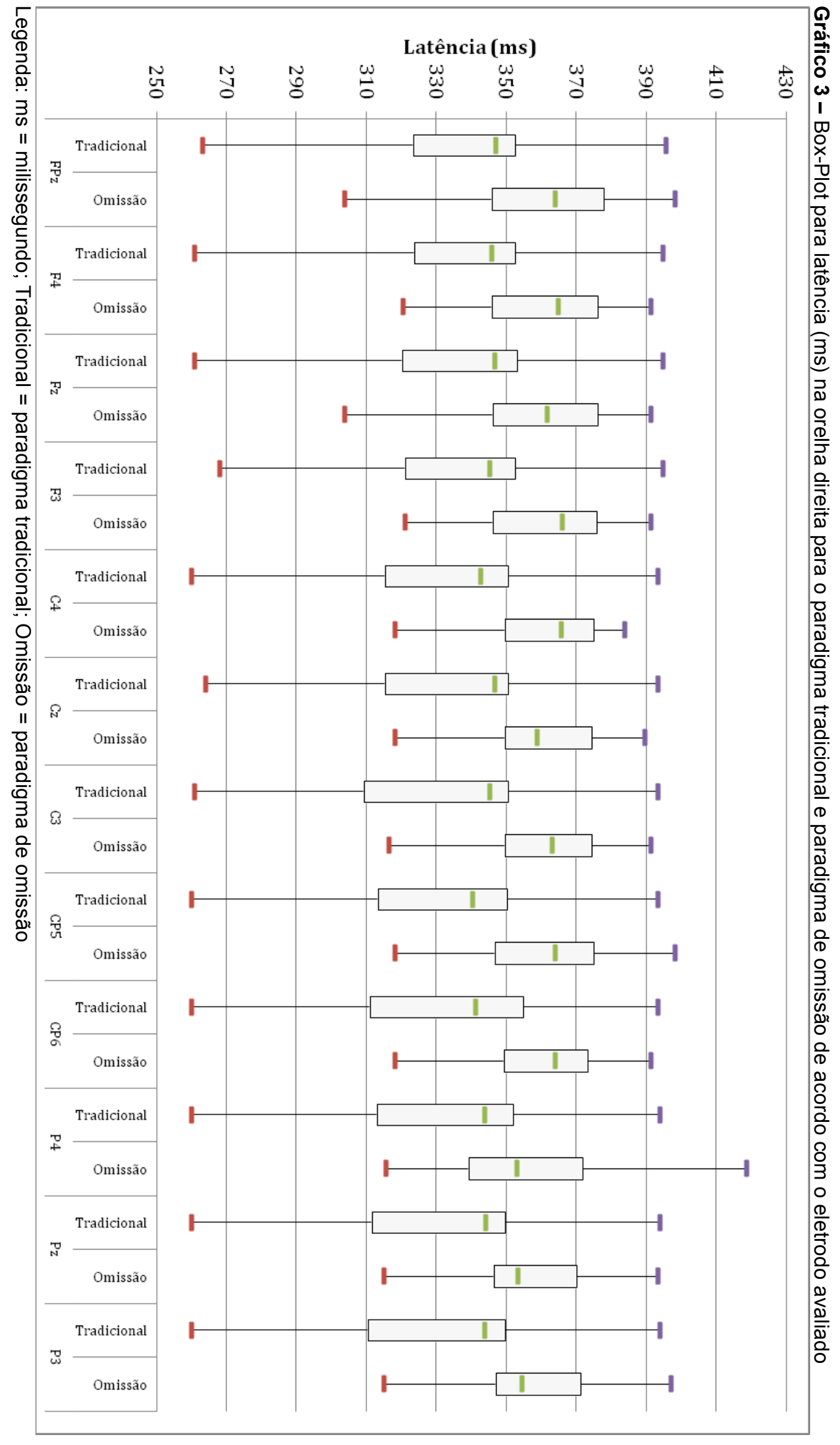




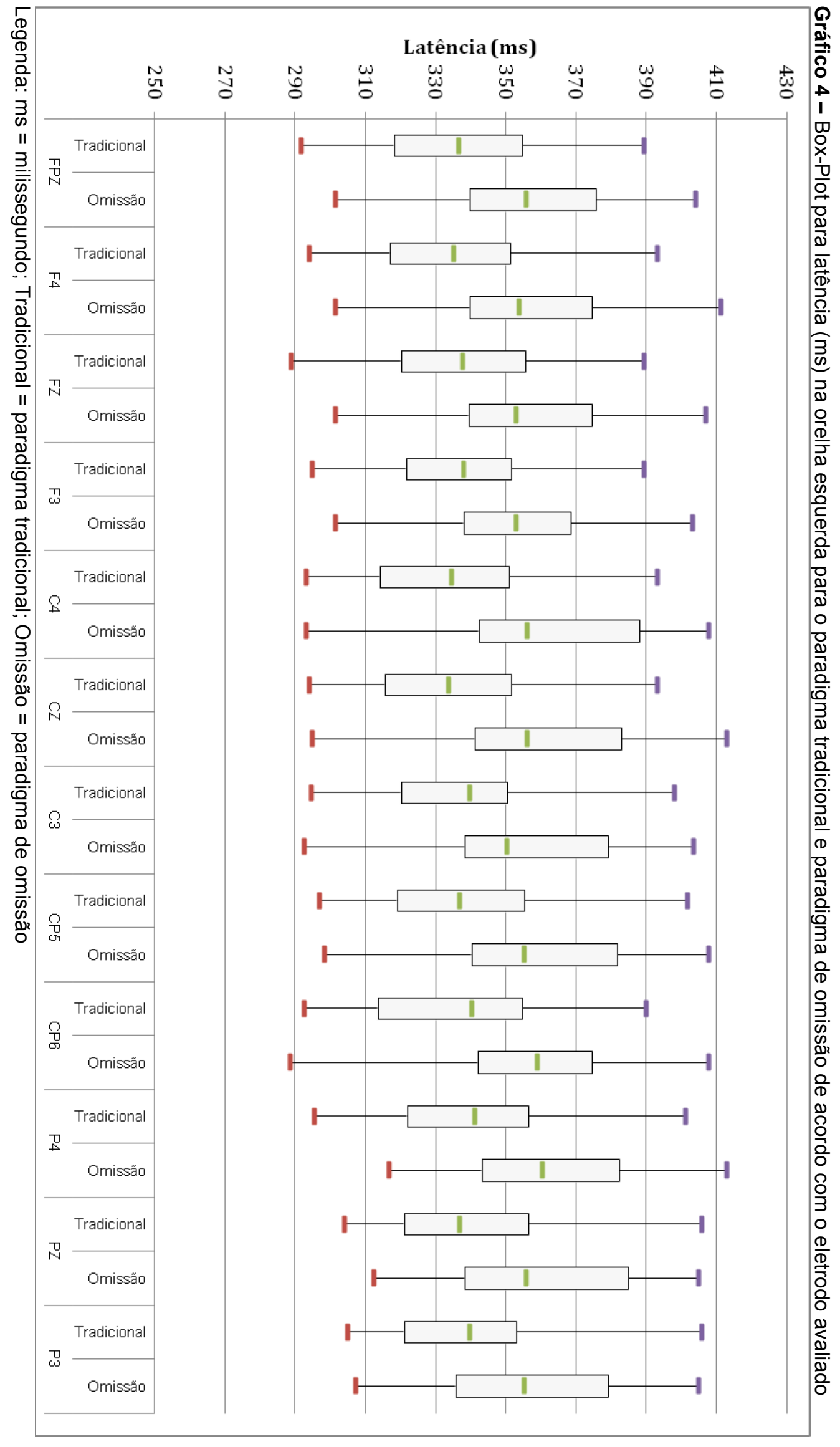


Pode-se observar que todas as medianas do paradigma tradicional são menores do que as medianas do paradigma de omissão. Todas as caixas dos box-plots no paradigma tradicional quase não se sobrepõem às caixas do paradigma de omissão, evidenciando que aproximadamente $50 \%$ dos dados no paradigma tradicional são menores do que os valores do paradigma de omissão.

Considerando que o resultado obtido com o paradigma de omissão elimina a contribuição exógena do P300, é possível quantificar, de acordo com as diferenças obtidas entre os paradigmas, a contribuição do estímulo acústico para a formação do potencial na medida da latência. Para verificar se houve diferença significante entre os paradigmas, foi aplicada a ANOVA com medidas repetidas e nível de significância de 0,05. Os p-valores e as diferenças encontradas para cada eletrodo são apresentados na Tabela 11.

Tabela 11 - Diferenças médias e p-valor encontrado para latência (ms) do P300 entre o paradigma tradicional e o paradigma de omissão para orelha direita e esquerda

\begin{tabular}{llllll}
\hline & \multicolumn{2}{l}{ Orelha Direita } & & \multicolumn{2}{c}{ Orelha Esquerda } \\
\cline { 2 - 3 } \cline { 6 - 6 } Eletrodo & Diferença & p-valor & & Diferença & p-valor \\
\hline FPz & 21,90 & $0,000^{* * *}$ & & 20,74 & $0,001^{* * *}$ \\
F4 & 23,83 & $0,000^{* * *}$ & & 21,36 & $0,001^{* * *}$ \\
Fz & 21,87 & $0,000^{* * *}$ & & 18,82 & $0,002^{* *}$ \\
F3 & 23,33 & $0,000^{* * *}$ & & 17,99 & $0,002^{* *}$ \\
C4 & 28,12 & $0,000^{* * *}$ & & 24,74 & $0,000^{* * *}$ \\
Cz & 25,87 & $0,000^{* * *}$ & & 24,87 & $0,000^{* * *}$ \\
C3 & 27,39 & $0,000^{* * *}$ & & 19,86 & $0,003^{* *}$ \\
CP5 & 29,34 & $0,000^{* * *}$ & & 22,50 & $0,000^{* * *}$ \\
CP6 & 26,49 & $0,000^{* * *}$ & & 21,68 & $0,000^{* * *}$ \\
P4 & 22,35 & $0,000^{* * *}$ & & 21,35 & $0,000^{* * *}$ \\
Pz & 23,62 & $0,000^{* * *}$ & & 21,12 & $0,001^{* * *}$ \\
P3 & 24,37 & $0,002^{* *}$ & & 15,54 & $0,015^{*}$ \\
\hline
\end{tabular}

*diferença $\leq 0,05$

** diferença $\leq 0,01$;

${ }^{* * *}$ diferença $\leq 0,001$ 
A maior diferença encontrada entre os paradigmas foi no eletrodo CP5 $(29,34 \mathrm{~ms})$ na orelha direita, e a menor diferença, no eletrodo P3 (15,54 ms), na orelha esquerda. Houve diferença estatisticamente significante para latência em todos os eletrodos analisados. Para complementar a análise estatística, foi realizado o intervalo de confiança no nível de 95\% para orelha direita (Gráfico 5) e também para a orelha esquerda (Gráfico 6). Nenhum intervalo no paradigma tradicional se sobrepõe ao paradigma de omissão. 
Gráfico 5 - Intervalo de confiança da média no nível de 95\% para a latência no paradigma tradicional e no paradigma de omissão na orelha direita

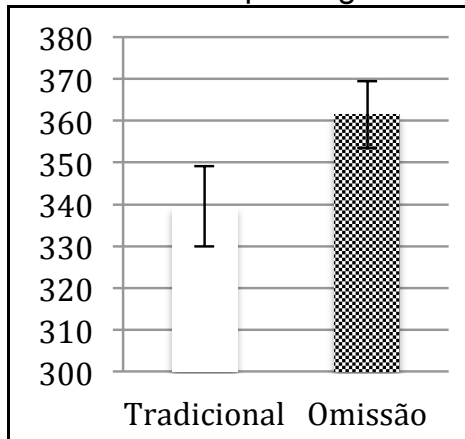

$\mathrm{FPz}$

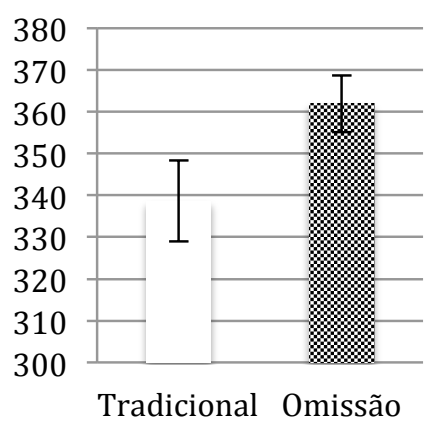

F3

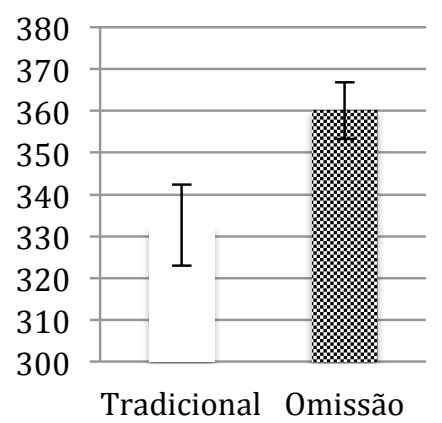

C3

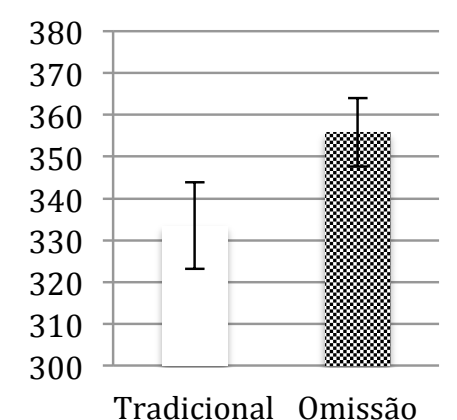

P4

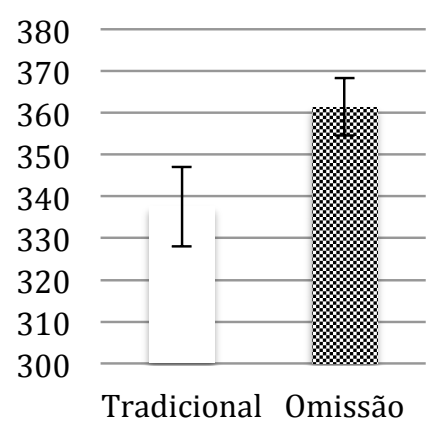

F4

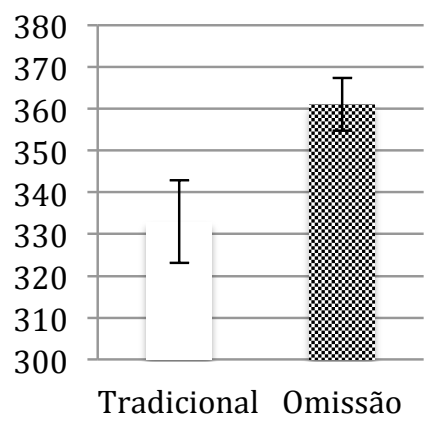

C4

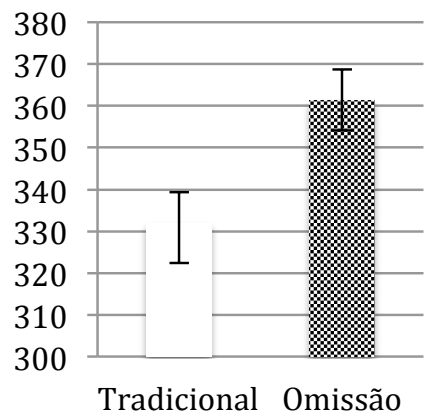

CP5

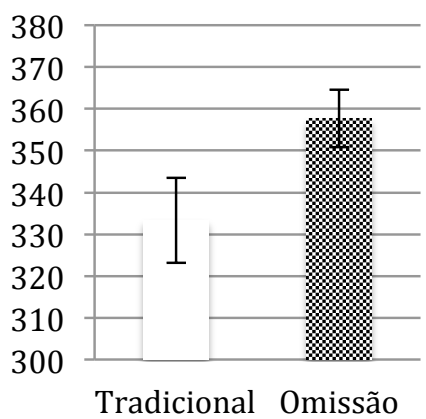

P3

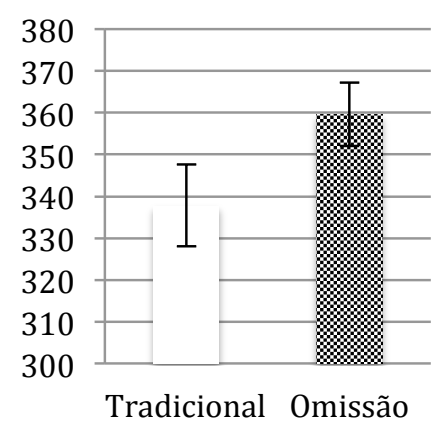

$\mathrm{Fz}$

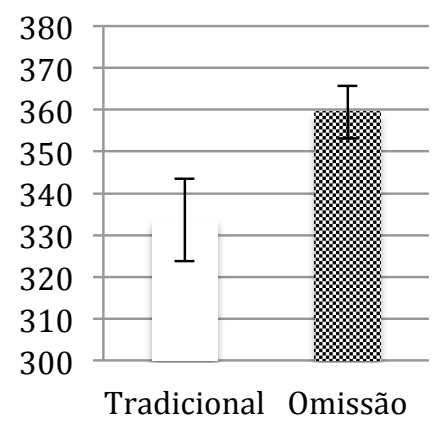

$\mathrm{Cz}$

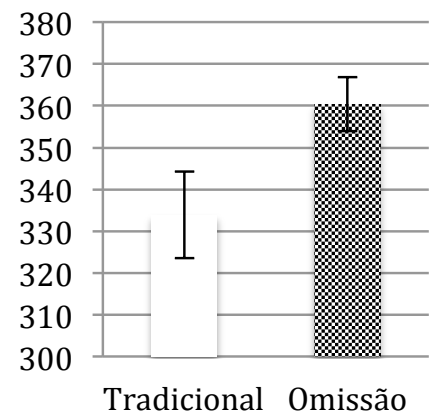

CP6

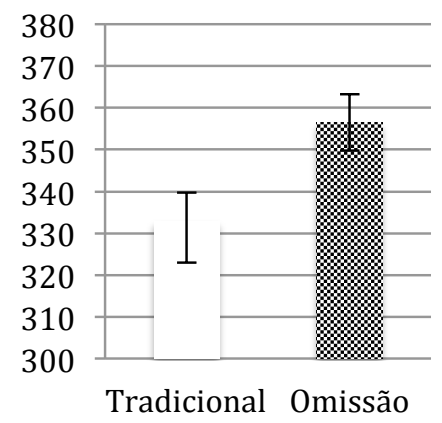

Pz 
Gráfico 6 - Intervalo de confiança da média no nível de 95\% para a latência no paradigma tradicional e no paradigma de omissão na orelha esquerda

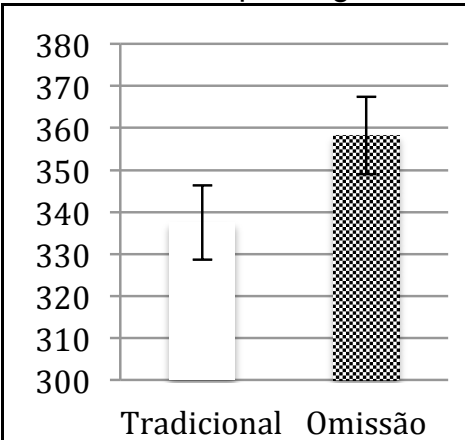

$\mathrm{FPz}$

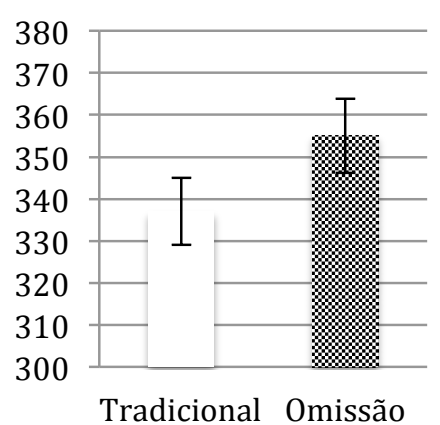

F3

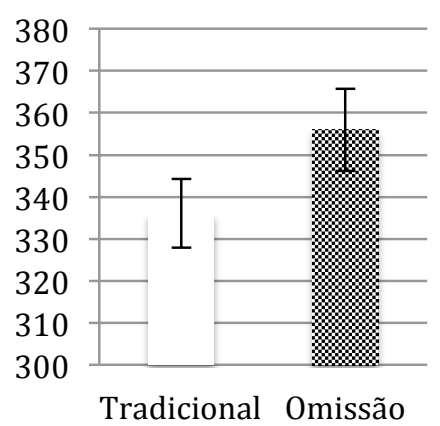

C3

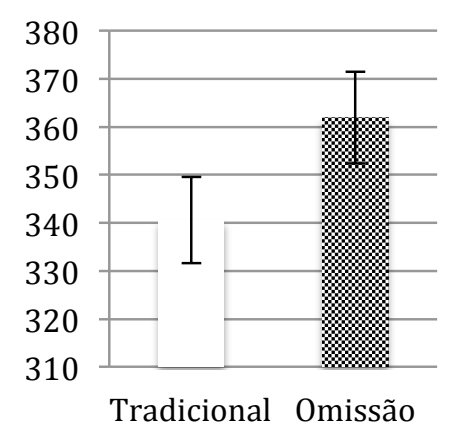

P4

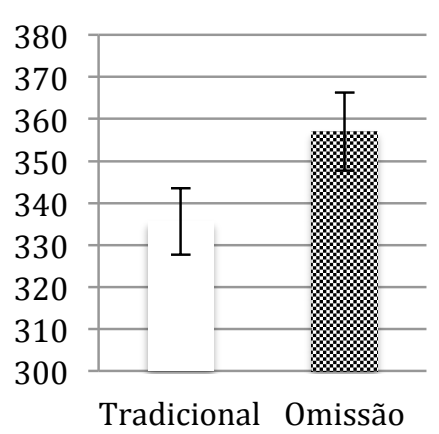

F4

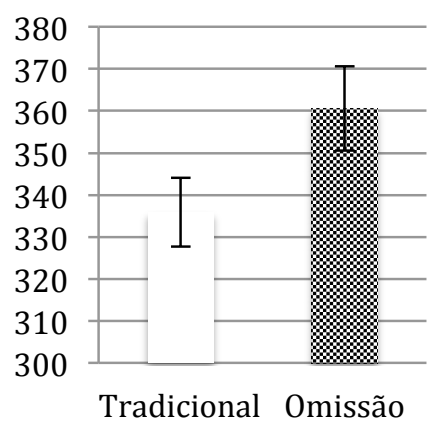

$\mathrm{C} 4$

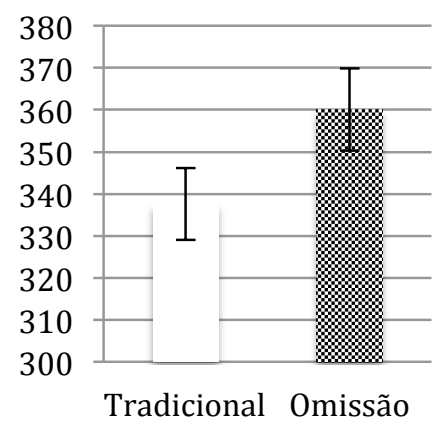

CP5

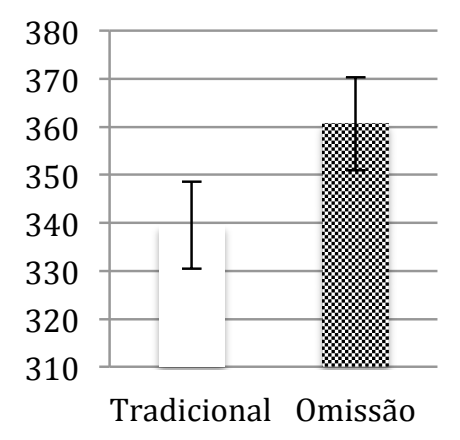

$\mathrm{Pz}$

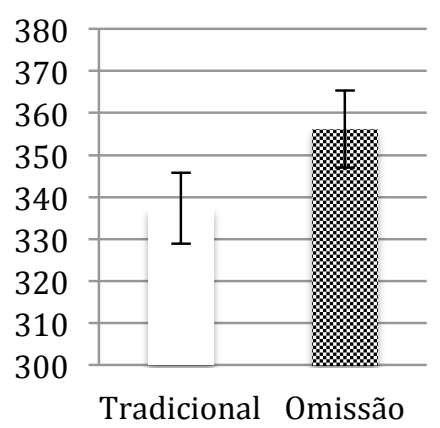

$\mathrm{Fz}$

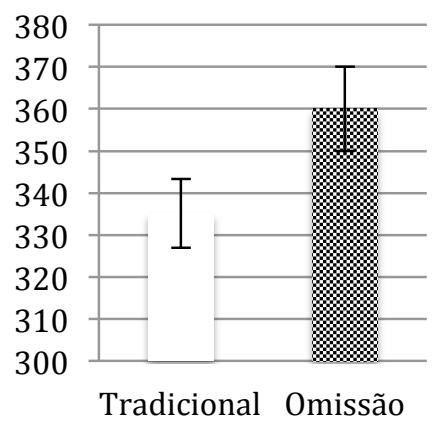

$\mathrm{Cz}$

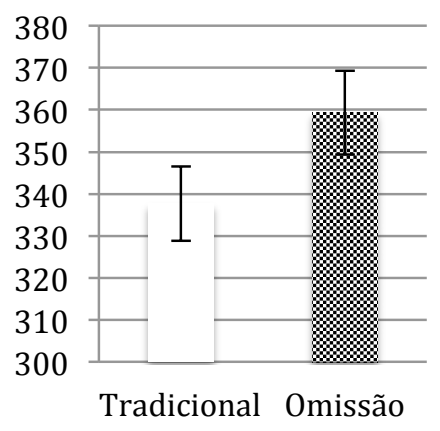

CP6

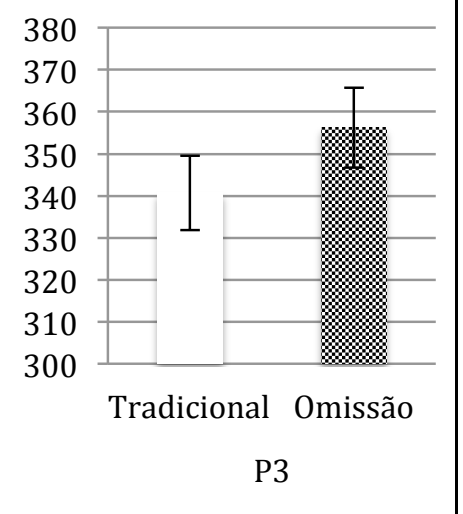


5.4 Descrição dos resultados encontrados para a amplitude do P300

Primeiramente, foram realizadas estatísticas descritivas dos 12 eletrodos ativos (FPz, F3, Fz, F4, C3, Cz, C4, CP5, CP6, P3, Pz e P4) para o paradigma tradicional e para o paradigma de omissão, considerando a amplitude $(\mu \mathrm{V})$ para ambas as orelhas. As medidas de amplitude foram calculadas levando-se em consideração a correção (Baseline Correction) do intervalo pré-estímulo.

Os valores de amplitude foram analisados seguindo o seguinte cálculo: diferença do pico negativo anterior ao P300 com o maior pico positivo do P300. A Tabela 12 apresenta os valores médios, desvio padrão, mínimo e máximo para cada eletrodo na orelha direita, considerando o paradigma tradicional e o paradigma de omissão.

Tabela 12 - Estatística descritiva (média, desvio padrão, mínimo e máximo) da amplitude $(\mu \mathrm{V})$ do P300 para os 12 eletrodos da orelha direita no paradigma de tradicional e no paradigma de omissão

\begin{tabular}{|c|c|c|c|c|c|c|c|c|c|}
\hline \multirow[b]{2}{*}{ Eletrodo } & \multirow[b]{2}{*}{$n^{1}$} & \multicolumn{4}{|c|}{ Paradigma Tradicional } & \multicolumn{4}{|c|}{ Paradigma de Omissão } \\
\hline & & Méd. $^{2}$ & D.P. ${ }^{3}$ & Mín. ${ }^{4}$ & Máx. $^{5}$ & Méd. & D.P. & Mín. & Máx. \\
\hline FPz & 30 & 7,31 & 5,96 & 1,21 & 26,73 & 5,40 & 4,25 & 1,31 & 22,31 \\
\hline $\mathrm{F} 4$ & 30 & 7,95 & 4,72 & 2,56 & 23,19 & 5,96 & 4,12 & 1,64 & 18,69 \\
\hline $\mathrm{Fz}$ & 30 & 9,05 & 5,70 & 2,11 & 23,67 & 5,53 & 3,56 & 1,33 & 17,55 \\
\hline F3 & 30 & 7,70 & 5,07 & 1,46 & 24,39 & 5,65 & 3,65 & 1,17 & 17,76 \\
\hline C4 & 30 & 7,50 & 4,24 & 1,86 & 17,39 & 5,23 & 3,33 & 1,13 & 13,69 \\
\hline $\mathrm{Cz}$ & 30 & 7,74 & 4,30 & 2,08 & 18,27 & 5,45 & 3,45 & 1,19 & 13,88 \\
\hline C3 & 30 & 7,67 & 4,38 & 2,00 & 19,31 & 5,30 & 3,34 & 1,06 & 12,93 \\
\hline CP5 & 30 & 6,85 & 3,69 & 2,08 & 14,87 & 4,63 & 2,48 & 1,46 & 10,24 \\
\hline CP6 & 30 & 6,99 & 3,75 & 1,06 & 16,02 & 4,86 & 2,65 & 1,05 & 10,45 \\
\hline P4 & 30 & 6,96 & 4,06 & 1,79 & 17,43 & 5,27 & 3,16 & 1,32 & 14,35 \\
\hline $\mathrm{Pz}$ & 30 & 6,76 & 3,89 & 1,64 & 17,5 & 5,09 & 3,14 & 1,41 & 14,71 \\
\hline P3 & 30 & 6,96 & 3,99 & 1,98 & 17,48 & 5,10 & 2,89 & 1,48 & 12,36 \\
\hline
\end{tabular}

1 $\mathrm{n}$ = Número de sujeitos;

${ }^{2}$ Méd. = Média;

${ }^{3}$ D.P. = Desvio Padrão;

${ }^{4}$ Mín. = Mínimo;

${ }^{5}$ Máx. =Máximo 
Foram realizadas estatísticas descritivas para o paradigma tradicional e para o paradigma de omissão, considerando a amplitude $(\mu \mathrm{V})$ para orelha esquerda (Tabela 13).

Tabela 13 - Estatística descritiva (média, desvio padrão, mínimo e máximo) da amplitude $(\mu \mathrm{V})$ do P300 para os 12 eletrodos da orelha esquerda no paradigma de tradicional e no paradigma de omissão

\begin{tabular}{|c|c|c|c|c|c|c|c|c|c|}
\hline \multirow[b]{2}{*}{ Eletrodo } & \multirow[b]{2}{*}{$n^{1}$} & \multicolumn{4}{|c|}{ Paradigma Tradicional } & \multicolumn{4}{|c|}{ Paradigma de Omissão } \\
\hline & & Méd. $^{2}$ & D.P. ${ }^{3}$ & Mín. ${ }^{4}$ & Máx. $^{5}$ & Méd. & D.P. & Mín. & Máx. \\
\hline $\mathrm{FPz}$ & 30 & 7,17 & 5,35 & 1,29 & 25,48 & 4,72 & 1,98 & 2,04 & 9,4 \\
\hline $\mathrm{F} 4$ & 30 & 8,07 & 5,18 & 1,69 & 26,38 & 5,68 & 3,1 & 1,55 & 16,47 \\
\hline $\mathrm{Fz}$ & 30 & 7,84 & 5,06 & 1,42 & 26,12 & 5,33 & 2,38 & 2,29 & 11,17 \\
\hline F3 & 30 & 7,84 & 5,36 & 1,58 & 26,74 & 5,01 & 2,21 & 1,73 & 11,21 \\
\hline C4 & 30 & 7,71 & 4,73 & 1,58 & 19,25 & 5,28 & 2,52 & 1,84 & 11,9 \\
\hline $\mathrm{Cz}$ & 30 & 7,88 & 4,76 & 1,35 & 19,55 & 5,29 & 2,39 & 1,6 & 11,89 \\
\hline $\mathrm{C} 3$ & 30 & 7,44 & 4,38 & 1,45 & 17,71 & 4,90 & 2,75 & 1,27 & 12,65 \\
\hline CP5 & 30 & 7,14 & 4,12 & 2,12 & 16,37 & 4,43 & 2,4 & 1,02 & 10,85 \\
\hline CP6 & 30 & 7,44 & 4,30 & 1,17 & 16,73 & 5,00 & 2,18 & 1,86 & 9,43 \\
\hline P4 & 30 & 7,61 & 4,64 & 1,55 & 17,44 & 4,98 & 2,14 & 1,67 & 9,7 \\
\hline $\mathrm{Pz}$ & 30 & 7,37 & 4,39 & 1,73 & 19,35 & 4,79 & 2,63 & 1,46 & 13,27 \\
\hline P3 & 30 & 7,27 & 4,46 & 1,65 & 19,83 & 4,59 & 2,64 & 1,00 & 13,63 \\
\hline
\end{tabular}

$\sqrt[1]{\mathrm{n}=\text { Número de sujeitos; }}$

${ }^{2}$ Méd. = Média;

${ }^{3}$ D.P. = Desvio Padrão;

${ }^{4}$ Mín. = Mínimo;

${ }^{5}$ Máx. = Máximo

A média das respostas na orelha direita variou de 6,85 a 9,05 para o paradigma tradicional e de 4,63 a 5,96 para o paradigma de omissão; na orelha esquerda de 7,14 a 8,07 para o paradigma tradicional e de 4,43 a 5,68 para 0 paradigma de omissão. Os menores valores encontrados em ambas as orelhas e para todos os eletrodos foram observados para o paradigma de omissão.

Para complementar a análise descritiva, foram realizados Box-Plots tanto para a orelha direita (Gráfico 7) quanto para orelha esquerda (Gráfico 8), os quais exemplificam as diferenças encontradas entre os paradigmas. 


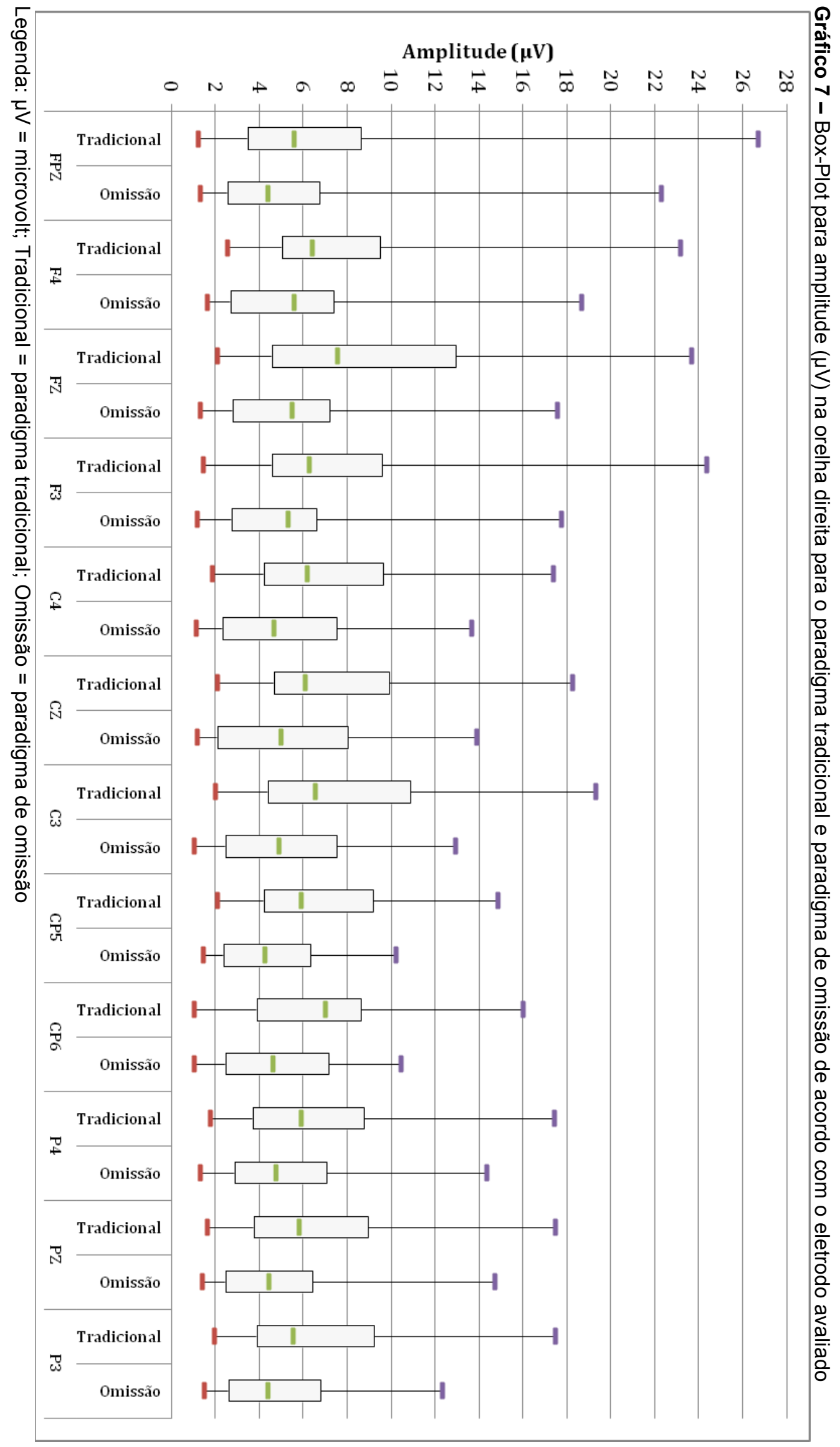




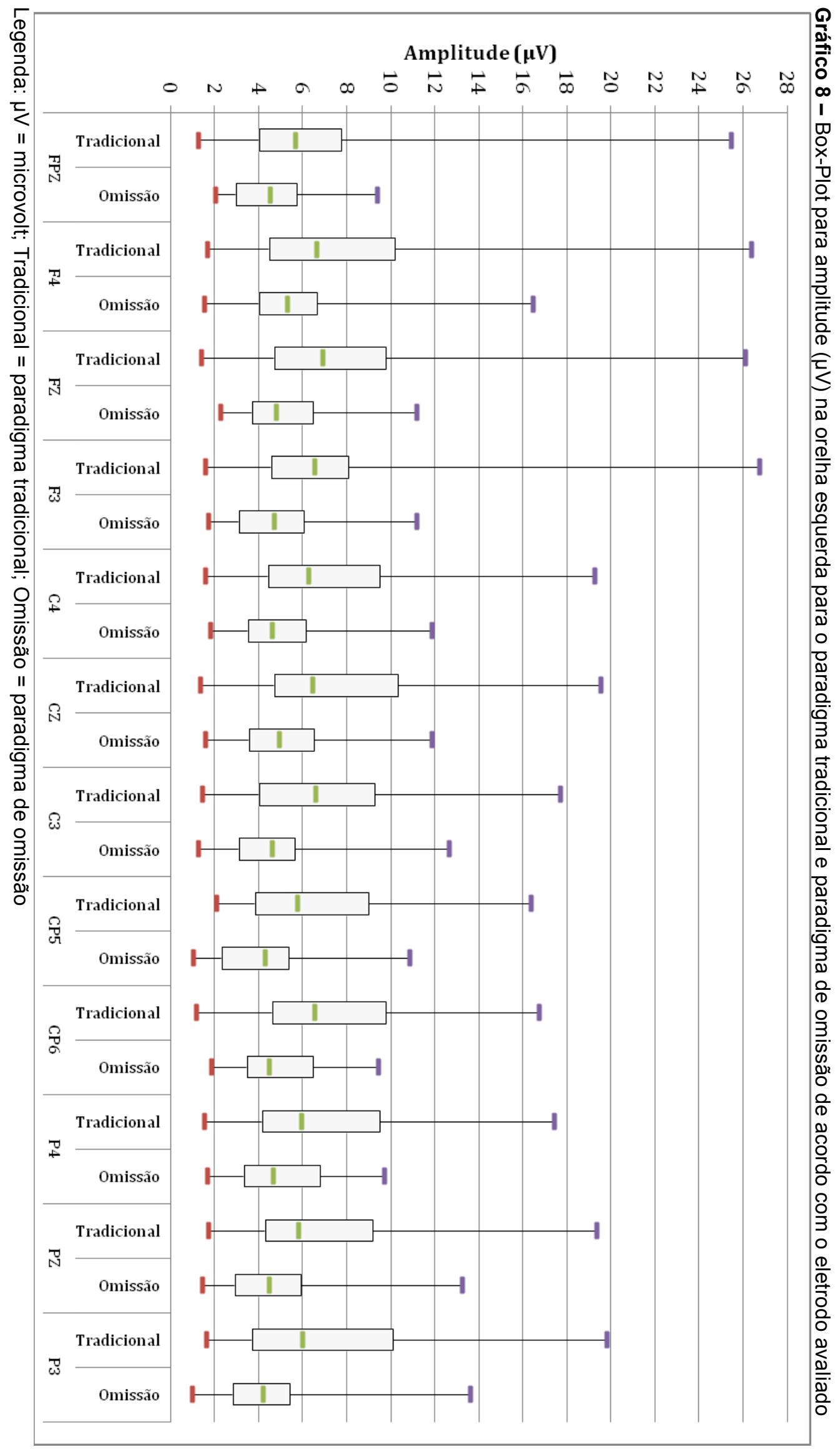


Pode-se observar que todas as medianas do paradigma tradicional são maiores do que as medianas do paradigma de omissão. Na orelha direita, houve maior variabilidade das respostas no eletrodo $\mathrm{Fpz}$ em ambos os paradigmas, e nos eletrodos F4, Fz e F3, no paradigma tradicional. Na orelha esquerda, as maiores variabilidades das respostas ocorreram nos eletrodos FPz, F4, Fz e F3 para o paradigma tradicional. Nota-se que, em ambas as orelhas, as maiores amplitudes ocorreram no paradigma tradicional.

Considerando que ao se utilizar o paradigma de omissão elimina-se a colaboração exógena do P300, também foram realizadas as diferenças médias entre os paradigmas para a amplitude $(\mu \mathrm{V})$. A mesma medida estatística foi aplicada para comparar as amplitudes em ambos paradigmas, ou seja, a ANOVA com medidas repetidas. Os $p$-valores e as diferenças encontradas para cada eletrodo são apresentados na Tabela 14.

Tabela 14 - Diferenças médias e p-valor encontrado para amplitude $(\mu \mathrm{V})$ do P300 entre o paradigma tradicional e o paradigma de omissão para orelha direita e esquerda

\begin{tabular}{|c|c|c|c|c|}
\hline \multirow[b]{2}{*}{ Eletrodo } & \multicolumn{2}{|c|}{ Orelha Direita } & \multicolumn{2}{|c|}{ Orelha Esquerda } \\
\hline & Diferença & p-valor & Diferença & p-valor \\
\hline FPz & 1,91 & $0,028^{*}$ & 2,45 & $0,003^{* *}$ \\
\hline $\mathrm{F} 4$ & 1,99 & $0,015^{*}$ & 2,39 & $0,003^{* *}$ \\
\hline $\mathrm{Fz}$ & 3,52 & $0,011^{*}$ & 2,51 & $0,005^{\star *}$ \\
\hline F3 & 2,05 & $0,006^{* *}$ & 2,83 & $0,003^{* *}$ \\
\hline $\mathrm{C} 4$ & 2,27 & $0,003^{* *}$ & 2,43 & $0,002^{* *}$ \\
\hline $\mathrm{Cz}$ & 2,29 & $0,030^{*}$ & 2,59 & $0,001^{* * *}$ \\
\hline C3 & 2,37 & $0,030^{*}$ & 2,54 & $0,000^{* * *}$ \\
\hline CP5 & 2,22 & $0,001^{* * *}$ & 2,71 & $0,000^{* * *}$ \\
\hline CP6 & 2,13 & $0,003^{* *}$ & 2,44 & $0,001^{* * *}$ \\
\hline P4 & 1,69 & $0,011^{*}$ & 2,63 & $0,001^{* * *}$ \\
\hline $\mathrm{Pz}$ & 1,67 & $0,027^{*}$ & 2,58 & $0,000^{* * *}$ \\
\hline P3 & 1,86 & $0,018^{*}$ & 2,68 & $0,000^{* * *}$ \\
\hline
\end{tabular}


A maior diferença encontrada entre os paradigmas foi de $3,52 \mu \mathrm{V}$ no eletrodo $\mathrm{Fz}$, e a menor diferença foi de $1,67 \mu \mathrm{V}$ no eletrodo $\mathrm{Pz}$, ambas na orelha direita. As diferenças variaram de 1,67 a 3,52 $\mu \mathrm{V}$ na orelha direita, e de 2,39 a $2,83 \mu \mathrm{V}$ na orelha esquerda.

Para complementar a análise estatística, foi realizado o intervalo de confiança no nível de 95\% para orelha direita (Gráfico 9) e esquerda (Gráfico 10). Observa-se que, para a amplitude, os intervalos entre os paradigmas se sobrepõem devido à variabilidade dos dados. A média das repostas para o paradigma de omissão é menor em todos os eletrodos analisados em ambas as orelhas. 
Gráfico 9 - Intervalo de confiança da média no nível de 95\% para a amplitude $(\mu \mathrm{V})$ no paradigma tradicional e no paradigma de omissão na orelha direita

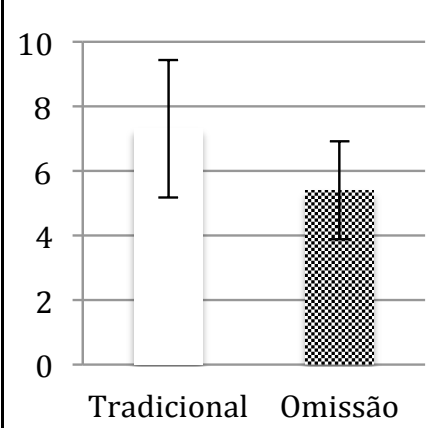

$\mathrm{FPz}$

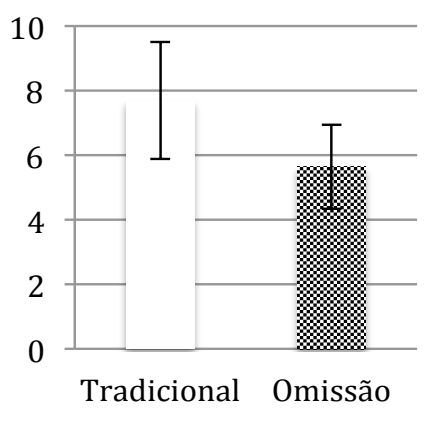

F3

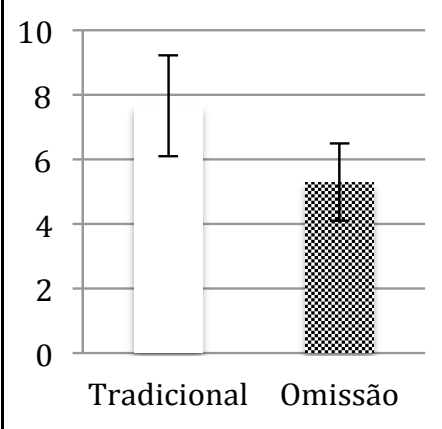

C3

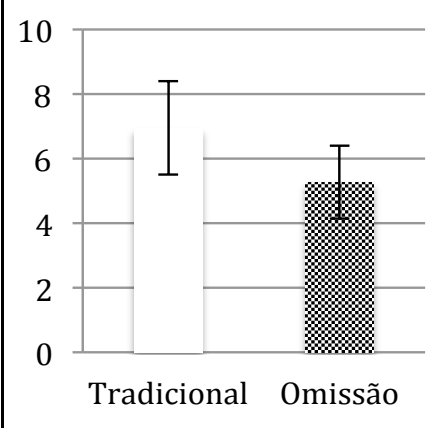

P4

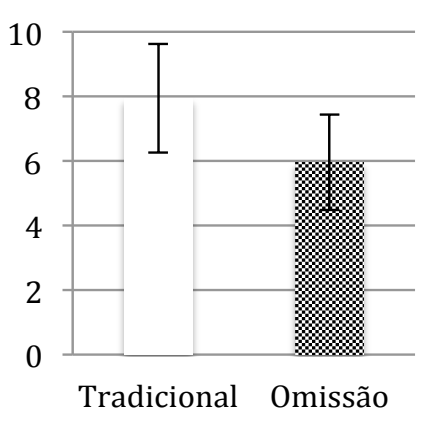

F4

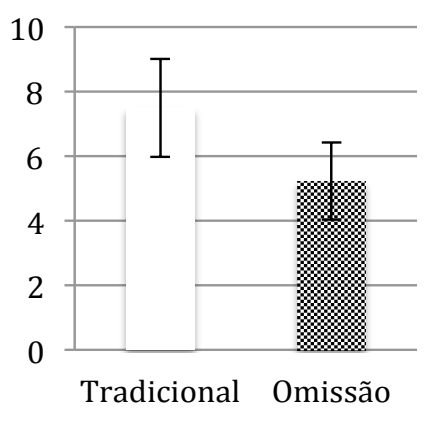

C4

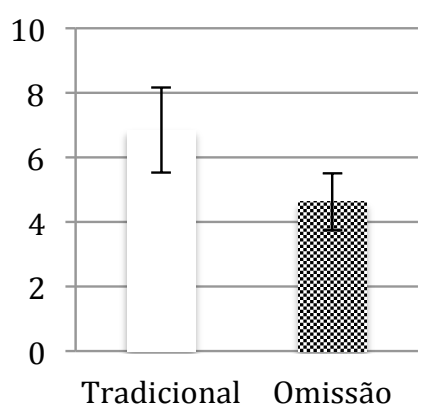

CP5

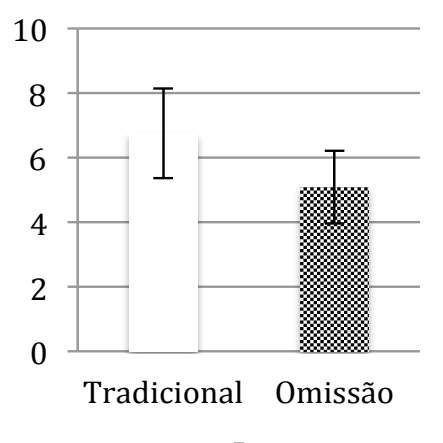

$\mathrm{Pz}$

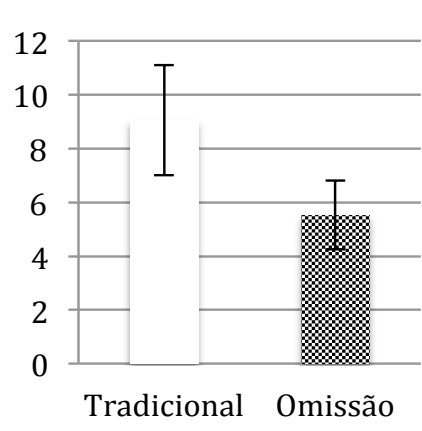

FZ

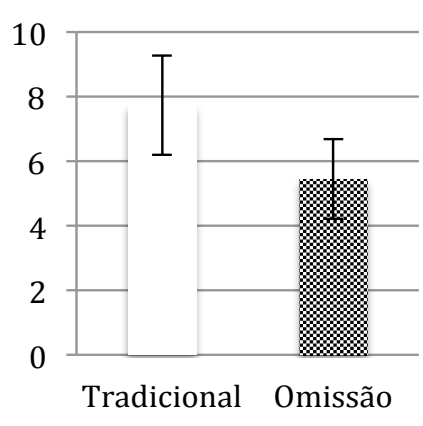

$\mathrm{Cz}$

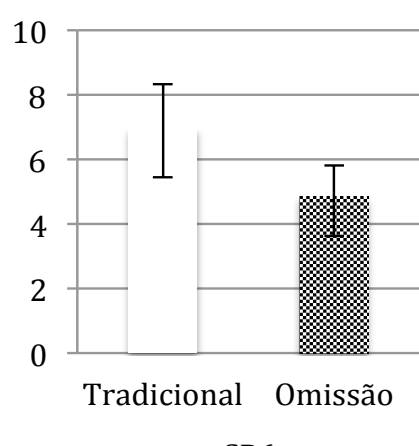

CP6

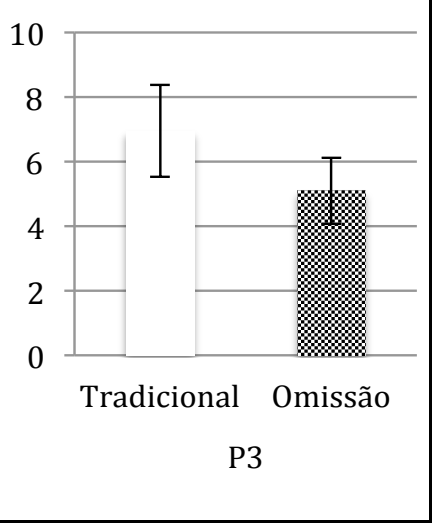


Gráfico 10 - Intervalo de confiança da média no nível de $95 \%$ para a amplitude $(\mu \mathrm{V})$ no paradigma tradicional e no paradigma de omissão na orelha esquerda

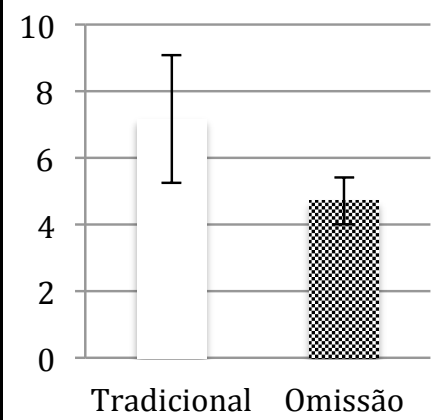

$\mathrm{FPz}$

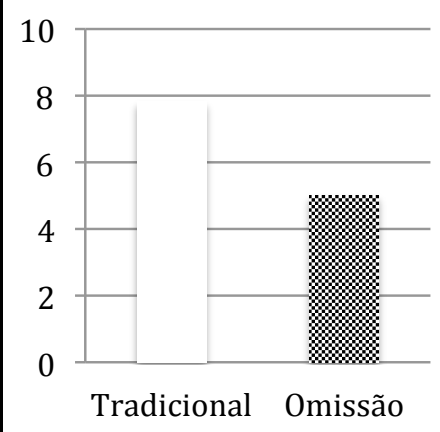

F3

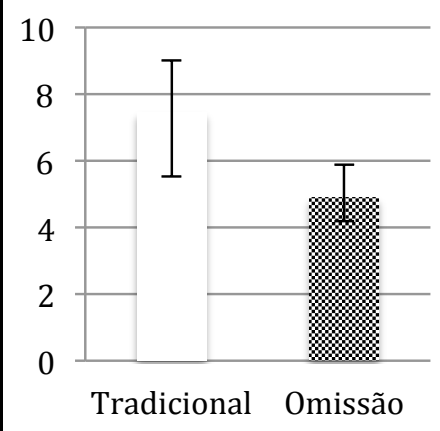

C3

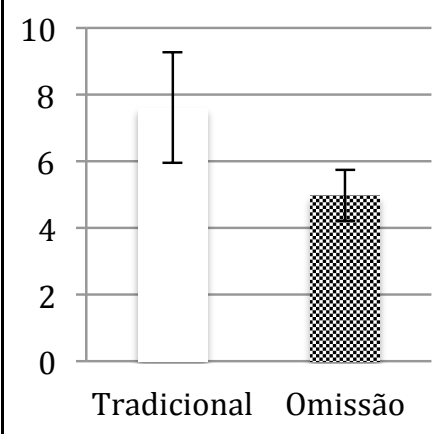

P4

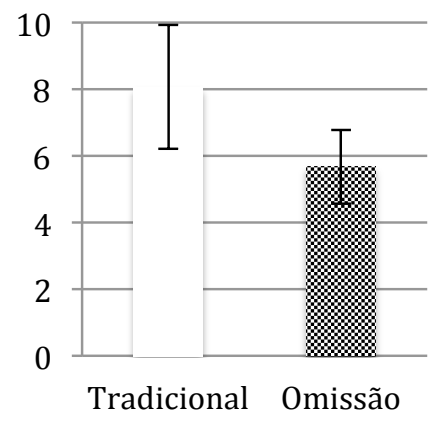

F4

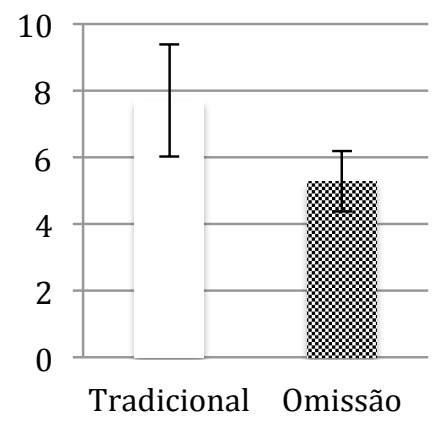

C4

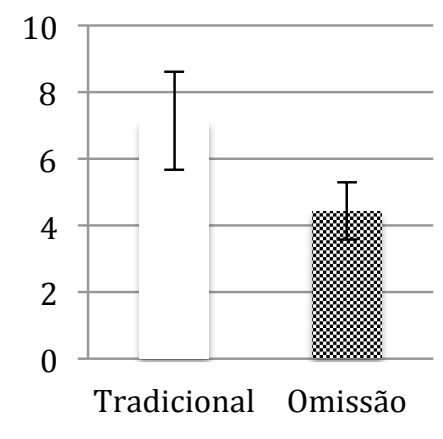

CP5

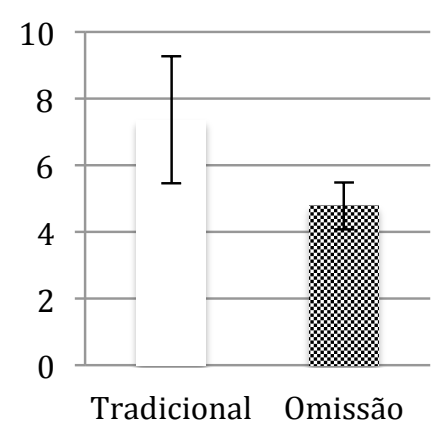

$\mathrm{Pz}$

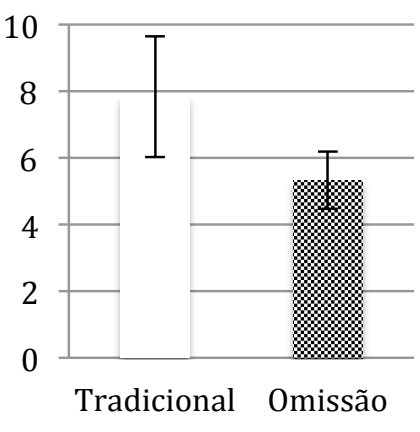

FZ

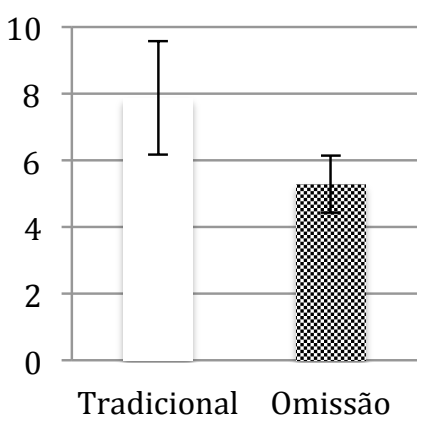

$\mathrm{Cz}$

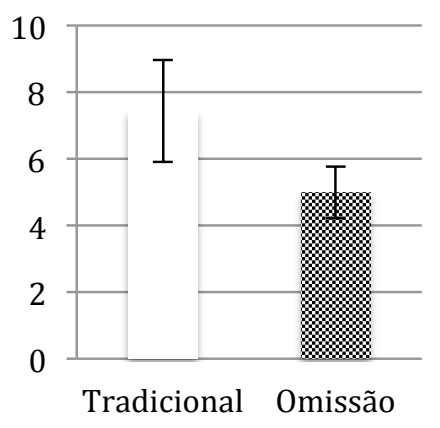

CP6

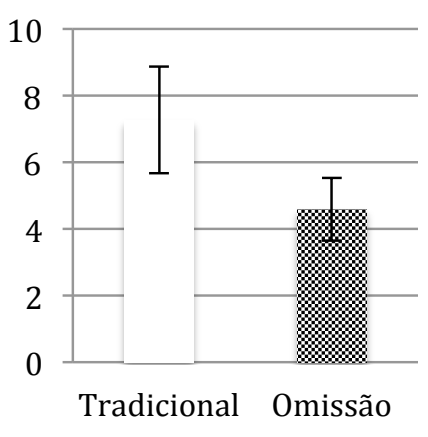

P3 
Para avaliar o P300, foram realizadas as subtrações da estimulação rara com a frequente. Na Figura 6, é apresentado um exemplo de subtração. Notase que os componentes N1-P2-N2 precedem o P300 no paradigma de omissão. Isto ocorreu devido à subtração da estimulação rara com a frequente. No paradigma tradicional a estimulação rara, que também contém os componentes exógenos e obrigatórios N1-P2-N2, é subtraída da estimulação frequente, resultando em uma onda com uma diminuição do complexo N1-P2N2. No paradigma de omissão, o traçado referente à estimulação rara não apresentou os componentes N1-P2-N2 devido à ausência da estimulação sensorial. Dessa forma, ao se realizar a subtração, obtém-se uma onda com a presença desses componentes, com a polaridade invertida.

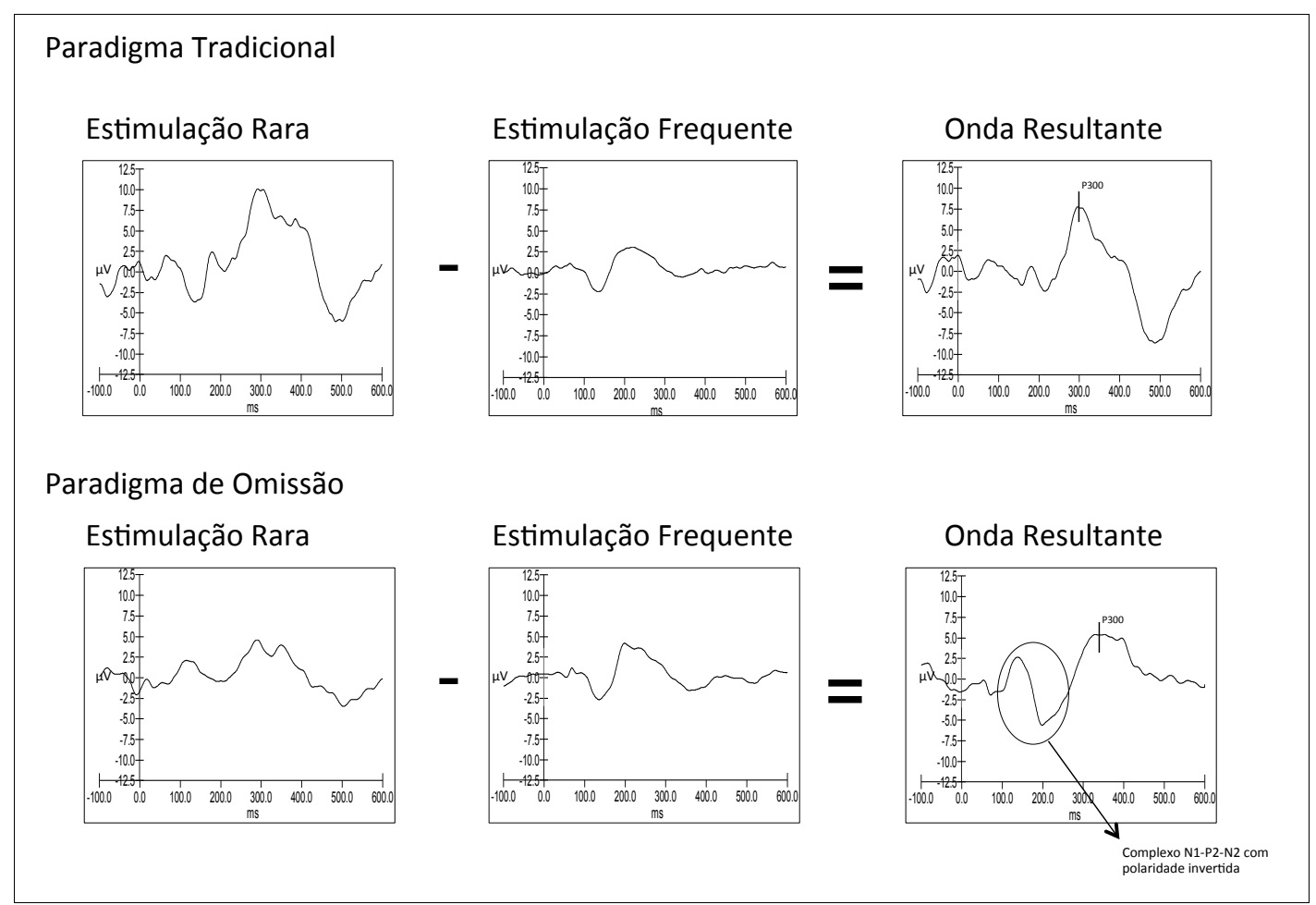

FONTE: Retirada do equipamento Neuroscan, modelo Stim2

Figura 6 - Representação gráfica de um eletrodo da subtração realizada no paradigma tradicional e no paradigma de omissão.

Legenda $\mu \mathrm{V}=$ microvolt, $\mathrm{ms}=$ milissegundos 
A seguir, será apresentada a representação gráfica da soma dos resultados obtidos após a subtração no paradigma tradicional e no paradigma de omissão para a orelha direita (Figura 7) e para orelha esquerda (Figura 8).

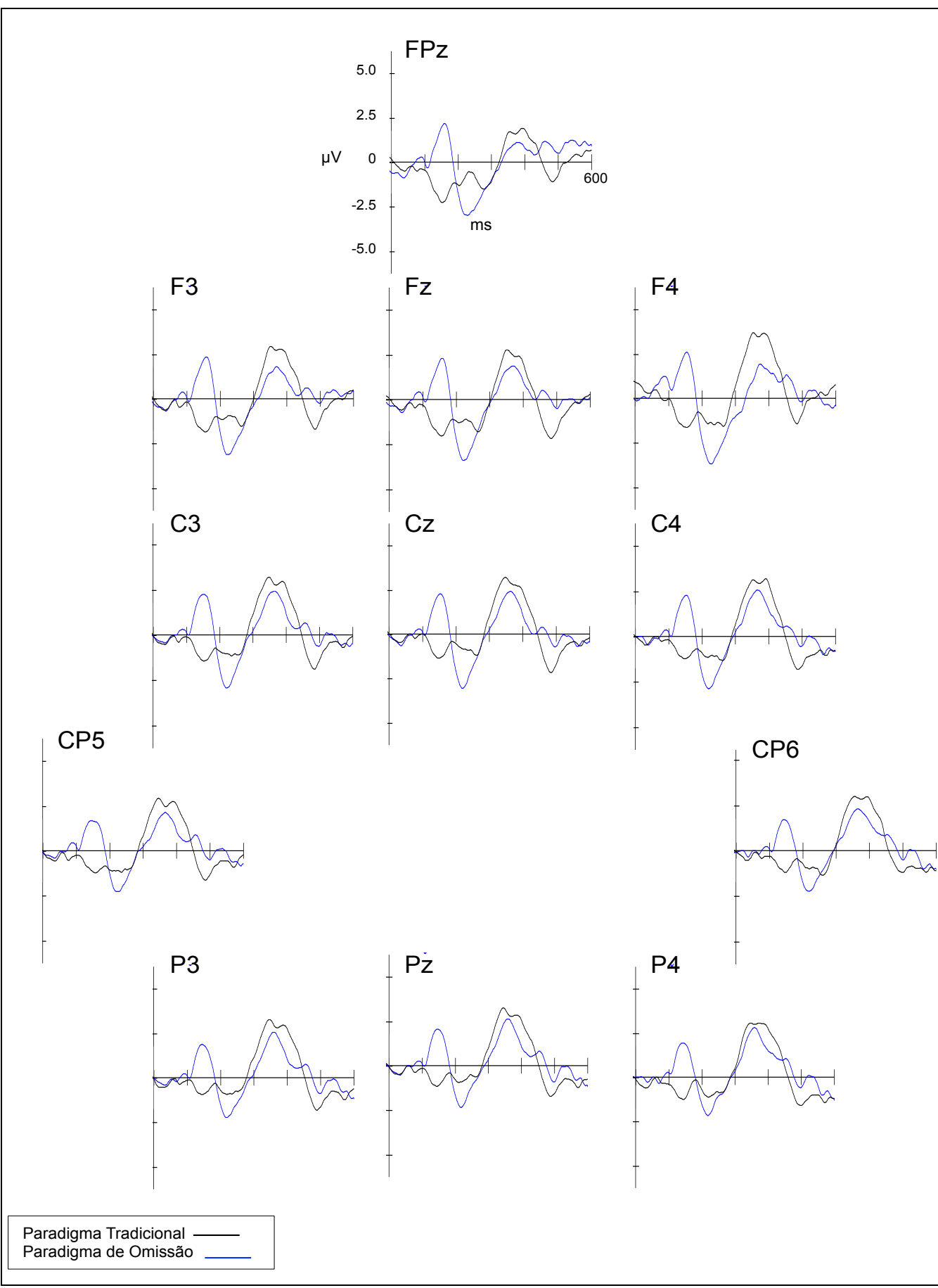

FONTE: Retirada do equipamento Neuroscan, modelo Stim2

Figura 7 - Representação gráfica da soma das 30 ondas resultantes para a visualização do P300 no paradigma tradicional e no paradigma de omissão na orelha direita.

Legenda: $\mu \mathrm{V}=$ microvolts, $\mathrm{ms}=$ milissegundos, em preto o paradigma tradicional, em azul o paradigma de omissão 


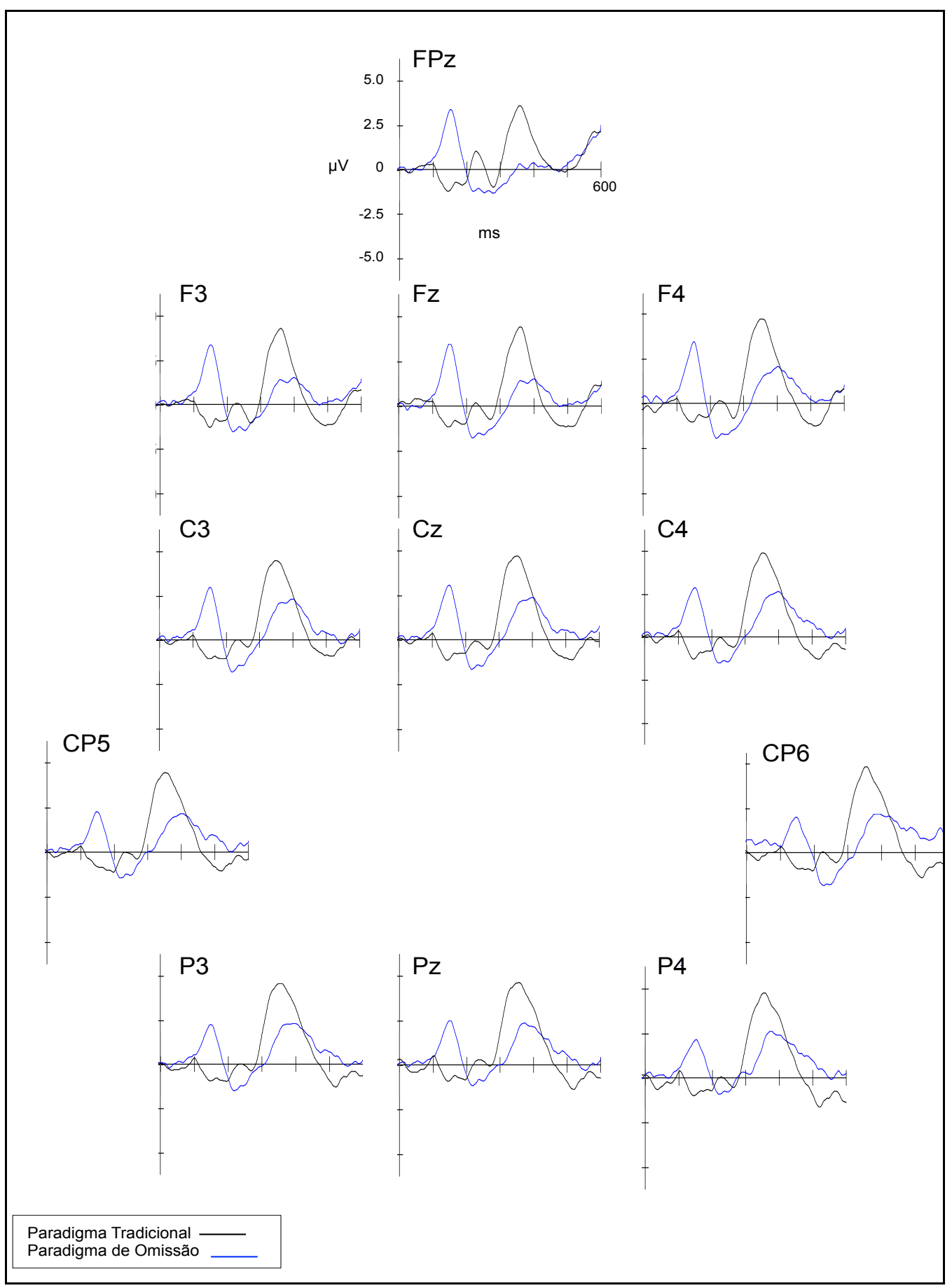

FONTE: Retirada do equipamento Neuroscan, modelo Stim2

Figura 8 - Representação gráfica da soma das 30 ondas resultantes para a visualização do P300 no paradigma tradicional e no paradigma de omissão na orelha esquerda.

Legenda: $\mu \mathrm{V}=$ microvolts, $\mathrm{ms}=$ milissegundos; em preto, o paradigma tradicional; em azul, o paradigma de omissão

Pode-se observar que, no paradigma de omissão, os componentes N1P2-N2, com polaridade invertida, tornam-se visíveis, o que não ocorre no paradigma tradicional. 
Em ambos os paradigmas, a visualização do P300 foi possível, contudo a morfologia do paradigma tradicional torna o pico do P300 mais evidente. Nos 12 eletrodos pesquisados, o paradigma de omissão teve menor amplitude e maior latência.

5.5 Descrição dos resultados encontrados nos mapas topográficos do escalpo

Os mapas topográficos do escalpo foram obtidos a partir da média da soma das 30 ondas resultantes no paradigma tradicional e no paradigma de omissão em ambas as orelhas. A cada $10 \mathrm{~ms}$ foram realizadas médias das imagens, compreendendo o intervalo de 250 e $450 \mathrm{~ms}$ para ambos os paradigmas. A escala de cores utilizada diz respeito à amplitude da resposta em $\mu \mathrm{V}$. Os pontos pretos observados nos mapas topográficos referem-se aos 12 eletrodos ativos no escalpo durante a coleta de dados, conforme apresentado na Figura 1 (pág. 54). Nota-se que, quanto mais vermelha a região no mapa, mais positiva estava a resposta.

De acordo com a onda resultante, o P300, na orelha direita, apresenta amplitude média de $3,11 \mu \mathrm{V}$ no paradigma tradicional e de $2,41 \mu \mathrm{V}$ no paradigma de omissão. Na orelha esquerda, a amplitude média é de 4,68 $\mu \mathrm{V}$ no paradigma tradicional e de 2,94 $\mathrm{V} \mathrm{V}$ no paradigma de omissão. Dessa forma, apenas para melhor visualização das áreas mais positivas ativadas em cada paradigma, foram adotadas escalas de amplitude diferentes para as apresentações dos mapas. 
Na Figura 9, podemos observar os mapas topográficos obtidos para os paradigmas tradicional (escala $-3.2 \mathrm{a}+3.2 \mu \mathrm{V}$ ) e de omissão (escala $-2.5 \mathrm{a}$ $+2.5 \mu \mathrm{V})$ na orelha direita.

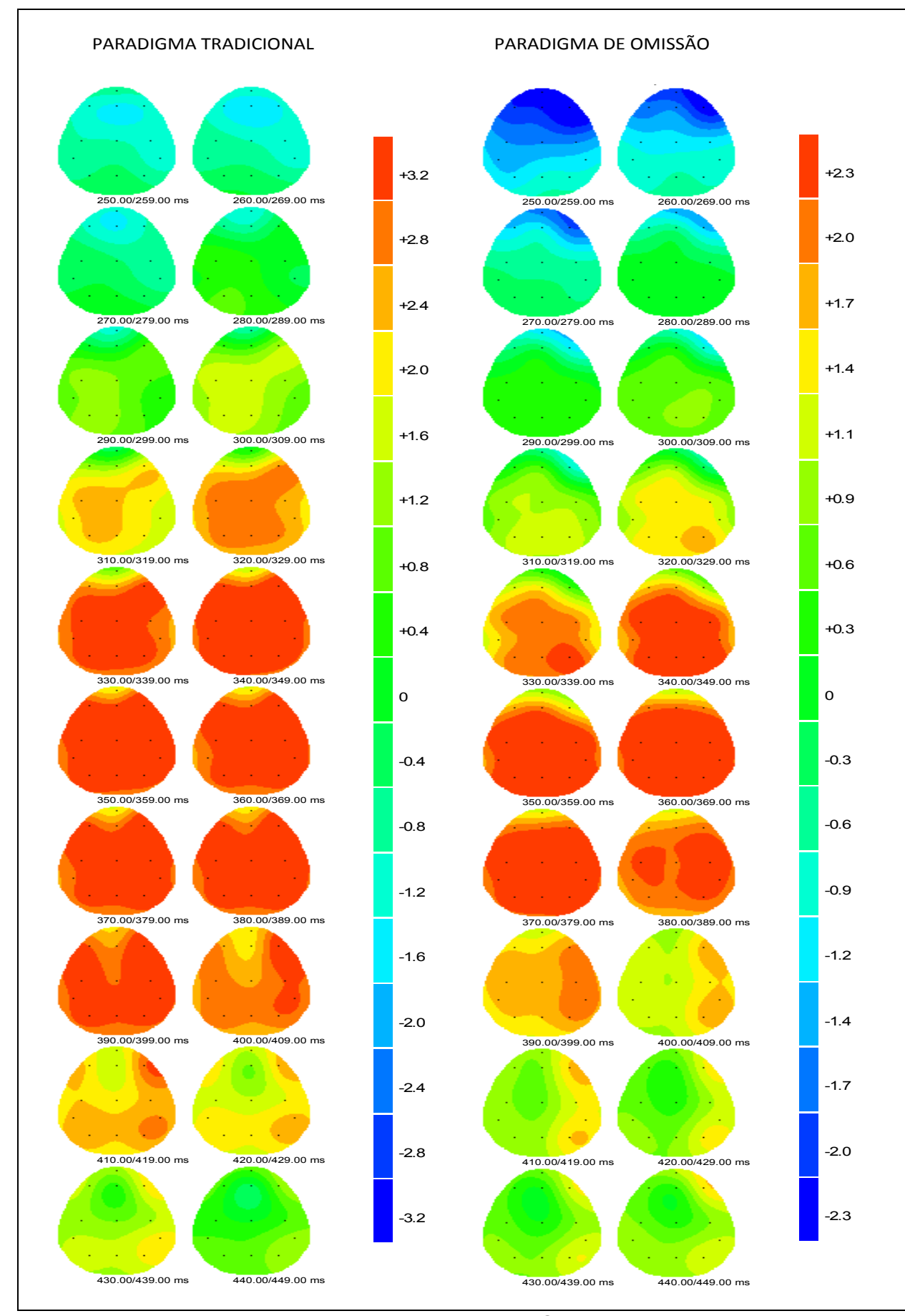

FONTE: Retirada do equipamento Neuroscan, modelo Stim2

Figura 9 - Mapa topográfico do escalpo mostrando a distribuição dos P300 no paradigma tradicional e no paradigma de omissão na orelha direita em cortes a cada $10 \mathrm{~ms}$ (250 a 450ms). Legenda: $\mathrm{ms}=$ milissegundos 
Na Figura 10, podemos observar os mapas topográficos obtidos para os paradigmas tradicional (escala $-4.6 \mathrm{a}+4.6 \mu \mathrm{V}$ ) e de omissão (escala $-2.2 \mathrm{a}+2.2$ $\mu \mathrm{V}$ ) na orelha esquerda.

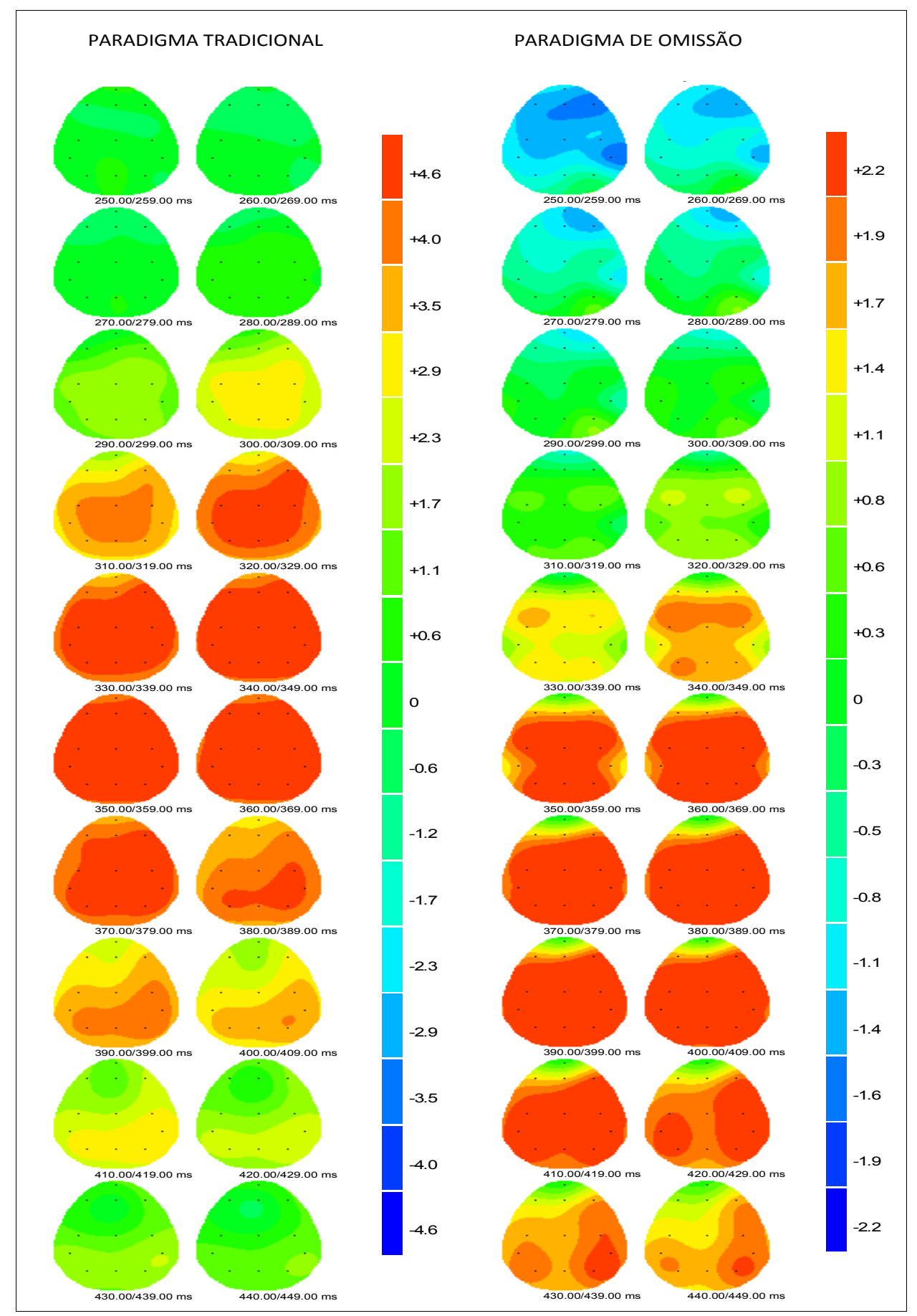

FONTE: Retirada do equipamento Neuroscan, modelo Stim2

Figura 10 - Mapa topográfico do escalpo mostrando a distribuição dos P300 no paradigma tradicional e no paradigma de omissão na orelha esquerda em cortes a cada 10ms (250 a 450ms).

Legenda: $\mathrm{ms}=$ milissegundos 
$\mathrm{Na}$ inspeção visual, a Figura 9 revela maior positividade em ambos os hemisférios para a orelha direita, de 330 a 360 ms para o paradigma tradicional, e de 340 a 360 ms para o paradigma de omissão. A Figura 10 revela maior positividade em ambos os hemisférios para a orelha esquerda, de 320 a $380 \mathrm{~ms}$ no paradigma tradicional e de 350 a $410 \mathrm{~ms}$ no paradigma de omissão.

Nota-se que as áreas positivas no paradigma tradicional ocorrem antes do que no paradigma de omissão em ambas as orelhas, devido a diferença de latência dos picos do P300. Para melhor exemplificar os mapas topográficos, foram realizados cortes nos picos positivos para o eletrodo $\mathrm{Cz}$, no paradigma de omissão e no paradigma tradicional, para as orelhas direita (Figura 11) e esquerda (Figura 12). As escalas foram escolhidas para melhor visualização da área positiva ativada referente a cada paradigma. 


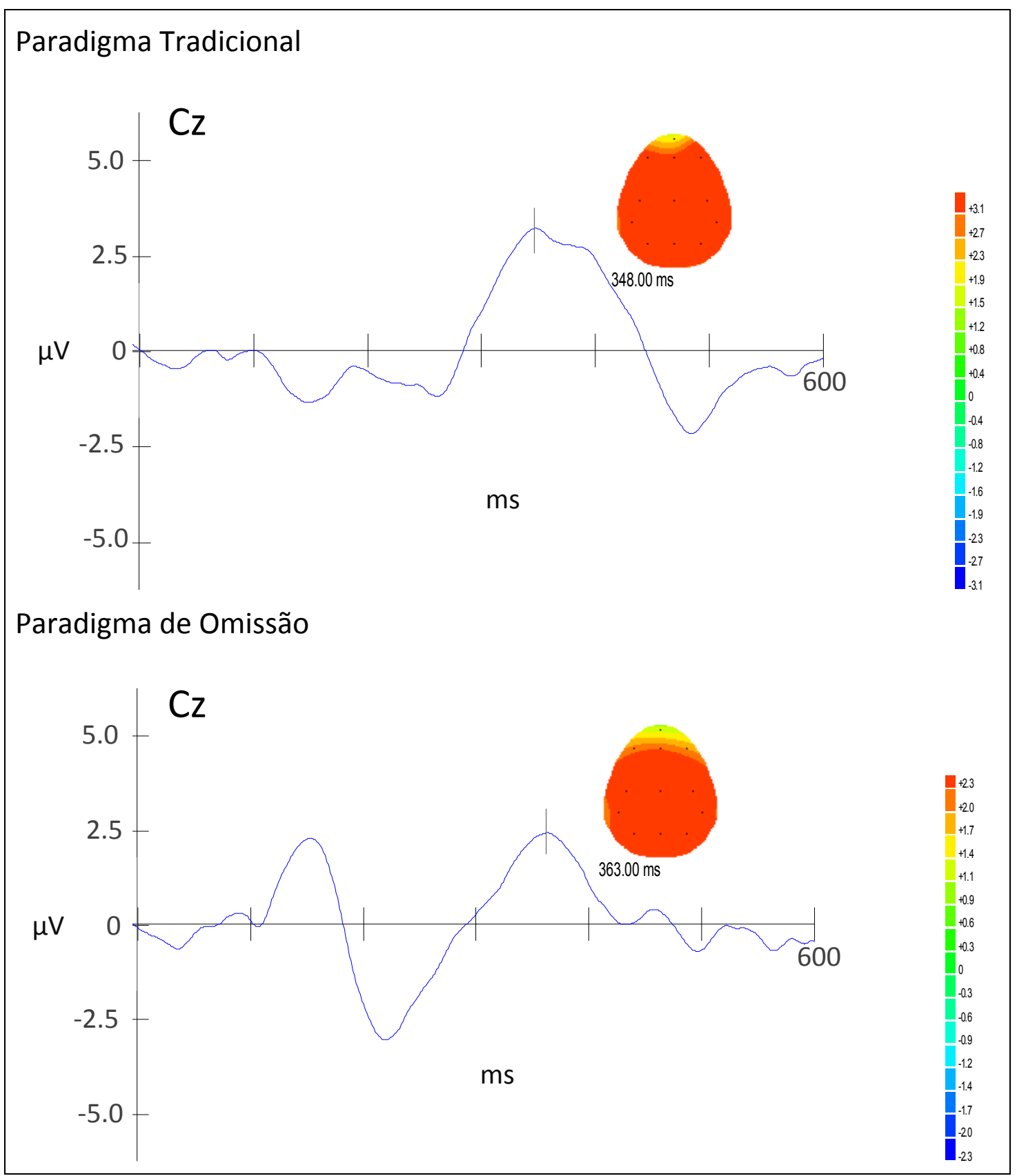

FONTE: Retirada do equipamento Neuroscan, modelo Stim2

Figura 11 - Representação gráfica da soma das 30 ondas resultantes para o eletrodo $\mathrm{Cz}$ com corte do mapa topográfico do escalpo no paradigma tradicional e no paradigma de omissão na orelha direita.

Legenda: $\mu \mathrm{V}=$ microvolts, $\mathrm{ms}=$ milissegundos. 


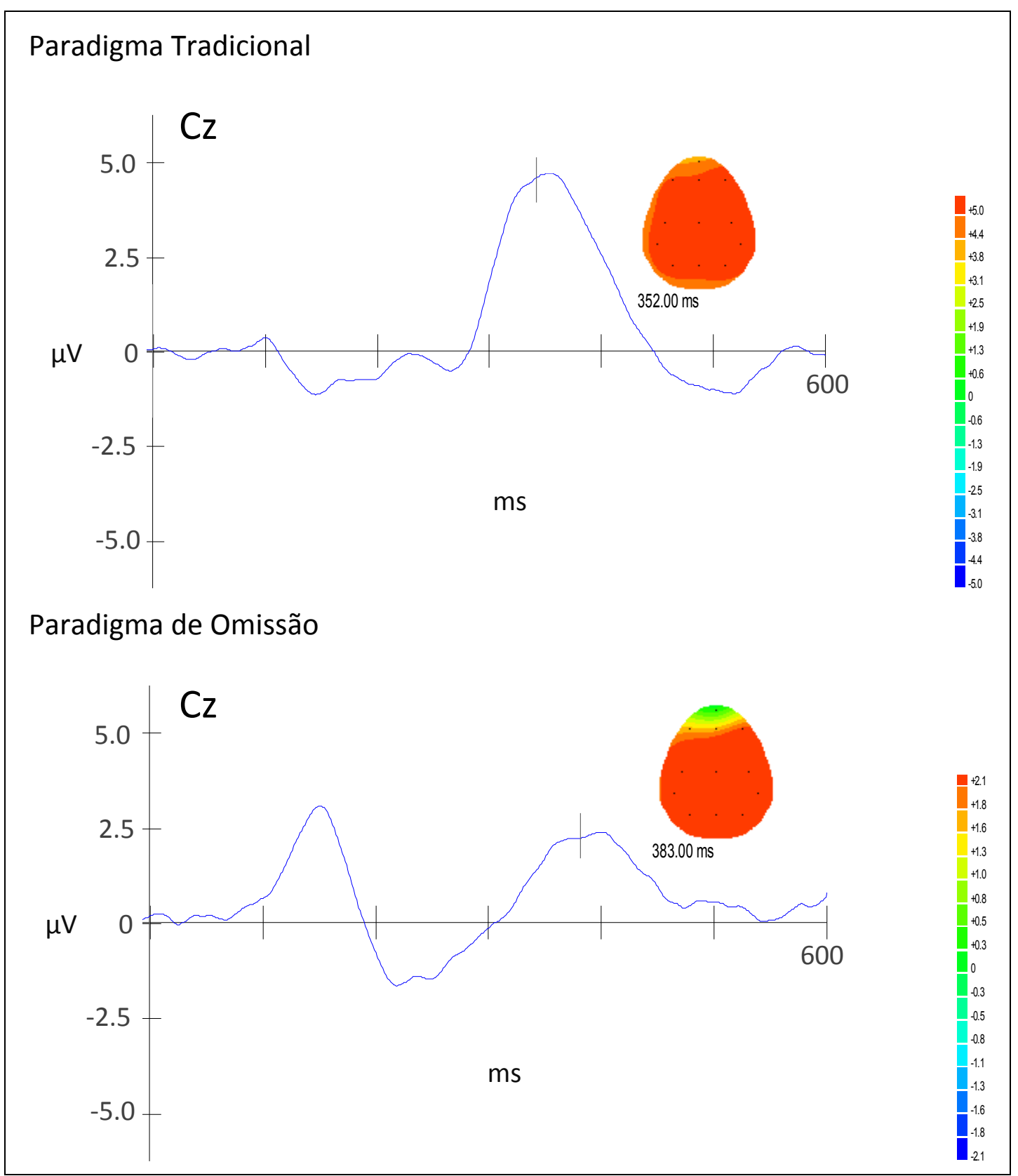

FONTE: Retirada do equipamento Neuroscan, modelo Stim2

Figura 12 - Representação gráfica da soma das 30 ondas resultantes para o eletrodo $\mathrm{Cz}$ com corte do mapa topográfico do escalpo no paradigma tradicional e no paradigma de omissão na orelha esquerda.

Legenda: $\mu \mathrm{V}=$ microvolts, $\mathrm{ms}=$ milissegundos.

Apesar de as amplitudes das positividades encontradas nos mapas diferirem para ambos os paradigmas em ambas as orelhas, a mesma região cerebral foi ativada paras todas as estimulações. 
Discussão 


\section{DISCUSSÃO}

Neste capítulo, será apresentada a análise crítica dos resultados encontrados com base na literatura revisada. O objetivo do presente estudo foi descrever e analisar os resultados obtidos para a latência dos componentes N1-P2-N2, a latência e a amplitude do P300, assim como os mapas obtidos durante as estimulações.

Conforme descrito no capítulo 4 (Métodos), foram utilizados dois protocolos: o paradigma tradicional e o paradigma de omissão. Esses protocolos já foram utilizados em estudos anteriores para elucidar a contribuição exógena e endógena do P300 (Tarkka e Stokic, 1998; Polich e Heine, 1996; Musiek et al., 2005; McCullagh et al., 2009), no entanto, ainda não existe um consenso a respeito dessas contribuições.

Além disso, uma vez que foram utilizados 12 eletrodos ativos no escalpo, foi possível realizar a análise visual dos mapas topográficos para ambos os paradigmas. Cabe ressaltar que, até onde pôde ser observado na literatura, esse tipo de análise ainda não foi realizada.

Esse capítulo está dividido da seguinte maneira:

6.1 Caracterização da amostra;

6.2 Análise dos resultados encontrados para latência do N1-P2-N2;

6.3 Análise dos resultados encontrados para latência e amplitude do P300;

6.4 Análise dos resultados encontrados para os mapas topográficos do escalpo; 


\subsection{Caracterização da Amostra}

A amostra foi composta por homens e mulheres. Os resultados indicaram semelhança de idade entre o sexo masculino (média 25,4) e feminino (média 26,0). Cabe ressaltar que a idade mínima dos indivíduos estudados foi de 19,2 anos, e a máxima, de 34,4 anos, conforme apresentado na Tabela 1. Todos os indivíduos apresentaram audição normal, timpanometria tipo A, integridade das vias auditivas no PEATE e avaliação comportamental do processamento auditivo (TDD e GIN) dentro da normalidade para a faixa etária, conforme os critérios de inclusão.

Sabe-se que o P300 é afetado pelo processo maturacional do sistema nervoso auditivo central e que, nos indivíduos adultos, os valores de amplitude e latências são mais estáveis (Hall, 1992; Picton, 1992; Duncan et al., 2009). Dessa forma, a faixa etária utilizada foi escolhida a fim de descartar possíveis influências maturacionais da via auditiva, assim como da degeneração da mesma causada pelo envelhecimento. Além disso, adotamos os critérios de inclusão acima citados para excluir voluntários com alterações cocleares e retrococleares, com o objetivo de serem obtidas apenas respostas de indivíduos normo-ouvintes, sem alteração sensorial, a qual poderia interferir nos resultados deste estudo.

Os mesmos parâmetros de promediação foram utilizados em ambos os paradigmas estudados, sendo a única diferença a ausência do estímulo raro no paradigma de omissão. A tarefa cognitiva envolvida em ambos os paradigmas 
foi mesma. Assim, a contribuição endógena foi equivalente, mas houve diferença na contribuição exógena, ou seja, na contribuição sensorial.

\subsection{Análise dos resultados encontrados para latência do N1-P2-N2}

Não foram encontrados, na literatura, estudos que tenham averiguado os componentes N1-P2-N2 comparando o paradigma de omissão com o tradicional. Essa análise foi realizada para assegurar que as mesmas condições de estimulação fossem aplicadas em ambos os paradigmas.

Foram realizadas comparações da latência das ondas N1, P2 e N2 entre os paradigmas, para ambas as orelhas (Tabelas 2 a 7). Não foram observadas diferenças estatisticamente significantes para a latência de nenhum dos três componentes analisados (Tabela 8). Os potenciais N1, P2 e N2 são respostas evocadas pela estimulação acústica externa, componentes exógenos e obrigatórios, dependentes apenas das características acústicas do estímulo, diferentemente do $\mathrm{P} 300$, que não é totalmente dependente do estímulo acústico (Picton e Hillyard, 1974; Hall, 1992).

Os resultados obtidos confirmam que os componentes N1, P2, N2 ocorrem como resposta à apresentação dos estímulos. São considerados componentes exógenos, influenciados, principalmente, por aspectos físicos e temporais do estímulo (intensidade, frequência, duração). Contudo, McPherson (1996) afirma que o estado geral ou nível de atenção dirigido ao estímulo acústico podem alterar esses componentes. Para este autor, apesar de serem componentes obrigatórios e ocorrerem mesmo sem a participação ativa da atenção, há uma melhor morfologia da onda nos aspectos relacionados à 
latência, dependendo do nível de atenção dirigido ao estímulo e do estado de alerta do indivíduo.

Como mencionado anteriormente, não foram observadas diferenças estatisticamente significantes para nenhum dos componentes do complexo N1P2-N2 quando se compara o paradigma de omissão com o tradicional. Estas similaridades nos resultados podem ser explicadas pelo fato do nível de atenção ter sido mantido para ambos os paradigmas em ambas as orelhas. Não houve influência desse aspecto para a formação destes componentes portanto, pode-se concluir que o mesmo nível de atenção foi mantido para ambas as estimulações.

Como observado nos box-plots apresentados nos Gráficos 1 e 2, os valores mínimos e máximos estão bem próximos para cada um dos componentes (N1-P2-N2) em todos os eletrodos, em ambas as orelhas. É válido ressaltar que o desempenho das orelhas para os dois paradigmas foi similar para os componentes descritos.

Nas ondas obtidas para o paradigma tradicional, podem ser identificados os componentes N1-P2-N2 tanto no traçado da estimulação frequente quanto na estimulação rara devido às suas características predominantemente exógenas. Já no paradigma de omissão, esse fato não ocorre, provavelmente devido à ausência da estimulação acústica, demonstrando, portanto, ser este um potencial puramente exógeno. Para todos os eletrodos pesquisados, tanto para a orelha direita quanto para a esquerda, não houve sequer tendência à significância quando os paradigmas são comparados. Esse achado pode ser 
justificado devido ao uso dos mesmos parâmetros para o estímulo frequente em ambos os paradigmas, com diferença apenas na apresentação do estímulo raro, o qual foi omitido no paradigma de omissão.

Neste estudo, as latências médias encontradas para o componente N1 ocorreram entre 148,03 a 157,98 ms; para o componente P2, ocorreram entre 212,95 e $219,60 \mathrm{~ms}$; e para o componente N2, entre 246,55 a $258,50 \mathrm{~ms}$ para ambos os paradigmas no traçado do estímulo frequente. Esses achados vão ao encontro dos descritos na literatura para indivíduos jovens normo-ouvintes (Hall, 1992; McPherson, 1996).

Como observado nas Figuras 4 e 5, os componentes N1-P2-N2 não sofreram alteração de morfologia no traçado do estímulo frequente quando visualmente comparados a partir dos dois paradigmas pesquisados.

6.3 Análise dos resultados encontrados para latência e amplitude do P300

Como referido no Capítulo 2 (Objetivos), os P300s evocados pelo paradigma de omissão e pelo paradigma tradicional foram analisados para determinar os efeitos da contribuição exógena (estimulação acústica) nos aspectos relacionados a amplitude, latência e morfologia.

Esse estudo utilizou 12 eletrodos ativos no escalpo para analisar a latência, amplitude e morfologia do P300. A escolha desses eletrodos ocorreu de forma que as regiões frontal, central, parietal e temporal fossem analisadas em ambos os hemisférios para realizar comparações e verificar se houve 
diferença entre as regiões ativadas no P300 evocado pelo paradigma tradicional e as regiões ativadas no P300 evocado pelo paradigma de omissão.

Não foram encontrados, na literatura, outros estudos que tivessem utilizado essa quantidade de eletrodos para avaliar a contribuição exógena do P300 ou quantificar a diferença entre os paradigmas, tampouco que tivessem analisado o mapa topográfico do P300 evocado pelo paradigma de omissão para esse fim.

No presente estudo, para o paradigma tradicional, observou-se P300 com médias de latência para a orelha direita entre 332,07 e 339,53 ms (Tabela 9) e para a orelha esquerda entre 335,12 e 340,49 ms (Tabela 10). Em relação à amplitude, foram encontradas respostas entre 6,76 e 9,05 $\mu \mathrm{V}$ (Tabela 12) para orelha direita e entre 7,17 a $8,07 \mu \mathrm{V}$ para orelha esquerda (Tabela 13). Esses achados corroboram estudos que utilizaram o paradigma tradicional para avaliar o P300 (Picton, 1992; Tarkka e Stokic, 1998; Polich e Heine 1996; Musiek et al., 2005; McCullagh et al., 2009) e que encontraram latência entre 280 e $350 \mathrm{~ms}$, e amplitude entre 5 e $15 \mu \mathrm{V}$.

O P300 evocado pelo paradigma de omissão apresentou respostas médias de latência entre 359,47 e 361,43 ms para a orelha direita (Tabela 9) e entre 355,06 e 361,95 ms para a esquerda (Tabela 10). Para a amplitude, foram encontradas respostas entre 4,63 e 5,96 $\mu \mathrm{V}$ para a orelha direita (Tabela 12) e entre 4,43 e $15,29 \mu \mathrm{V}$ para a esquerda (Tabela 13). Esses achados corroboram estudos que utilizaram o paradigma de omissão (Tarkka e Stokic, 
1998; Polich e Heine, 1996, Musiek et al., 2005; McCullagh, 2009) e que encontraram valores muito próximos ao do presente estudo.

Os paradigmas foram comparados utilizando a ANOVA com medidas repetidas. As diferenças médias encontradas podem ser observadas na Tabela 11, para a latência, e na Tabela 14, para a amplitude, nas quais pode ser observada diferença estatisticamente significante para todos os 12 eletrodos pesquisados.

Esses achados indicam que a ausência do estímulo raro no paradigma de omissão afetou significativamente as respostas encontradas no P300. Observa-se que houve aumento da latência e diminuição da amplitude do P300 em todos os eletrodos pesquisados no paradigma de omissão em relação ao paradigma tradicional, para ambas as orelhas.

As diferenças médias encontradas entre os paradigmas para a latência e para amplitude vão ao encontro dos estudos realizados por Tarkka e Stokic (1998), Polich e Heine (1996), Musiek et al. (2005) e McCullagh et al. (2009), que realizaram o P300 com o paradigma de omissão comparando com o paradigma tradicional. Esses estudos também observaram que o P300 evocado pelo paradigma tradicional é menor em latência e maior em amplitude do que quando evocado pelo paradigma de omissão.

No presente estudo, as respostas encontradas para os 12 eletrodos pesquisados no paradigma de omissão foram, em média, 3,00 $\mu \mathrm{V}$ menores para a amplitude e 25,00 ms maiores para a latência quando comparadas com o paradigma tradicional. Apesar de os estudos encontrados na literatura não 
terem sido realizados com a mesma quantidade de eletrodos, os resultados são comparáveis aos do presente estudo, pois, pelo menos um dos eletrodos utilizados nesses estudos está incluído nos 12 aqui analisados.

Ruchkin e Sutton (1978) encontraram diferença de amplitude 3,78 $\mu \mathrm{V}$ maior para o paradigma tradicional no eletrodo Cz. Tarkka and Stokic (1998) encontraram diferença de aproximadamente $5 \mu \mathrm{V}$ maior para os eletrodos $\mathrm{F} 3$, $\mathrm{Fz}, \mathrm{F} 4, \mathrm{C} 3, \mathrm{Cz}, \mathrm{C} 4, \mathrm{P} 3, \mathrm{Pz}$ e $\mathrm{P} 4$, para o paradigma tradicional quando comparado ao de omissão.

Musiek et al. (2005) subtraíram as ondas evocadas pelos dois paradigmas e observaram diferença de amplitude de 3,03 $\mu \mathrm{V}$ no eletrodo $\mathrm{Cz}$, o qual os autores atribuíram ao componente exógeno. McCullagh et. al. (2009), que também estudaram a diferença entre o paradigma de omissão e o paradigma tradicional encontraram diferença de amplitude de 4,49 $\mu \mathrm{V}$ para o eletrodo $\mathrm{Cz}$.

Neste estudo, as médias das diferenças encontradas para amplitude foram menores do que a relatada na literatura. Isso pode ser explicado pelo fato de ter sido utilizada a intensidade de 80 dBNPS e não 80 dBNA o que significa aproximadamente $10 \mathrm{~dB}$ a menos do que a maior parte dos estudos que avaliaram o P300 (Hall, 1992; Tarkka and Stokic 1998; Musiek et al. 2005; McCullagh et. al. 2009). Mais uma vez demonstrando que o componente exógeno influencia na captação do potencial.

Conforme relatado na literatura, a amplitude do P300 varia de acordo com a atenção consciente dada ao estímulo. Segundo Picton (1992), a resposta mais proeminente do P300 ocorre quando o indivíduo está atento ao estímulo. 
O mesmo pesquisador também afirma que deve ser mantido um nível de dificuldade desafiador para a percepção do tom.

O nível de atenção requerido para a realização da tarefa no presente estudo, provavelmente, foi mantido em ambas as estimulações, visto que a promediação de cada onda foi curta com duração aproximada de cinco minutos para cada uma delas portanto, a duração total do exame foi de aproximadamente 20 minutos. Há que se levar em conta que a tarefa solicitada aos voluntários era relativamente simples e todos os participantes identificaram no mínimo $90 \%$ dos estímulos demonstrando assim, a manutenção da atenção durante toda a coleta. Portanto este não foi um fator que interferiu nos resultados encontrados.

Considerando que o nível de atenção dirigida ao estímulo alvo foi o mesmo em ambos os paradigmas, as menores amplitudes encontradas para o paradigma de omissão provavelmente são resultado da ausência da contribuição sensorial para a formação do P300.

Por não ter sido observada nenhuma diferença significativa entre os componentes exógenos na comparação entre os paradigmas, pode-se inferir que a ausência da estimulação sonora no paradigma de omissão foi a única diferença que pode ter influenciado a obtenção da onda do P300 no que diz respeito a amplitude, latência e morfologia.

De acordo com os resultados encontrados para a comparação das latências entre os paradigmas (Tabela 11), as maiores diferenças observadas foram para o eletrodo CP5 (29,34 ms), para a orelha direita, e no eletrodo Cz 
$(24,87 \mathrm{~ms})$, para a orelha esquerda. Os menores valores encontrados foram para o eletrodo Fz $(21,87 \mathrm{~ms})$, para orelha direita, e P3 (15,54 ms), para a esquerda, em ambos os paradigmas. A latência do P300 está relacionada ao tempo necessário para que a decisão pela ocorrência do estímulo raro seja tomada (Sutton et al., 1965).

Segundo Picton (1992), a latência varia de acordo com a dificuldade em discriminar o tom raro do tom frequente. Em relação a dificuldade para realizar a tarefa no paradigma de omissão, pode-se deduzir que, quando a discriminação entre o estímulo raro e o estímulo frequente é difícil - por exemplo, para tons muito próximos - a amplitude do P300 diminui, e a latência aumenta, demonstrando a necessidade de um maior tempo para realizar a discriminação entre os dois tons.

Os resultados encontrados no presente estudo podem ser justificados a partir de duas explicações. A primeira está relacionada à contribuição sensorial. As diferenças encontradas na amplitude, latência e morfologia podem ser consequência da ausência da contribuição do estímulo acústico para a formação do componente P300 (Polich et al., 1996; Musiek et al., 2005; McCullagh et al., 2009). Como, no paradigma de omissão, não houve contribuição sensorial para a formação do potencial, houve diminuição na amplitude e aumento da latência. Dessa forma, pode-se inferir que os resultados encontrados no presente estudo, para o paradigma de omissão, aparentam ser puramente endógenos, uma vez que houve falta da contribuição sensorial. 
A segunda explicação para os resultados encontrados está relacionada à tomada de decisão: se houve ou não a presença do estímulo raro. De acordo com a literatura pesquisada, no paradigma tradicional, a tomada de decisão do indivíduo é mais precisa e mais imediata para a presença do estímulo raro (tom de $1200 \mathrm{~Hz}$ ). Em outras palavras, no paradigma tradicional, a tomada de decisão, para diferenciar o estímulo frequente do estímulo raro, ocorre no momento em que o estímulo raro é percebido pelo indivíduo.

No paradigma de omissão, entretanto, o estímulo raro está ausente (intervalo de silêncio). Nesse caso, o indivíduo precisa fazer uso de uma estimativa temporal para tomar a decisão de que houve a presença do estímulo raro ou não. Ou seja, essa decisão somente ocorre quando o próximo estímulo frequente é percebido, e o indivíduo detecta que aquele silêncio foi maior que o intervalo interestímulo habitual e decide que houve o "estímulo" raro (Ruchkin e Sutton 1978; McCullagh et al., 2009).

Assim, esse atraso na tomada de decisão para processar que houve o estímulo raro pode resultar em imprecisão, levando a uma menor amplitude e maior latência de resposta, o que também poderia justificar os achados encontrados.

Pode-se associar essa diferenciação na tomada de decisão entre o paradigma tradicional e o paradigma de omissão ao mecanismo de resolução temporal. O processamento auditivo temporal (resolução temporal) é definido como a percepção do som ou da alteração do som dentro de um período restrito e definido de tempo (Shin, 2003), ou seja, refere-se à habilidade de 
perceber ou diferenciar estímulos que são apresentados numa rápida sucessão.

Segundo Abeles e Goldstein Jr. (1972), a base fisiológica para resolução temporal está na existência de fortes respostas neurais de rápida duração referentes às células on (octopus), que são ativadas no início da estimulação acústica. Esse padrão de respostas (curtas e rápidas) codificam a informação temporal do som, e o córtex auditivo tem uma participação importante nesse processamento. No final da estimulação acústica, há disparos de outros tipos de neurônios, as células off.

As células on e off têm uma interação antagônica inibitória. No início da estimulação, as células on disparam com uma resposta transitória que, gradualmente, decai para um nível de atividade que se mantém até o fim do estímulo. Por sua vez, as células off são hiperpolarizadas no início da estimulação, e esta inibição decai gradativamente até que as células off disparem indicando o fim da estimulação. A percepção do silêncio só ocorre quando as células off disparam, revelando que ocorreu a ausência de energia.

Os mecanismos que delineiam a detecção do silêncio podem se pautar na adaptação neural. Quando o estímulo é iniciado, ocorre uma resposta transitória que decai rapidamente a um nível estável de resposta neural. No momento em que esse marcador é finalizado, a taxa de disparo neural decai rapidamente a zero, e assim permanece até que o segundo estímulo comece (Schineider e Hamstra, 1999). 
Ao se relacionar a segunda explicação de um ponto de vista fisiológico sobre resolução temporal, no presente estudo, o estímulo raro utilizado foi o tom de $1200 \mathrm{~Hz}$ no paradigma tradicional. Dessa forma, quando o estímulo raro é iniciado, ocorre também uma resposta sensorial, visto que as células da via auditiva também são recrutadas. Essa resposta é enviada para o córtex auditivo, que processa a informação sensorial, e assim é tomada a decisão que ocorreu a partir do estímulo raro. No paradigma de omissão, o estímulo-alvo é a ausência de som. Dessa forma, não há ativação da via sensorial para auxiliar a tomada de decisão.

À inspeção visual das ondas (Figuras 7 e 8), observa-se que o P300 evocado pelo paradigma tradicional apresentou morfologia melhor definida quando comparado ao P300 evocado pelo paradigma de omissão. Pode-se notar um pico mais bem definido, assim como uma melhor amplitude no paradigma tradicional. Esses resultados confirmam que deve existir uma participação exógena para a formação do potencial, indicando que a ausência da estimulação sensorial pode influenciar a latência e amplitude do P300, assim como na morfologia. Consequentemente, pode-se inferir que o componente exógeno no P300 verdadeiramente direciona a forma da onda, e sem ele o P300 é alterado em termos de amplitude, latência e morfologia.

Sabe-se que as fibras do nervo auditivo têm grande participação no processo de detecção do som, mas esse processamento ocorre na porção mais central da via auditiva. A precisão do primeiro disparo neural, que responde ao início do som, é proporcional à latência da resposta neural, e sabe-se que a fidelidade temporal para as respostas transitórias é preservada 
na via auditiva até o córtex auditivo primário. O grau de precisão no tempo de resposta dá suporte à resolução temporal nos limites da performance comportamental, sendo o córtex auditivo importante para essa tarefa (Hall, 1992).

Observou-se, no presente estudo, que quando há presença de estímulo há uma melhor resolução temporal para tomada de decisão e que o córtex auditivo tem papel nesse processamento temporal, evidenciando uma resposta mais precoce e robusta no paradigma tradicional.

Dessa forma, no paradigma tradicional, quando ocorre o estímulo raro há uma ativação de mecanismos neurais que não ocorre no silêncio, justificando, assim, a diminuição da amplitude e o aumento da latência tanto pela resolução temporal, para determinar se houve ou não o estímulo raro, quanto pela ausência sensorial, decorrente do não recrutamento de mecanismos neurais para determinar a presença da estimulação rara.

Por ser um potencial preciso no domínio do tempo, no momento em que ocorre a discriminação do estímulo alvo se dá a formação do potencial. Segundo Kalaiah e Sahstri (2016), a latência do P300 reflete o tempo requerido para a classificação do estímulo, a qual é proporcional ao tempo necessário para detectar e discriminar o estímulo-alvo. Como no paradigma de omissão não houve estimulação acústica há um atraso maior para detectar o estímulo, consequentemente um atraso na formação da onda.

De acordo com os resultados encontrados, constata-se que, se esse potencial fosse puramente endógeno, as características físicas do estímulo 
acústico, como a intensidade ou ausência de som, não deveriam ter um efeito significativo na amplitude, latência e morfologia do P300.

Considera-se que as justificativas apresentadas para os resultados encontrados no paradigma de omissão se completam: como houve evidências, no presente estudo, de que não existe a contribuição sensorial, há uma imprecisão na tomada de decisão relacionada à ocorrência da estimulação rara e, consequentemente, um atraso na latência, bem como um decréscimo na amplitude. Entretanto, o motivo para essa "imprecisão" aparenta ser a ausência da contribuição sensorial que deflagra os outros processos.

Apesar de serem utilizadas predominantemente na literatura, as terminologias endógeno e exógeno não são adequadas para serem usadas nos potenciais evocados auditivos, de acordo com os resultados encontrados. O termo endógeno significa "originado dentro", e o termo exógeno significa "originado fora". No entanto, todas as respostas auditivas, na realidade, decorrem de dentro do sujeito, e todas essas respostas são evocadas por estímulos auditivos externos (Hall, 1992).

O ponto importante é ter em mente o contraste entre a resposta que não depende de atenção ao estímulo ou participação ativa do paciente e a resposta que depende das características acústicas do estímulo independente da atenção ou processamento dos sons pelo indivíduo. Conforme apresentado neste estudo, a terminologia "puramente endógeno" não é correta para ser utilizada para referir-se ao $\mathrm{P} 300$, visto que a contribuição sensorial guia a formação desse componente. 
De acordo com os resultados, há uma contribuição exógena, sensorial, no P300, a qual influencia na latência e amplitude deste. Sabe-se que, em indivíduos que apresentam habilidades auditivas alteradas, a amplitude do P300 é menor e a latência da resposta é maior (Rocha-Muniz, 2011). Portanto, seria interessante comparar as respostas evocadas pelo paradigma tradicional com aquelas evocadas pelo paradigma de omissão nessa população, para verificar se as diferenças encontradas seriam as mesmas observadas neste estudo, para a população com audição normal.

6.4 Análise dos resultados encontrados para os mapas topográficos no escalpo

Os mapas topográficos obtidos no escalpo podem apresentar grande contribuição para a verificação das regiões corticais participantes para evocar a resposta do P300. Contudo, com as respostas obtidas por meio dos mapas, não se pode inferir o sítio gerador exato que contribuiu para a resposta. Conforme apresentado nos mapas topográficos, diversas regiões são ativadas para processar a informação requerida para se obter o P300.

Muitas dessas regiões podem gerar campos elétricos no escalpo. A identificação correta e a mensuração da onda do P300 requer uma diferenciação desses campos elétricos. A distribuição de eletrodos no escalpo é um importante parâmetro para ajudar na identificação dos mapas topográficos do P300. De acordo com alguns estudos (Picton e Hillyard, 1974; Picton 1992), os maiores registros do P300 são encontrados na linha média centro-parietal. No presente estudo, os 12 eletrodos utilizados estavam 
distribuídos na linha média, nos hemisférios direito e esquerdo e nas regiões frontal, central, temporal e parietal. Com esta configuração foi possível evocar o P300 com boa percepção visual em todos os eletrodos.

Para a obtenção dos mapas, foram realizados cortes a cada $10 \mathrm{~ms}$, abrangendo a janela de 250 a 450 ms, visto que a média para o aparecimento do $\mathrm{P} 300$, no paradigma tradicional, foi em torno de 330 a $340 \mathrm{~ms}$, e no paradigma de omissão, entre 355 e 365 ms.

Neste estudo, pode-se observar que existem áreas de maior positividade no escalpo. No entanto, não se pode inferir sobre os sítios geradores exatos do P300. De acordo com a literatura, não há uma definição exata das fontes que contribuem para a formação desse potencial. Apesar de os sítios geradores exatos do cérebro que eliciam o P300 ainda não serem completamente conhecidos, Tarkka e Stokic (1998) sugerem múltiplas regiões cerebrais como áreas do lobo temporal superior, córtex auditivo primário e secundário, áreas do lobo temporal medial, como hipocampo e para-hipocampo, assim como a ativação da insula, contribuem para a formação do componente do P300.

Consoante com as Figuras 9 e 10, que retratam os mapas topográficos em ambos os paradigmas e em ambas as orelhas, constata-se uma ativação mais positiva na região centro-parietal do mapa topográfico correspondente aos eletrodos C3, Cz, C4, CP5, CP6, P3, PZ e P4, em ambos os hemisférios. A distribuição topográfica das positividades observadas mostrou que ambos os paradigmas acionam os mesmos mecanismos cognitivos próprios dos 
processos que envolvem a discriminação, atenção e memória para a obtenção dos P300.

Apesar de não poder inferir acertadamente sobre os sítios geradores do P300, a partir do EEG, podem-se observar as áreas que participam da formação do potencial em ambas as condições. No paradigma de omissão, as maiores positividades ocorreram entre 350 e $400 \mathrm{~ms}$ para ambas as orelhas, e no paradigma tradicional, as maiores positividades ocorreram entre 320 e 390 ms, em ambas as orelhas. As positividades em ambos os paradigmas se mantêm por um tempo maior devido ao alargamento dos picos após a soma das ondas resultantes.

A partir das Figuras 11 e 12, que retratam o corte na maior positividade no eletrodo $\mathrm{Cz}$, em ambos os paradigmas pode-se observar que fontes da região centro-parietal têm participação mais evidente para evocar o potencial. A distribuição topográfica das positividades do P300 em ambos os paradigmas, nas orelhas direita e esquerda, mostram que áreas positivas ativadas na região temporal-central estão contribuindo para evocar a resposta. As regiões temporal, central e parietal são ativadas em ambos os paradigmas pode ser reflexo da habilidade de atenção que envolve o lobo parietal. Os processos de memória, discriminação e atenção são elementos endógenos importantes para a morfologia, assim como para o aparecimento da resposta.

A localização fisiológica dos mecanismos de atenção e discriminação é mais central no córtex (Hall, 1992), no entanto o presente estudo mostrou que o P300 pode também ser evocado com boa amplitude em todos eletrodos 
colocados nas regiões frontal, central e parietal em ambos os hemisférios, com maior amplitude nas regiões central e parietal.

O eletrodo $\mathrm{FPz}$, em ambos os paradigmas, demonstrou a menor amplitude, apesar de ter sido captada respostas nessa região. Pode-se observar que no sentido antero-posterior a partir dos eletrodos F3, Fz e F4 há um aumento da amplitude e uma maior positividade pode ser observada no mapa topográfico, evidenciando que as respostas mais positivas são captadas nos eletrodos C3, Cz, C4, CP5, CP6, P3, Pz e P4.

Para justificar os achados dos mapas topográficos, deve-se atentar ao fato de os neurônios do córtex auditivo serem particularmente sensíveis a estímulos transitórios (como os tone burst) que respondem de forma breve e transitória ao início dos sons, independentemente da duração do sinal. São sensíveis à frequência do som, bem como a seu tempo de surgimento (ataque).

Nota-se que a formação do P300 evocada pelo paradigma tradicional teve ativação positiva nas mesmas áreas que as do P300 referentes ao paradigma de omissão, evidenciando que não houve diferença cognitiva para a tomada de decisão a respeito do estímulo raro. A contribuição exógena pode ser inferida a partir dos mapas topográficos em virtude da diferença das positividades (amplitude) e semelhança das áreas ativadas entre os dois paradigmas.

Foi possível observar respostas do $\mathrm{P} 300$ na região central, que provavelmente tem origem no córtex auditivo primário, pois nesta área está 
localizado o giro temporal, ao longo do giro de Heschl, entre o giro temporal superior e o sulco lateral.

Métodos não invasivos, como o EEG, têm grande valor para registrar as regiões topográficas ativadas para evocar o P300. No entanto, não se pode inferir o sítio gerador exato responsável pela resposta apenas pela observação das positividades encontradas na análise dos mapas topográficos. Novos estudos comparando os achados encontrados no EEG (Mapas em 2D e Mapas em 3D) com ressonância e PET devem ser realizados para inferir o sítio gerador exato para esse potencial, assim como para verificar a correlação entre eles, visto que os métodos que utilizam EEG são menos invasivos e menos custosos. 


\section{Conclusões}

\section{CONCLUSÕES}

Pode-se concluir que há uma contribuição exógena para a formação do P300 com influência na amplitude, latência e morfologia da onda. Observa-se, neste estudo, que os componentes N1-P2-N2 são dependentes do estímulo acústico e que não sofrem alteração em relação à latência quando se compara o paradigma tradicional com o paradigma de omissão.

Apesar do P300 ser formado, em grande parte, pela atividade cognitiva em discriminar o estímulo-alvo, a contribuição sensorial também está envolvida na formação deste potencial implicando em menor latência, maior amplitude e melhor morfologia da onda.

As áreas cerebrais envolvidas nesse potencial são generalizadas e distribuídas em todo o escalpo, com maior ativação na região centro-parietal. 
Anexos 


\title{
8 ANEXOS
}

ANEXO I - Aprovação no Comissão de Ética e Pesquisa da Faculdade de Medicina da Universidade de São Paulo (CEP -FMUSP)

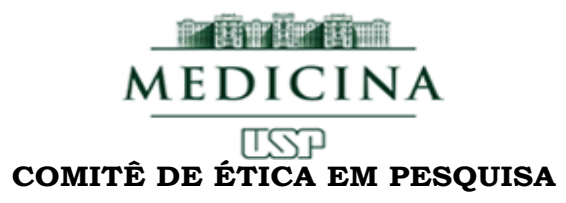

\section{APROVAÇÃo}

O Comitê de Ética em Pesquisa da Faculdade de Medicina da Universidade de São Paulo, em sessão de 11/12/2013, APROVOU o Protocolo de Pesquisa $\mathrm{n}^{\circ}$ 501/13 intitulado: "IMPLICAÇÕES DA CONTRIBUIÇÃO ENDÓgENA E EXógenA PARA OBTENÇÃo DOS P3Oo UTILIZANDO PARADIGMA DE OMISSÃo " apresentado pelo Departamento de Fisioterapia, Fonoaudiologia e Terapia Ocupacional

Cabe ao pesquisador elaborar e apresentar ao CEPFMUSP, os relatórios parciais e final sobre a pesquisa (Resolução do Conselho Nacional de Saúde no 466/12).

Pesquisador (a) Responsável: Eliane Schochat Pesquisador (a) Executante: Taise Argolo Sena

CEP-FMUSP, 12 de Dezembro de 2013.

\author{
Rhaminn. \\ Prof. Dr. Roger Chammas \\ Coordenador \\ Comitê de Ética em Pesquisa
}


ANEXO II - Termo de Consentimento Livre e Esclarecido

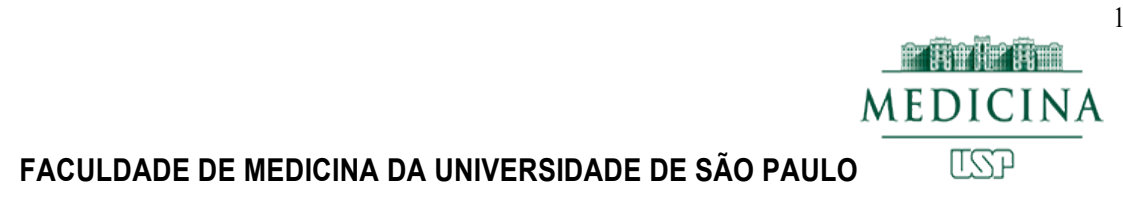

TERMO DE CONSENTIMENTO LIVRE E ESCLARECIDO

1. DADOS DE IDENTIFICAÇÃO DO SUJEITO DA PESQUISA

NOME:

DOCUMENTO DE IDENTIDADE N : SEXO: $M(\quad) F(\quad)$

DATA NASCIMENTO: .......................

ENDEREÇO

№

APTO:

BAIRRO:

CIDADE

CEP:

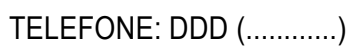

\section{DADOS SOBRE A PESQUISA}

Título do protocolo de pesquisa: Implicações da contribuição endógena e exógena para obtenção dos P300 utilizando paradigma de omissão.

Pesquisador Responsável: Profa. Dra. Eliane Schochat (CRFa 2937)

Pesquisador Executante: Fga. Taise Argolo Sena (CRFa 17655)/ Unidade do HCFMUSP: Departamento de Fisioterapia, Fonoaudiologia e Terapia Ocupacional.

Avaliação do Risco da Pesquisa: Risco mínimo ou sem risco

Duração da Pesquisa: 36 meses

3. INFORMAÇÕES AO PACIENTE

O objetivo desse estudo é estudar o efeito da contribuição endógena e exógena para obtenção dos Potencias Evocado Auditivo P300 utilizando duas estimulações, paradigma tradicional e o paradigma de omissão. Vocês serão submetidos aos seguintes procedimentos:

3.1. Avaliação Audiológica Básica:

Meatoscopia - será realizada uma breve inspeção do meato acústico externo para verificar se existe excesso de cera ou algum impedimento para realização dos exames.

Audiometria Tonal e Vocal - será realizada para saber o quanto você ouve. Você será instruído apertar o botão de resposta toda vez que ouvir um apito. Para a audiometria vocal você terá que repetir as palavras que o examinador solicitar.

Medidas de Imitância Acústica - será realizada para verificar o funcionamento da sua orelha média. Você não precisará responder para este exame, será colocado um fone e uma sonda em cada ouvido respectivamente e você sentirá primeiramente uma pressão em seguida ouvirá uma série de apitos.

3.2. Avaliação Comportametal do Processamento Auditivo:

Teste Gaps-in-Noise (GIN) - será apresentadas várias sequências de estímulos de seis segundos de ruído que possuem intervalos de silêncio. Você terá que apertar o botão resposta toda vez que perceber esse intervalo.

Teste Dicótico de Dígitos - será apresentada 20 sequências de quatro dígitos e você terá que repetir os quatro número ouvidos a cada sequencia 
(cont.)

3.3. Avaliação Eletrofisiológica

Potencial Evocado Auditivo de Tronco Encefálico - será colocados 4 eletrodos de superfície, atrás das duas orelhas e dois na testa para captar as respostas neuroelétricas evocadas por um estímulo auditivo que você ouvirá através de um fone de ouvido. Você não precisará responder, apensas ficar quieto e relaxado.

P300 - será colocado uma touca com eletrodos, você ouvirá uma série de apitos onde possuem alguns apitos diferentes ou intervalo de silencio que você deverá contar todas vezes que aparecer. No final do exame você precisará dizer quantos apitos diferentes ou intervalos de silêncio que você percebeu.

Não existe nenhum risco ou desconforto ao paciente, e esta bateria de exames durará em torno de 50 a 60 min para serem realizadas. Não há, também, benefício direto para o participante.

Em qualquer momento do estudo, você pode ter acesso aos profissionais responsáveis pela pesquisa, para esclarecimento de eventuais dúvidas. Os principais investigadores são a Profa. Dra. Eliane Schochat e Fga. Taise Argolo Sena, que podem ser encontradas no endereço - Rua Cipotânia, 51, Telefone(s) 3091-8442. Se você tiver alguma consideração ou dúvida sobre a ética da pesquisa, entre em contato com o Comitê de Ética em Pesquisa (CEP) -Av. Dr. Arnaldo, 455 - Instituto Oscar Freire $\quad-\quad 2^{\circ}$ andar- tel: 3061-8004, FAX: 3061-8004- E-mail: cep.fm@usp.br

É garantida a liberdade da retirada de consentimento a qualquer momento e deixar de participar do estudo, sem qualquer prejuízo à continuidade de seu tratamento na Instituição.

Os resultados obtidos serão analisados pelas investigadoras e poderão ser publicados em revistas científicas e/ou apresentados em congressos profissionais, não sendo divulgada a identificação de nenhum paciente.

Você tem o direito de ser mantido atualizado sobre os resultados parciais da pesquisa, ou de resultados que sejam do conhecimento dos pesquisadores.

Não há despesas pessoais em qualquer fase do estudo, incluindo exames e consultas. Também não há compensação financeira relacionada à sua participação. Se existir qualquer despesa adicional, ela será absorvida pelo orçamento da pesquisa.

Os dados e o material coletados serão utilizados somente para esta pesquisa.

Acredito ter sido suficientemente esclarecido a respeito das informações que foram lidas para mim, descrevendo o estudo "Implicações da contribuição endógena e exógena para obtenção dos P300 utilizando paradigma de omissão".

Eu discuti com a Profa. Dra. Eliane Schochat e a Fga. Taise Argolo Sena sobre a minha decisão em participar nesse estudo. Ficaram claros para mim quais são os propósitos do estudo, os procedimentos a serem realizados, seus desconfortos e riscos, as garantias de confidencialidade e de esclarecimentos permanentes. Ficou claro também que minha participação é isenta de despesas e que tenho garantia do acesso a tratamento hospitalar quando necessário. Concordo voluntariamente em participar deste estudo e poderei retirar o meu consentimento a qualquer momento, antes ou durante 0 mesmo, sem penalidades ou prejuizo ou perda de qualquer benefício que eu possa ter adquirido, ou no meu atendimento neste Serviço.

Assinatura do participante

Data: 1

Declaro que obtive de forma apropriada e voluntária o Consentimento Livre e Esclarecido deste paciente para a participação neste estudo.

Data: 1 
Referências Bibliográficas 


\section{REFERÊNCIAS BIBLIOGRÁFICAS}

Abeles M, Goldstein MH Jr. Responses of single units in the primary auditory cortex of the cat to tones and to tone pairs. Brain Res. 1972 2:337-52.

Bussab WO, Morettin, PA. Estatística Básica. São Paulo: Ed. Saraiva, 2002.

Cone-Wesson B, Wunderlich J. Auditory evoked potentials from the cortex: auditory applications. Curr Opin Otolaryngol Head Neck Surg. 2003 11: 372377.

Davis H, Davis PA, Loomis AL Havervey PN, Hobart G. Eletrical Reactions of the human brain to auditory stimulation during sleep. J. Neurophysiol. 1939 2: $500-14$.

Duncan CC1, Barry RJ, Connolly JF, Fischer C, Michie PT, Näätänen R, Polich J, Reinvang I, Van Petten C. Event-related potentials in clinical research: guidelines for eliciting, recording, and quantifying mismatch negativity, P300, and N400. Clin Neurophysiol. 2009 Nov;120(11):1883-908.

Fjell AM, Walhovd KB. Effects of auditory stimulus intensity and hearing threshold on the relationship among P300, age, and cognitive function. Clin Neurophysiol. 2003 May; 114(5):799-807.

Ford MR, Sidman RD, Ramsey G. Spatio-temporal progression of the AEP P300 component using the cortical imaging technique. Brain Topogr. 1993 Fall: 6(1):43-50.

Hall, J.W. Handbook of auditory evoked responses. Boston: Allyn and Bacon, 1992. 
Jasper HA. The ten-twenty system ofthe International Federation. Electroencepholography and Clinical Neurophysiology. 1958 10: 371-375.

Jerger, J. Clinical experience with impedance audiometry. Arch Otolaryngol, 1970 4: 311-24.

Kalaiah MK, Shastri U. Cortical Auditory Event Related Potentials (P300) for Frequency Changing Dynamic Tones. J Audiol Otol. 2016; 20: 22-30.

McCullagh J, Weihing J, Musiek F. Comparisons of P300s from standard oddball and omitted paradigms: implications to exogenous/endogenous contributions. J Am Acad Audiol. 2009 Mar; 20(3):187-95; quiz 219.

Musiek F, Froke R, Weihing J. The auditory P300 at or near threshold. J Am Acad Audiol. 2005a: 16:699-708.

Musiek FE, Shinn JB, Jirsa R, Bamiou DE, Baran JA, Zaidan E. GIN (Gaps in Noise) test performance in subjects with confirmed central auditory nervous system involvement. Ear Hear. 2005b 6: 608-18

Papanicolau AC, Loring DW, Raz N, Eisenberg HM. Relationship between stimulus intensity and P300. Psychophysiology. 1985; 22: 326-329.

Pereira LD, Schochat E. Testes auditivos comportamentais para avaliação do processamento auditivo central. Editora Pró Fono; 2011.

Picton TW, Hilyard SA. Human auditory evoked potential II: Effects of attention. Eletroenc. And Clinical Neurophysiology. 1974; 36:191-200.

Picton TW, Hyllyard SA, Krausz HI, Galambos R. Human Auditory Evoked Potentiais. I. Evaluation of components. 1974; 36:179-190. 
Picton TW. The P300 wave of the human event-related potential. J Clin Neurophysiol. 1992 Oct;9(4):456-79.

Polich J. Normal variation of P300 from auditory stimuli. Electroencephalogr Clin Neurophysiol. 1986; 3:236-40.

Polich J. Probability and inter-stimulus interval effects on the P300 from auditory stimuli. Int J Psychophysiol. 1990 Dec;10(2):163-70.

Polich J, Ellerson PC, Cohen J. P300, stimulus intensity, modality, and probability. Int J Psychophysiol 1996; 23:55-62.

Polich J, Heine MR. P300 topography and modality effects from a singlestimulus paradigm. Psychophysiology. 1996 Nov;33(6):747-52.

Rocha-Muniz CN. Processamento de sinais acústicos de diferentes complexidades em crianças com alteração de percepção da audição ou da linguagem [tese]. São Paulo: Faculdade de Medicina, Universidade de São Paulo; 2011.

Roth WT, Blowers GH, Doyle CM, Kopell BS. Auditory stimulus intensity effects on components of the late positive complex. Electroencephalogr Clin Neurophysiol. 1982 Aug;54(2):132-46.

Ruchkin DS, Sutton S. Emitted P300 potentials and temporal uncertainty. Electroencephaiography and Clinical Neurophysiology, 1978,45, 268-277.

Ruchkin DS, Sutton S, Munson R, Silver K e Macar F. P300 and Feedback Provided by Absence of the Stimulus. Psychophysiology. 1981; 18:271-282.

Rusiniak M, Lewandowska M, Wolak T, Pluta A, Milner R, Ganc M, Włodarczyk A, Senderski A, Sliwa L, Skarżyński H. A modified oddball paradigm for 
investigation of neural correlates of attention: a simultaneous ERP-fMRI study. MAGMA. 2013 Dec; 26(6): 511-26.

Santos TMM, Russo ICP. A prática da audiologia clínica. São Paulo: Cortez Editora; 1986.

Smith ME, Halgren E, Sokolik M, Baudena P, Musolino A, Liegeois-Chauvel C, et al. The intracranial topography of the $\mathrm{P} 3$ event-related potential elicited during auditory oddball. Electroencephogr Clin Neurophysiol 1990; 76:235-48.

Shin JB. Temporal Processing: the basics. Hear J. 2003; 56:52.

Sutton S, Braren M, Zubin J. Evoked-potential correlates to stimulus uncertainty. Science. 1965 150: 1187-1188.

Tarkka IM, Stokic DS. Source localization of P300 from oddball, single stimulus, and omitted-stimulus paradigms. Brain Topogr (1998) Winter; 11(2): 141-151. 